

\section{DISCLAIMER}

This report was prepared as an account of work sponsored by an agency of the United States Government. Neither the United States Government nor any agency Thereof, nor any of their employees, makes any warranty, express or implied, or assumes any legal liability or responsibility for the accuracy, completeness, or usefulness of any information, apparatus, product, or process disclosed, or represents that its use would not infringe privately owned rights. Reference herein to any specific commercial product, process, or service by trade name, trademark, manufacturer, or otherwise does not necessarily constitute or imply its endorsement, recommendation, or favoring by the United States Government or any agency thereof. The views and opinions of authors expressed herein do not necessarily state or reflect those of the United States Government or any agency thereof. 


\section{DISCLAIMER}

Portions of this document may be illegible in electronic image products. Images are produced from the best available original document. 


\title{
Mound Laboratory Activities for the Division of Physical Research: January-June 1976
}

\author{
Issued: September 30, 1976
}

\section{NOTICE}

This report was prepared as an account of work sponsored by the United States Government. Neither the United States nor the United States Energy Fesearch and Development Administration, nor any of their employees, nor any of their contractors, subcontractors, or their employees, makes any warranty, express or implied, or assumes any legal liability or responsibility for the accuracy. completeness or usefulness of any information, apparatus, product or process disclosed or represents that its use would not infringe privately owned rights.

PRINTED IN THE UNITED STATES OF AMERICA

Available from

National Technical Information Service

U. S. Department of Commerce 5285 Port Royal Road

Sprlinglielu, Virginia 32161

Price: Printed Copy \$4.00; Microfiche $\$ 2.25$

\section{MONSANTO RESEARCH CORPORATION}

A Subsidiary of Monsanto Company

\section{MOUND IABORATORY}

Miamisburg, Ohio

45342

operated for

\section{UNITED STATES ENERGY RESEARCH AND DEVELOPMENT ADMINISTRATION}

\section{U. S. Government Contract No. E-33-1-GEN-53}

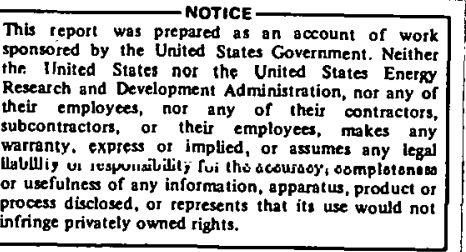
infringe privately owned rights. 


\section{Foreword.}

The Mound Laboratory Activities for the Division of Physical Research report, issued semiannually, replaces the previously published quarterly reports, Stable Gaseous Isotope Separation and Purification Report and the Mound Laboratory Chemistry and Physics Progress Report. Under the sponsorship of the ERDA. Division of Physical Research, Mound Laboratory is responsible for furnishing material to be used in the physical sciences to further the progress of science and technology in the public interest. Additional research activities of related interest under the sponsorship of the Division of Military Applications are also published in this report.

This report is submitted by $W$. T'. Cave, Director of Nuclear Operations, and R. E. Vallee, Manager of Technology Applications and Development, from contributions prepared by $W$. M. Rutherford, Science Fellow (Thermal Diffusion); W. L. Taylor, Science Fellow (Gas Dynamics and Cryogenics); G. L. Silver, Senior Research Specialist (Separation Chemistry); R. J. De Sando, Advanced Development Manager; and from members of the Isotope Separation Section: R. A. Schwind, Isotope Separation Manager; E. Michaels, Leader, Isotope Separations Development; W. J. Roos, Leader, Stable Isotopes Production; B. E. Jepson, Leader, Metal Isotope Separation; R. M. Watrous, Leader, Radioisotopes Separation; and V: L. Avona, Leader, Stable Isotope Sales.

These reports are not intended to constitute publication in any sense of the word. Final results will either be submitted for publication in regular professional journals or be published in the form of MLM topical reports.

R. E. Fitzharris, Editor 


\section{Table of Contents}

COMPUTER OPERATIONS

REAL-TIME COMPUTER OPERATIONS IN HH-BUILDING. . . . . . . . . . . . . . . . . . . . .

The HH-Building computer system is playing a central role in the development of several automation projects. Currently near completion are mass spectrometer systems for instrument control, data acquisition, and data reduction, as well as a control system for a beam scattering chamber. Work is also being conducted on computer-aided analysis of peak multiplets in complex mass spectra.

ISOTOPE SEPARATION

ARGON • . . . . . . . . . . . . . . . . . . . . . . . . . . . . . . . . . 10

Production of 78 argon-38 and 99.58 argon-36 continued during this period.

CARBON. . . . . . . . . . . . . . . . . . . . . . . . . . . . . . . .

Carbon dioxide, grading 998 carbon-13 and containing $147 \mathrm{~g}$ of carbon-13, was produced. Carbon dioxide, grading 99.98 carbon-12 and containing $610 \mathrm{~g}$ of carbon-12 was also produced.

Methane, grading 998 carbon-13 and containing $17 \mathrm{~g}$ of carbon-13, was produced. Methane, grading 908 carbon-13 and containing $10 \mathrm{~g}$ of carbon-13, was produced.

Barium carbonate, grading $90 \%$ carbon-13 and containing $710 \mathrm{~g}$ of carbon-13, was produced.

Elemental carbon, grading 908 carbon-13 and containing $303 \mathrm{~g}$ of carbon-13, was produced. Elemental carbon, grading 99.98 carbon-12 and containing $30 \mathrm{~g}$ of carbon-12; was produced.

During this period, two special enrichments of carbon-12 methane were performed. Computer calculations predict that the carbon-13 concentration in the product is $1-2 \mathrm{ppm}$ or less, relative to total carbon.

Production of highly enriched carbon-13 continued. A total of 290 STP liters of 998 carbon-13 methane was produced. Enrichment of a special batch of carbon-13 to 99.98 is currently under way.

HELIUM.

A totai of 3051 liters of helium, grading 99.98 helium-3, was produced.

The four-column helium thermal diffusion system was modified so that it can easily. be converted from a 3-1 configuration to a 2-2 configuration and vice versa. This has resulted in achieving optimum operating characteristics in the use of high, medium, and low helium-3 concentration feed gas.

A 19-column thermal diffusion cascade was modified for continuous production of 998 krypton-78; after sufficient krypton-78 had been collected, the system was modified for continuous production of 998 krypton-86. 
The nine-column, five-stage cascade is being used to produce feed for the krypton-86 system.

The 10-column, nine-stage cascade produced one batch of $70 \%$ krypton-83.

Column performance evaluation for the 19-column, seven-stage cascade has been completed, and the poorly performing columns have been replaced. currently, the system is being modified for continuous production of $90 \%$ krypton -84 .

Radiometric Krypton During this period, processing of the fourth batch of radiometric krypton was completed. The depletion factor for the krypton-85 was calculated to be greater than 1000 .

Upgrading of batches of neon-20 and neon-22, which are slightly below product specifications, has continued.

An electrolysis system, which utilizes a General Electric Polymer Electrolyte water Electrolysis Unit, has been designed to produce oxygen-16.

During this period, progress was made in two major areas of the sulfur34 project:

1. Completion of construction.

2. Preparation of the system for production.

The start-up phase has been implemented with the beginning of leak checking of the system.

XENON .

During this period, three thermal diffusion systems produced the following quantities of product: 0.6 STP liter of 408 xenon-124, 1.2 STP liters of 208 xenon-124, and 9 STP liters of $80 \%$ xenon-136.

\section{LOW TEMPERATURE RESEARCH}

VAPOR PRESSURE STUDIES . . . . . . . . . . . . . . . . . . . . . . . .

The vapor pressure difference has been measured for samples of $D_{2}$ with concentrations of para molecules of $2.28\left(\mathrm{eD}_{2}\right), 188$ and $33.38\left(\mathrm{nD}_{2}\right)$. Careful corrections. for the partial pressure of HD in the samples have been made. A new time dependent effect has been observed which may be a measure of clustering of para molecules in the solid.

\section{METAL HYDRIDE RESEARCH}

BAND THEORY AND ELECTRONIC STRUCTURE . . . . . . . . . . . . . . . . . . . . . .

The emphasis of band theory and electronic structure research has shifted from the self-consistent plane wave Gaussian (SCPWG) programs to ab initio, self-consistent field, molecular-orbital programs. In addition, the feasibility of using the local orbitals for polyatomic systems (LOPAS), ab initio, Hartree-Fock, computer codes is being investigated. 
Also, still larger efforts have been expended on evaluating the feasibility of performing accurate Hartree-Fock (HF), unrestricted.Hartree-Fock (UHF), and generalized valence bond calculations (GVB) on clusters of atoms rather than on perfect crystals.

ELECTRON PARAMAGNETIC RESONANCE STUDIES OF RHODIUM IONS IN LITHIUM HYDRIDE AND LITHIUM DEUTERIDE SINGLE CRYSTALS. . . . . . . . . . . . . . . . . . . . . . . . .

Current electron paramagnetic resonance (EPR) studies of transition metal and rare earth ions in diamagnetic metal hydrides should provide increased knowledge of metal hydrogen chemical bonding:

Lithium hydride was chosen as the initial host material for the EPR studies, and EPR spectra of $\mathrm{Rh}$ dissolved in $\mathrm{LiH}$ and LiD were investigated in the temperature range $77^{\circ}$ to $325^{\circ} \mathrm{K}$.

Results will be analyzed in terms of ligand-field theory and are expected to provide data on the extent of the covalent contribution in a metal hydrogen molecular complex.

PULSE NMR STUDIES. . . . . . . . . . . . . . . . . . . . . . . . . . . . . . .

Various pulse NMR techniques have been used to determine the proton line shapes and relaxation times for $\beta$-phase and $\gamma$-phase $\mathrm{TiFeH}_{\mathrm{x}}$. The proton resonance signals for both phases have very short free induction decays (that is, $\mathrm{T}_{2}{ }^{*} \approx 2-5 \mathrm{\mu sec}$ ), which are inhomogeneously broadened. The temperature and frequency dependences of the relaxation times have been measured. Spin echo measurements of $\mathrm{T}_{2}{ }^{\prime}$ indicate that hydrogen diffusion in both $\mathrm{TiFeH} x$ phases is insufficient to significantly reduce the dipolar interactions. The spin-lattice relaxation times for both phases are primarily caused by conduction electrons.

\section{SEPARATION CHEMISTRY}

PROBLEMS IN PLUTONIUM CHEMISTRY (III): CONDITIONS OF EQUILIBRIUM AND KINETIC VALENCE STATE DISTRIBUTIONS IN LABORATORY AND ENVIRONMENTAL CIRCUMSTANCES. • •

Some conditions applicable to equilibrium and nonequilibrium plutonium valence state distributions are described.

PROBLEMS IN PLUTONIUM (IV): IS A BATTERY A USEFUL TOOL FOR STUDYING DISPRÓPORTIONATION KINETICS? • • • . . . . . . . . . . . . . . . . . . . . . . . .

A method of studying the kinetics of plutonium disproportionation reactions by means of an electrochemical concentration cell is proposed.

STUDY OF THE REACTIONS OF BONE CHAR WITH PLUTONIUM AND URANIUM •. • . . . . .

A study of loading isotherms for bone char with uranium and plutonium indicate that bone char is a better absorbent for uranium than plutonium. 
The adsorption of hexavalent plutonium by bone char appears to be a more complicated phenomenon than the adsorption of plutonium polymer by bone char and may involve pentavalent plutonium as well as plutonium polymer.

THORIUM-229

$A$ total of $9.68 \mathrm{mg}$ of thorium-229 has been separated from aged uranium-233 during this reporting period. The extraction equipment has been doubled in volume, thereby resulting in an approximate $20 \%$ increase in the rate of processing.

THORIUM-230 AND PROTACTINIUM-231 . . . . . . . . . . . . . . . . . . . . . .

A shipment of $62.0 \mathrm{~g}$ thorium-230 was made to the Heavy Element Isotope Pool at ORNL, and a shipment of approximately $160 \mathrm{mg}$ protactinium-231 is being prepared. The rate of processing cotter concentrate has been. increased by the use of a 3 in. diam Karr column to extract and strip the uranium. A $1.0 \mathrm{~g}$ shipment of protactinium-231, received from ORNL in the form of $\mathrm{K}_{2} \mathrm{PaF}_{7}$, was purified, converted to oxide, and returned to ORNL.

URANIUM-234

The initial purification of solution Al0-P, containing an estimated four grams of uranium-234, has been completed. Solutions U-8, U-9, and U-10, containing an estimated three grams of uranium-234, have been prepared for intermediate purification. Processing of one-half of batch A15 has been completed. This product, designated A15-1, is expected to contain at least $20 \mathrm{~g}$ of uranium-234; and it will be shipped as soon as all analyses are completed.

\author{
SEPARATION RESEARCH
}

CHLORINE ISOTOPE SEPARATION. . . . . . . . . . . . . . . . . . . . . . . . .

Chlorine isotopes were separated in multiple column liquid thermal diffusion cascades. The first experiment, with 1-chloropropane as a working fluid, was ended when it was discovered that a reaction was taking place between 1-chloropropane and the hot walls of the columns. The experiment resulted in the production of material containing $90.78{ }^{35} \mathrm{Cl}$ and material containing $73.38^{3}{ }^{7} \mathrm{Cl}$.

A second experiment with chlorobenzene as the working fluid is still in progress. Chlorobenzene of $958^{35} \mathrm{Cl}$ enrichment has been produced and concentrations up to $87 \%{ }^{37} \mathrm{Cl}$ have been observed.

MOLECULAR BEAM SCATTERING. • . . . . . . . . . . . . . . . . . . . . . . .

Total scattering cross section measurements for the argon-krypton system in the low relative velocity range of 3 to $7\left(x 10^{4}\right) \mathrm{cm} / \mathrm{sec}$ have been completed. A well collimated supersonic molecular beam was passed through a target cell containing the scattering gas. The attenuation was measured with an ionization detector. A volumetric flow calibration method was used to obtain accurate pressures in the target cell. Both Ar and $\mathrm{Kr}$ were used as target gases, and good agreement was obtained between the absolute cross sections upon inversion of beam/target at the same relative 
velocities. These data overlap the, measurements of previous workers at the higher velocities and are in good agreement with those results. All of the data, some of which were reported previously, have been corrected for the angular resolution of the apparatus. Details of the method used are given. Several glory extrema were observed which, with those previously reported, were used to determine the product $\varepsilon \sigma$ for the argonkrypton interaction potential. Theoretical calculations of total cross sections using the WKB approximation were made for several interatomic potentials satisfying the $\varepsilon \sigma$ criterion. The results are compared to the experimental data. 


\section{Computer Operations}

REAL-TIME COMPUTER

OPERATIONS IN HH-BUILDING

\section{Introduction}

There are several current projects in HHBuilding centered around the MODCOMP IV computer system. This system, which was described previously, ${ }^{\prime}$ operates with a multiprogramming real-time Executive that supports real-time FORTRAN programs. This capability allows most of the process control and analytical instrument control programs to be written in FORTRAN, which results in much shorter development times than would be possible if these programs had to be written in an assembly language.

Current projects include the automation of two mass spectrometers and a beam scattering chamber. Additionally, work is progressing on the development of mathematical methods for the analysis of complex mass spectrometer spectra.

\section{Mass Spectrometer Automation}

At present, there are two mass spectrometers, a CEC 620 and an Extranuclear quadrupole, which are used for research, development; and production analyses of separation system samples. These analyses provide the central information for control of the separation systems and are necessary on a daily basis. Thus, automation of these mass spectrometers constitutes the first step in the overall goal of automating the process systems.

Both hardware and software have been developed for this purpose. In particular, digital (16-bit, parallel) and analog signal interfaces have been developed for interfacing the mass spectrometer signals to the computer process I/O subsystem. Additionally, a mass spectrometer sweep circuit has been designed and built for the CEC 620. This circuit develops the voltage necessary for mass dispersion in the cycloid tube. It includes an inverse voltage (I/V) transformation that results in a linear mass sweep over the full range of the instrument. The low voltage $(0-10 \mathrm{Vdc})$ section is isolated from the high voltage sweep supply $(0-200$ vdc) by a unity gain, isolation op amp, and results in a very stable, linear sweep.
Software for the cycloidal mass spectrometer has been developed over the past few months. Recently, the necessary routines have been incorporated for the operation of the computer controlled sweep circuit. Process samples are admitted manually to the inlet system; then, the remainder of the analysis is completed without further operator intervention.

The program provides for control of variables such as the sweep rate, mass resolution, and data sampling rate. It also allows for scanning multiple mass regions rather than requiring a full mass scan for each sample. An analyses consists of several steps. First, raw data are acquired and stored on a disk. This is followed by data reduction procedures that determine the spectrum background points, fit them to a specified polynomial curve, and then subtract the calculated background from the raw data. Next, peaks are located above a selected intensity level and tested for validity using criteria such as peak width and shape. The resulting valid peaks are further analyzed for accurate mass and peak height information. Peak heights are then corrected for sensitivity factors and pressure loss from the time spent in the inlet system.

$$
\text { ... }
$$

This mass and intensity information is then used to calculate relative mole percents for each species in the analysis. The results are printed in report form.

A similar system is being developed for the quadrupole mass spectrometer. Since many of the operations are similar to those in the cycloidal mass spectrometer, the goal is to combine the necessary routines into a single program that can be used for both mass spectrometers as well as for future instruments.

Hardware is being designed and built to interface the quadrupole mass spectrometer to the computer system. This includes a computer-controlled sweep circuit that incorporates a highly accurate 16-bit. DAC for providing the control voltage to the high voltage sweep supply. This mass spectrometer should be operating under computer control in the near future. 


\section{Scattering Chamber Automation}

Proposed cross section measurements, using the beam scattering chamber in HHBuilding, will be enhanced by computer assistance. A quadrupole mass spectrometer has been developed to serve as the beam detector. It will be positioned on a turntable to allow scattered particles to be measured over both positive and negative angles with respect to the beam. The goal is to place the turntable movement and angle readout under computer control. In addition, the computer will acquire data and control the mass selection of the mass spectrometer as well as monitor the relevant system temperatures and pressures during the course of an experiment.

Data reduction and spectrum plotting will also be performed on-line with the computer. Towards this goal, a Remote Data Acquisition Subsystem (REMAC) has been installed to provide the interface for all analog and digital signals between the computer and the scattering chamber electronics. This interface is now operational, and cabling from it to the scattering chamber is now in the final stages.

The computer Executive software has been expanded to include the REMAC (handlers, interrupt routines, etc.). Also, routines have been written which provide FORTRAN access to all REMAC I/O functions.
Complex Spectrum Analysis

Because of multicomponent mixtures or low resolution of the mass spectrometer, it frequently happens that peaks are not completely resolved. The apparent peak heights and centroids are in error with the magnitude of the error dependent on the particular makeup of the peak multiplet.

Methods for computer-aided resolution of individual peaks in multiplets have been developed in several other disciplines and have been adopted as the starting point. The basic requirement is that an analytical description be found that describes the peaks in the multiplet and background of the spectrum. The set of equations resulting from this description must then be fit to the raw data by nonlinear regression techniques.

Methods of nonlinear analyses are being explored for use on mass spectra with multiplets containing up to six peaks. Various functional forms are being tested for use in accurately characterizing the mass spectrum.

Because of possible instabilities in the solution of such sets of equations, this technique will probably not be useful in a totally automatic mass spectrometer program. However, this technique will be useful in the analysis of "problem" areas in spectra where the analysis can be carried out in an interactive mode with a graphics terminal. (Richard E. Eppley) 


\section{Isotope Separation}

\section{ARGON}

The 13-column, hot wire, thermal diffusion cascade has continued to produce approximately 78 argon-38. This material is being collected and saved for later. enrichment to 95\%. The system also produced argon-36 at 99.58 enrichment. (Gilbert E. Stuber, Jr.)

\section{CARBON}

\begin{tabular}{|c|c|c|c|}
\hline${ }^{13} \mathrm{C}$ & $\begin{array}{l}\text { Produced } \\
\text { (g) }\end{array}$ & Product & $\begin{array}{c}{ }^{13} \mathrm{C} \text { Grading } \\
\text { (영) }\end{array}$ \\
\hline & 147 & $\mathrm{CO}_{2}$ & 99 \\
\hline & $610^{a}$ & $\mathrm{CO}_{2}{ }^{\mathrm{a}}$ & $99.9^{a}$ \\
\hline & 17 & $\mathrm{CH}_{4}$. & 99 \\
\hline & 10 & $\mathrm{CH}_{4}{ }^{\circ}$ & 90 \\
\hline & 710 & $\mathrm{BaCO}_{3}$ & 90 \\
\hline & 303 & $\mathrm{C}$ & 90 \\
\hline & $30^{a}$ & $c^{a}$ & $99.9^{a}$ \\
\hline
\end{tabular}

a The isotope of interest in these two cases is carbon-12. (Jerome C. Liner)

Also during this period, two special enrichments of carbon-12 methane were performed. Two batches of product, totaling approximately 25 STP liters, were recovered. The goal of the enrichment runs was to provide methane with a carbon-13 concentration less than $10 \mathrm{ppm}$, relative to total carbon. The enrichment runs were simulated on a computer, and the predicted carbon-13 concentrations in the two batches are in the range of 1-2 ppm or less. These predicted values will be checked independently by the customer.

Production of highly enriched carbon-13 continued during this period. Three batches of methane with carbon-13 concentrations greater than 998 were produced. These batches totalled 290 STP liters. Quantities of 978 and 208 carbon-13 methane were also recovered. Processing of a special batch of methane to produce material with a carbon-13 concentration of. 99.98 is currently underway; this material will be converted to carbon dioxide. (William J. Roos)
HEL IUM

A total of 3051 liters of helium, grading 99.98 helium-3, was produced.

The four-column, helium thermal diffusion system was modified so that it can easily be converted from a 3-1 configuration to a 2-2 configuration or back. A 3-1 configuration is the optimum configuration to process feed gas containing relatively low concentrations of helium-3. This can be done by collecting helium-3 as the product or by drawing and discarding helium-4. In the latter process, the objective is to reduce the pressure of the stored gas by eliminating a portion of the helium-4 content. The 2-2 configuration optimizes the production of high enrichment helium-3, using relatively high concentration helium-3 feed material. This arrangement has enabled us to increase our production rate at least 308 and at the same time helps us to reduce our total stored volume of helium. (Jerome $C$. Liner)

\section{KRYPTON}

A 19-column thermal diffusion cascade was modified by adding two columns in series to the top of the system. This enabled the system to produce 998. krypton-78 continuously at the top, while stripping the krypton-78 to approximately 0.048 in the raffinate (bottom) stream. After a sufficient quantity of 998 krypton-78 had been collected, the system was shut down, emptied, and modified by moving the four single-column stages from the top of the cascade to the bottom. The system was then filled with material partially enriched in krypton-86 and restarted. The system has now begun producing 998 krypton -86 at a rate of $200 \mathrm{ml} /$ day.

The nine-column, five-stage thermal diffusion cascade produced intermediate material for krypton-83 production during the first part of this period. It is now used to strip the light isotopes from the feed material for the krypton-86 system.

The 10-column, nine-stage cascade produced one batch of 708 krypton 83 . It was then shut down, and the gas was removed. 
The heater power was reset, and the system was filled with methane and restarted to produce methane highly depleted in carbon-13.

The columns in the 19-column, seven-stage cascade have been evaluated. The five columns with the lowest separation factors were replaced with new columns. The system is undergoing piping modifications to give it an eight-stage configuration, which will be used to produce $908 \mathrm{kryp}-$ ton-84. (Gilbert E. Stuber, Jr.)

Radiometric Krypton During this period, processing of the fourth batch of aged krypton was completed. The reduction factor for the krypton-85 concentration relative to that in the feed material was calculated to be greater than 1000. This material will be shipped to the customer in the near future. Assuming that the material is satisfactory, the radiometric krypton comitment is fulfilled.

(William J. Roos)

\section{NEON}

Upgrading of neon-20 and neon-22 to product grade has continued in a four-column thermal diffusion system. The materials being upgraded are slightly below product specifications. (Gilbert $E$. Stuber, Jr.)

\section{OXYGEN}

An electrolysis system has been designed that utilizes a General Electric Solid Polymer Electrolyte Water Electrolysis Unit. This system will produce oxygen16 gas, grading 99.988 oxygen-16, from oxygen-16 water. A pilot plant model is currently being built to test the electrolysis and the reliability of maintaining the oxygen-16 enrichment. After the test, the pilot scale system will be used for oxygen-18 and oxygen-17 electrolyses. (Jerome $C$. Liner)

\section{SULFUR}

Construction of the sulfur-34 chemical exchange system was essentially completed by the contractor on May 7, 1976. This completion date was preceded by approximately three weeks of preliminary Freon and nitrogen leak checking by the contractor; during this period, the contractor found and repaired approximately 10 leaks.

On May 10, 1976, Mound personnel began vacuum and helium leak checking in preparation for actual runs with chemicals in the system. Approximately 15 leaks have been found thus far and are in the process of being repaired by the contractor. When the leak checking and repair phases are finished, start-up will continue - the equipment will be checked out using nitrogen, air, and water; and runs will be made using actual system chemicals. (Regis F. Cmar)

\section{XENON}

During this period, a 19-column thermal diffusion system produced approximately 0.6 STP liter of 408 xenon-124. A 24column thermal diffusion system produced approximately 1.2 STP liters of 208 xenon-124. An eight-column thermal diffusion system produced approximately 9 STP liters of 808 xenon-136. (William J. Roos) 


\section{Low Temperature Research}

\section{VAPOR PRESSURE STUDIES}

Measurements of the vapor pressure difference between mixtures of ortho-para deuterium and equilibrium deuterium (2.15\% para) are continuing. The principal problem in making precise deuterium vapor pressure measurements is in accounting for the HD in the system, but this problem has been largely overcome. The $\mathrm{eD}_{2}$ now contains $\sim 350 \mathrm{ppm} \mathrm{HD}$, and the $\mathrm{nD}_{2}$ contains $\sim 700 \mathrm{ppm} \mathrm{HD}$.

Measurements of the vapor pressure difference between $\mathrm{nD}_{2}\left(33.3 \%\right.$ para) and $\mathrm{eD}_{2}$ and between $\operatorname{mix} D_{2}\left(17.98\right.$ para) and $e D_{2}$ have been made with varying amounts of HD in the samples. Almost all of the samples were measured twice, and a time dependent effect was found. A description of the samples is given in Table 1 . Sample numbers 1 and 3 were prepared from research grade Air Products $\mathrm{D}_{2}$ gas. Sample numbers 5 and 7 were prepared from isotopically purified $\mathrm{D}_{2}$ gas obtained from William Rutherford. The following equations $^{2}$ were used to correct for the HD partial pressure in the vapor pressure measurements:

Liquid HD, $\log P$

$$
=5.04964-\frac{55.2495}{\mathrm{~T}}+0.01479 \mathrm{~T}
$$

Solid HD, $\log P$

$$
=4.70260-\frac{56.7154}{T}+0.04101 \mathrm{~T}
$$

Table 1

\begin{tabular}{|c|c|c|c|}
\hline $\begin{array}{l}\text { Sample } \\
\text { Number }\end{array}$ & $\begin{array}{l}O-D_{2} \\
(z) \\
\end{array}$ & $\begin{array}{l}P-D_{2} \\
(\%)\end{array}$ & $\begin{array}{c}\text { Total HD } \\
(8) \\
\end{array}$ \\
\hline $\begin{array}{l}1 \\
2 \\
3 \\
4 \\
5 \\
6 \\
7 \\
8\end{array}$ & $\begin{array}{l}66.6 \\
98.8 \\
82.4 \\
98.8 \\
66.6 \\
98.8 \\
84.0 \\
98.8\end{array}$ & $\begin{array}{r}33.3 \\
2.2 \\
17.9 \\
2.2 \\
33.3 \\
2.2 \\
16.0 \\
2.2\end{array}$ & $\begin{array}{l}0.72 \\
0.035 \\
0.44 \\
0.035 \\
0.07 \\
0.035 \\
0.05 \\
0.035\end{array}$ \\
\hline
\end{tabular}

\section{COMPOSITION OF SAMPLE MIXTURES}

A study of the $D_{2}$ vapor pressure work performed by Meckstroth and White ${ }^{3}$ revealed that no correction had been made for HD in their samples. Their assumption was that HD concentration $\leqslant 0.18$, but that amount can contribute 108 to the $D_{2}$ vapor pressure difference.

Vapor pressure data were taken on the four sets of samples listed in Table 1 . In three of the four experiments, the samples remained cold for two or three days; and a time dependent effect was seen. This effect may be because of diffusion of HD in the sample or caused by clustering of para molecules. Further work is necessary to clarify this point.

Typical data are shown in Tables 2 and 3 where the magnitude of the HD correction can be seen. It is clearly preferable to have the HD concentration as low as possible. If one calls the pressure corrected for the Baratron calibration $\mathrm{P}_{\mathrm{c}}$, then $P_{n}$ and $P_{e}$ are given by:

$$
\begin{aligned}
& P_{n}=P_{c}-P(H D \text { in } n) \\
& P_{c}=P_{c}+\Delta P_{m}-P(H D \text { in } e) .
\end{aligned}
$$

As given in a previous report, ${ }^{4}$ the quantity to be compared to theory is:

$$
J=-\ln \left(1-\frac{\Delta \mathrm{P}}{\mathrm{P}_{\mathrm{e}}}\right)+\frac{\mathrm{B}_{11} \Delta \mathrm{P}}{\mathrm{RT}},
$$

where $\Delta P=\Delta P_{m}-[P(H D$ in e) $-P(H D$ in $n)]$ and $\ln \left(1-\Delta \mathrm{P} / \mathrm{P}_{\mathrm{e}_{\mathrm{a}}}\right)=\ln \left(\mathrm{P}_{\mathrm{n}} / \mathrm{P}_{\mathrm{e}}\right)$. Meckstroth and white $e^{3}$ have shown that the quantity $J$ is related to the differences in the excess free energies of the ortho-para mixtures in the following way:

$$
J=-\left(\frac{G^{E}-G_{e}^{E}}{R T}\right)-\left(X-X_{e}\right) \frac{\ln P_{2}{ }^{0}}{\ln P_{1}} d^{*} !
$$

where the $\mathrm{P}_{\mathrm{i}}{ }^{\circ}$ * is the fugacity of the pure component $i$ given by $P_{i} \circ \star=p_{e}(B P / R T)$ and where $P$ is the vapor pressure at temperature $T$ of either ortho $D_{2}$ or para $D_{2}$. On the basis of a lattice model with a random distribution of para molecules, Bellemans and Babloyantz ${ }^{5}$ have worked out a formula for $\mathrm{J}$ in terms of molecular parameters of the following form: 
Table 2

DATA FOR eD $-\mathrm{nD}_{2}$ WITH 0.448 HD IN $\mathrm{nD}_{2}$ AND 0.058 HD IN eD 2

$\frac{1}{\mathrm{~T}}$ Temperature

0.0760

0.0733

0.0710

0.0693

0.0668

0.0647

0.0629

0.0613

0.0597

0.0584

0.0571

0.0559

0.0547

0.0537

13.15
13.65
14.07
14.43
14.96
15.46
15.89
16.32
16.74
17.12
17.50
17.89
18.26
18.63

Corrected

Pressure Pressure
HD

2.62
4.14
5.85
8.01
11.96
16.94
23.32
31.14
41.05
52.46
65.87
81.92
100.66
122.72

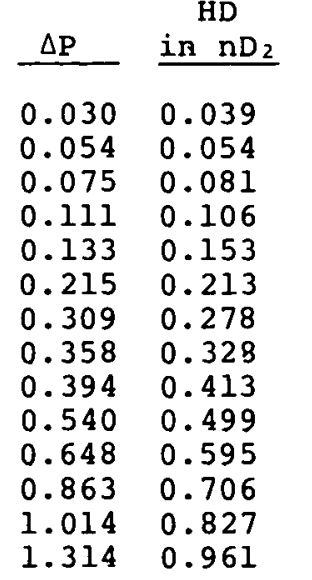

2.58
4.10
5.80
7.94
11.88
16.83
23.18
30.96
40.82
52.17
65.49
81.49
100.15
122.13

\begin{tabular}{c}
$\mathrm{HP}$ \\
in $\mathrm{eD}_{2}$ \\
\hline
\end{tabular}

0.006

0.008

0.012

0.015
0.022

0.030

0.040

0.048

0.060

0.085

0.101

0.118

0.137

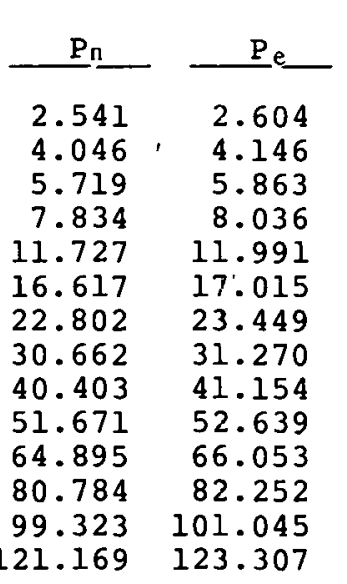

\begin{tabular}{l} 
ln(Pn/Pe) \\
\hline-0.0245 \\
-0.0244 \\
-0.0248 \\
-0.0256 \\
-0.0223 \\
-0.0236 \\
-0.0279 \\
-0.0209 \\
-0.0184 \\
-0.0186 \\
-0.0177 \\
-0.0180 \\
-0.0172 \\
-0.0175
\end{tabular}

$\frac{B \Delta P}{R T}$

0.0000

0.0000

0.0000

0.0001

0.0001 .

0.0001

0.0002

0.0002

0.0002

0.0002

0.0003

0.0003

0.0003

0.0003
$\frac{J}{\left(x-x_{e}\right)}$

0.0785

0.0783

0.0797

0.0817

0.0711

0.0851

0.0663

0.0583

0.0590

0.0560

0.0567

0.0541

0.0551

Table 3

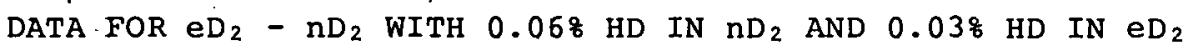

$\frac{1}{T} \quad$ Temperature Pressure $\begin{aligned} & \text { Corrected } \\ & \text { Pressure }\end{aligned}$

$\begin{array}{lrrr}0.0852 & 11.74 & 0.52 & 0.50 \\ 0.0809 & 12.36 & 1.19 & 1.16 \\ 0.0765 & 13.08 & 2.48 & 2.44 \\ 0.0776 & 12.88 & 2.06 & 2.03 \\ 0.0739 & 13.54 & 3.78 & 3.74 \\ 0.0710 & 14.07 & 6.02 & 5.97 \\ 0.0685 & 14.59 & 9.12 & 9.05 \\ 0.0662 & 15.11 & 13.74 & 13.64 \\ 0.0641 & 15.59 & 19.07 & 18.95 \\ 0.0629 & 15.91 & 26.26 & 26.10 \\ 0.0612 & 16.35 & 34.69 & 34.49 \\ 0.0597 & 16.75 & 44.90 & 44.66 \\ 0.0583 & 17.16 & 57.32 & 57.01 \\ 0.0570 & 17.54 & 71.81 & 71.43 \\ 0.0355 & 18.02 & 88.74 & 88.28 \\ 0.0546 & 18.33 & 104.41 & 103.87 \\ 0.0538 & 18.58 & 121.26 & 120.68 \\ 0.0535 & 18.69 & 126.65 & 126.05\end{array}$

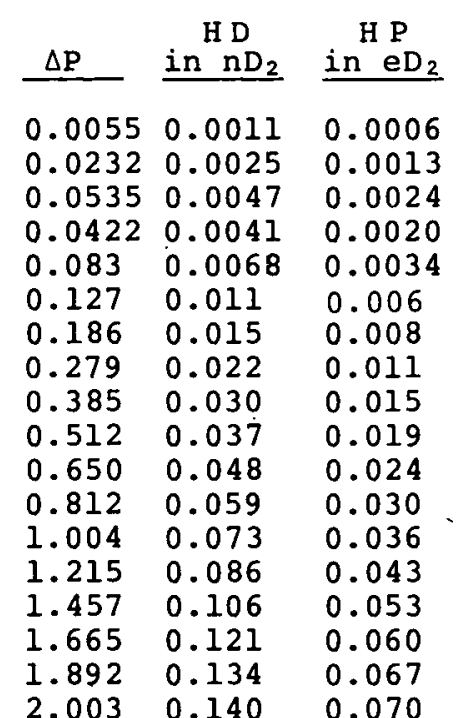

0.070

\begin{tabular}{|c|c|}
\hline$\underline{P}_{n}$ & $\mathrm{Pe}$ \\
\hline 0.499 & 0.505 \\
\hline 1.158 & 1.182 \\
\hline 2.435 & 2.491 \\
\hline 2.026 & 2.070 \\
\hline 3.733 & 3.815 \\
\hline 5.959 & 6.091 \\
\hline 9.035 & 9.228 \\
\hline 13.628 & 13.918 \\
\hline 18.920 & 19.320 \\
\hline $\begin{array}{l}26.063 \\
34.442\end{array}$ & $\begin{array}{l}26.593 \\
35: 116\end{array}$ \\
\hline 44.601 & 45.442 \\
\hline 56.937 & 57.978 \\
\hline 71.344 & 72.602 \\
\hline 88.174 & 89. \\
\hline 103.749 & 105. \\
\hline 120.546 & 122. \\
\hline 125.910 & 127. \\
\hline
\end{tabular}

$\ln (\mathrm{Pn} / \mathrm{Pe})$
-0.0120
-0.0204
-0.0227
-0.0216
-0.0229
-0.0219
-0.0211
-0.0210
-0.0209
-0.0201
-0.0194
-0.0186
-0.0181
-0.0175
-0.0169
-0.0165
-0.0161
-0.0163

\begin{tabular}{ll}
$\frac{B \Delta P}{R T}$ & $\frac{J}{\left(X-X_{e}\right)}$ \\
\hline 0.0000 & 0.0385 \\
0.0000 & 0.0647 \\
0.0000 & 0.0727 \\
0.0000 & 0.0692 \\
0.0000 & 0.0734 \\
0.0000 & 0.0702 \\
0.0001 & 0.0673 \\
0.0001 & 0.0669 \\
0.0001 & 0.0666 \\
0.0001 & 0.0641 \\
0.0002 & 0.0615 \\
0.0002 & 0.0588 \\
0.0002 & 0.0574 \\
0.0003 & 0.0551 \\
0.0003 & 0.0532 \\
0.0003 & 0.0519 \\
0.0004 & 0.0506 \\
0.0004 & 0.0513
\end{tabular}




$$
\begin{aligned}
& \frac{J}{X-X_{e}}=-\frac{G^{E}-G_{e}^{E}}{R T}\left(X-X_{e}\right)-\ln \frac{P_{2} \circ *}{P_{1} \circ *} \\
& =-\frac{\Lambda}{R}\left[\frac{\theta_{r} D^{2}}{T^{2}}-\frac{59}{80 T}\right]\left(X-X_{e}\right) \\
& -\left[\frac{25}{48} \frac{\Lambda}{R T}+\frac{12 N}{R T}\left(U_{01}-U_{0}\right)\right] .
\end{aligned}
$$

The rotational Debye temperature for deuterium is $\theta_{\mathrm{I}} \mathrm{D}_{2}$. The difference in radial interaction between a pair of ortho and para molecules and a pair of ortho molecules is $\mathrm{U}_{01}-\mathrm{U}_{00}$. The quantity $\Lambda=70 / 3$ $\left(\mathrm{N} \Gamma^{2} / \mathrm{R} \theta_{\mathrm{I}} \mathrm{D}_{2}\right)$, where $\Gamma$ is the electric quadrupole constant. A determination of this quantity is the aim of the present experiments.

The data taken using the samples listed in Table 1 are plotted in the form $\mathrm{J} / \mathrm{X}-\mathrm{X}_{\mathrm{e}}$ vs. $\mathrm{l} / \mathrm{T}$ in Figures 1,2 , and 3 . The normal vs. equilibrium concentrations or $(\mathrm{X}-\mathrm{Xe})=0.333-0.021=312$ are shown in Figure 1. The scatter is much greater in the data with the higher concentration in the normal sample. This fact is also true in Figure. 2, where $\mathrm{x}-\mathrm{X}_{\mathrm{e}}=0.139$; although in this case, the sample with high concentration HD was run only one day. It is clear that precise data cannot be obtained from samples with more than 0.18 HD concentration. The data for pairs of samples with the low HD concentration are shown again in Figure 3 where the time dependent effect at large $1 / T$ is clearly seen. This effect may be caused by diffusion of HD in the sample surface or it may be because of clustering of para molecules in the para-rich part of the pair of samples.

If one compares the values of $\mathrm{J} /\left(\mathrm{x}-\mathrm{x}_{\mathrm{e}}\right)$ from Figure 3 with the data of Meckstroth and White near $1 / T=0.0540$, one obtains the points on Figure 4 . Although the Meckstroth and White data are not corrected for HD content; the preliminary measure of the slopes for the two sets of data gives about the same value for the first term in Eq. 7. The work is being continued with higher concentration para samples. A $60 \%$ para sample has been obtained from Professor White that has a smaller HD concentration than those listed in Table 1 , and this sample should be a good test of the explanations of the time dependent effects seen in Figure 3 .

(George T. McConville)

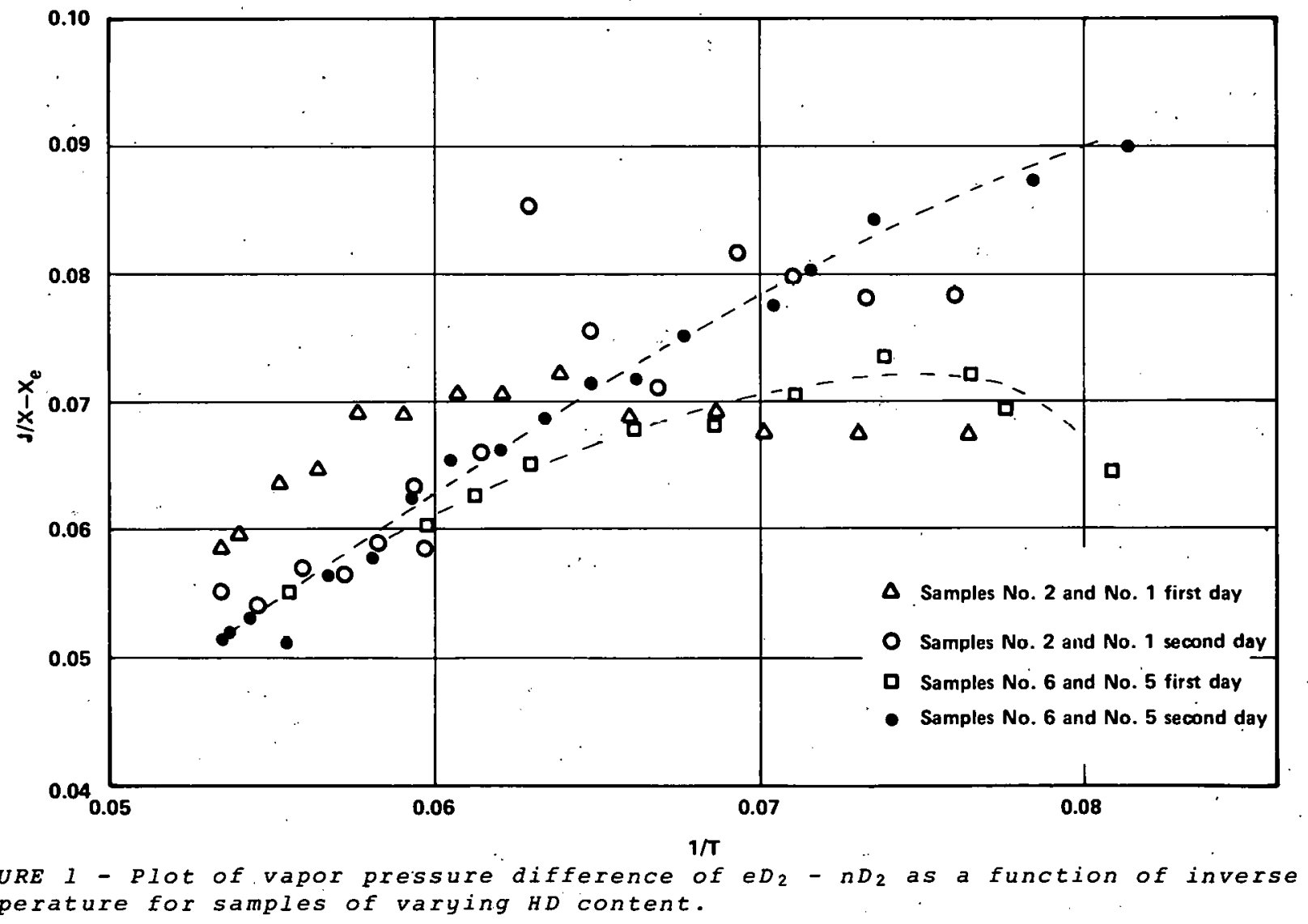




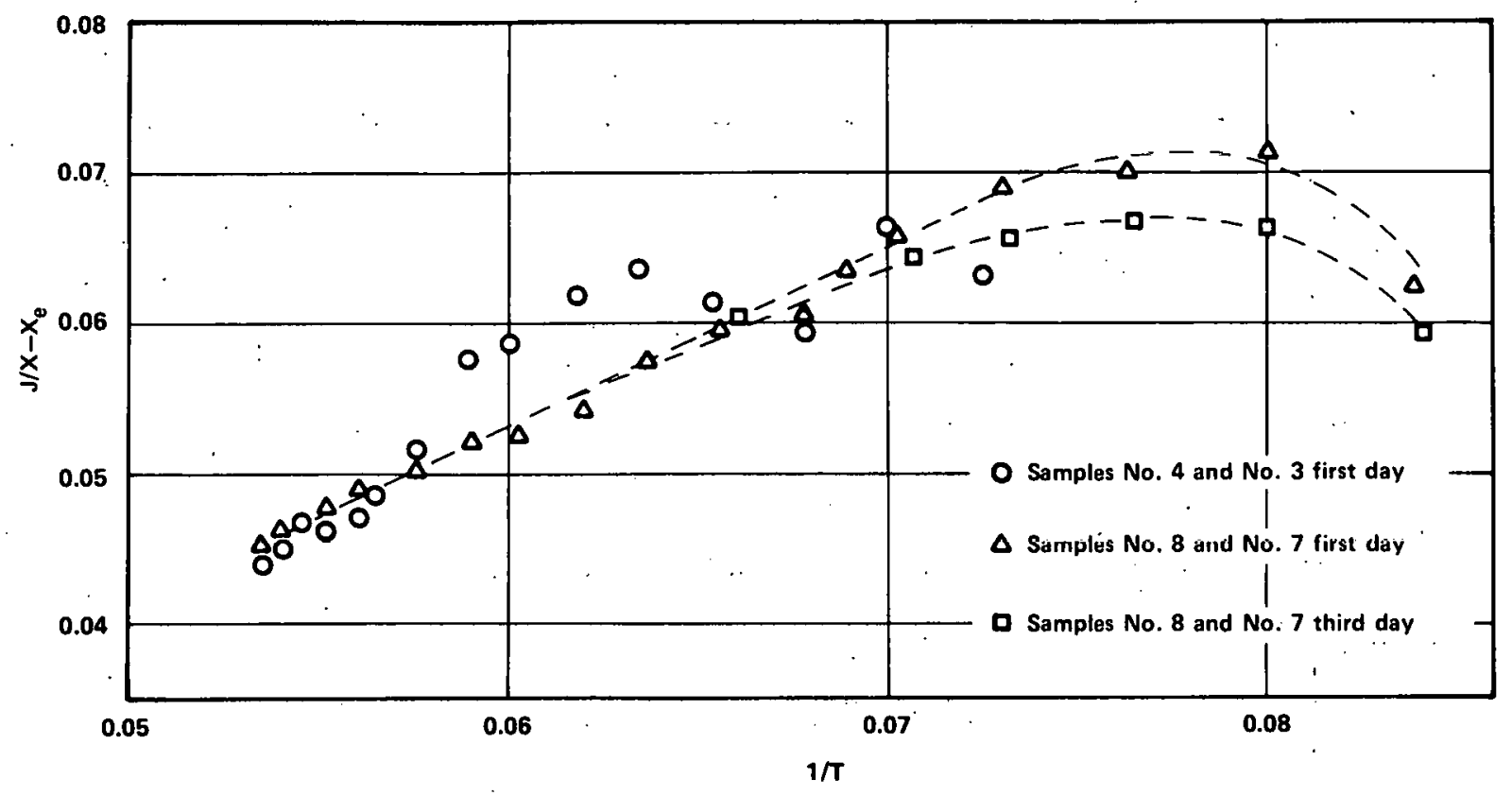

FIGURE 2 - Plot of vapor pressure differences of eD 2 - $18 \%$ para for different HD content.

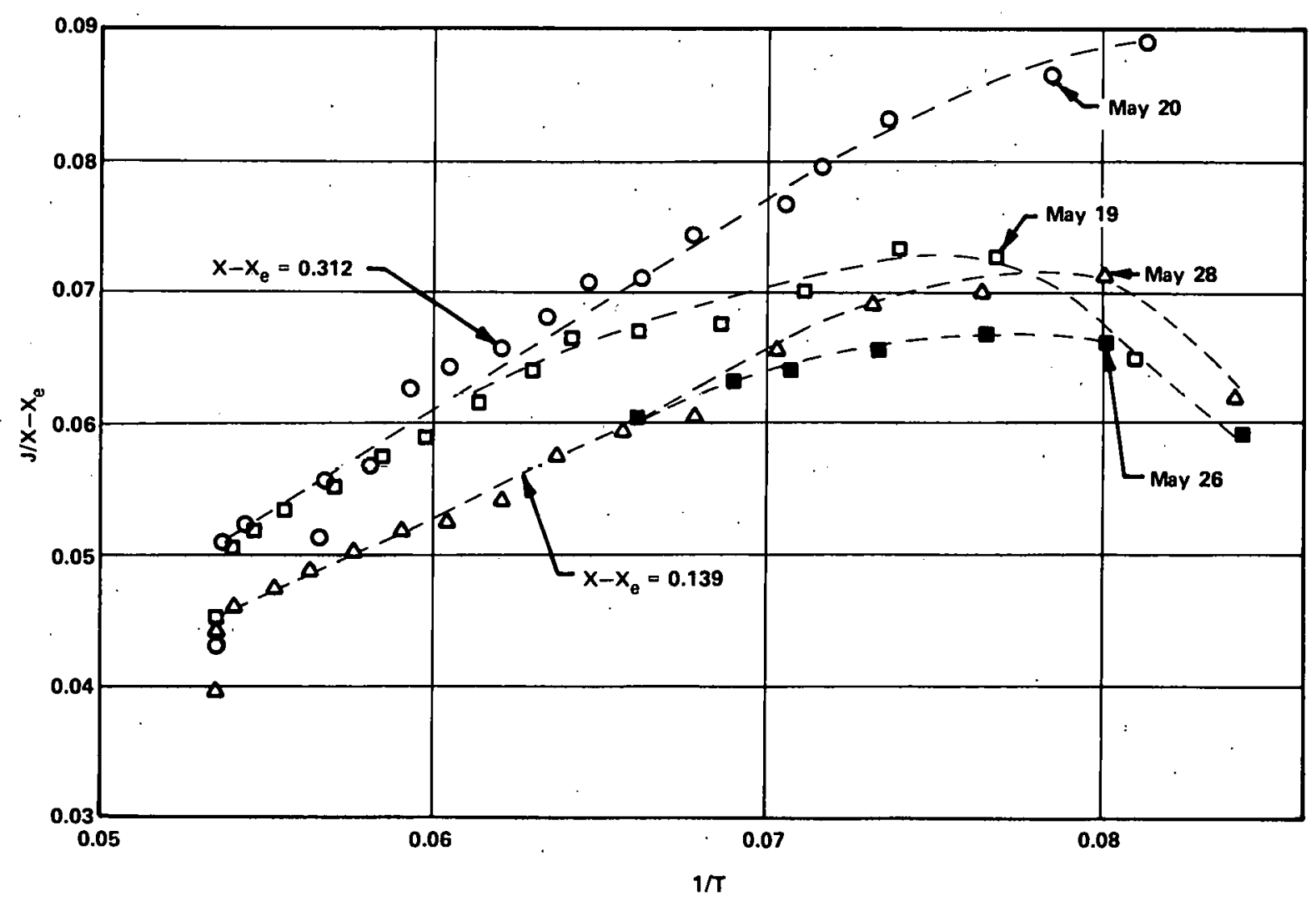

FIGURE 3 - Data taken from Figures 1 and 2 for samples containing the smaller HD concentrations. 


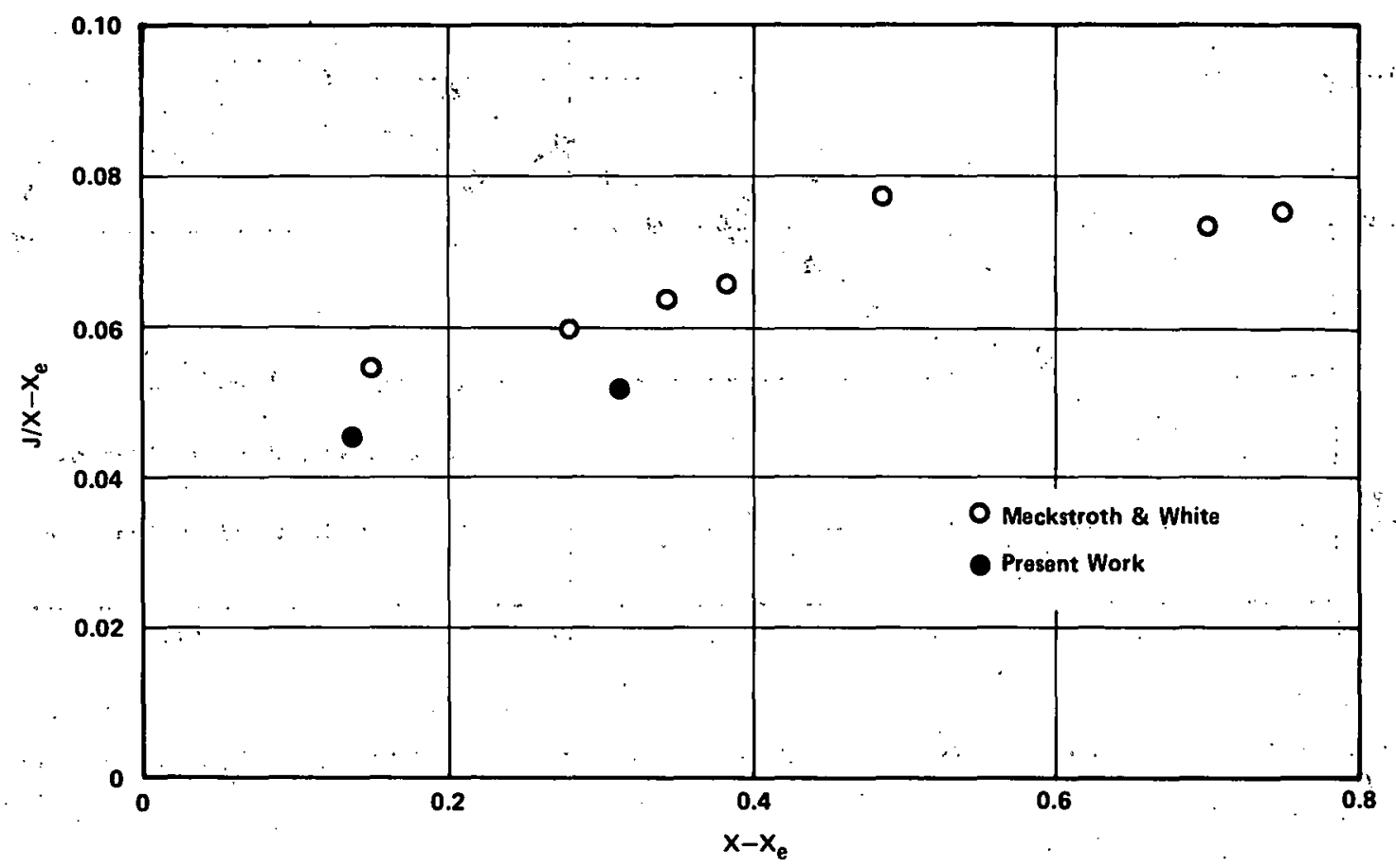

FIGURE 4 - Plot of $J /\left(X-x_{e}\right)$ vs $\left(X-x_{e}\right)$ to obtain value of first term in Eq. 7 . 


\section{Metaī Hydride Research}

\section{BAND THEORY AND ELECTRONIC STRUCTURE}

During the past six months, the emphasis of band theory and electronic structure research has shifted from the self-consistent plane wave Gaussian (SCPWG) programs to ab initio, self-consistent field, molecular-orbital programs. Attempts to use the SCPWG programs to calculate the electronic properties of titanium and titanium hydrides have foundered upon two major points :

(1) There seems to be a numerical instability in the approach to selfconsistency for metals or metallic compounds. To damp this instability, it is necessary to decrease the rate of approach to self-consistency and thereby increase the number of iterative cycles. In many self-consistent calculations, it is necessary to use 10 to 20 iterations to achieve self-consistency. In the past, it had been possible to achieve selfconsistency within 5 to 8 iterations with the SCPWG codes. It becomes relatively more expensive using the SCPWG codes for more iterations because the matrix elements of the Hamiltonian have to be recalculated during each iterative cycle, which becomes a severe limitation when it is necessary to use a larger number of values of the crystal momentum $\vec{k}$ to sample the Brillouin zone. This is as opposed to a linear combination of atomic orbitals (LCAO) basis set where the necessary integrals over local basis functions are independent of $\vec{k}$. It is necessary to carry only one set of integrals that can be used with orly a change in multiplying phase factors.

(2) One of the reasons for choosing the SCPWG programs for an initial investigation was because it was not believed economical to perform accurate $a b$ initio Hartree-Fock calculations on perfect crystals that involve first-row transition metals. The use of the local density approximation to the Hartree-Fock exchange generally results in a savings of computer resources. There has always been a serious question, however, of the dependence of the calculated results upon the magnitude of the approximation to the exchange potential, and it has been believed that the savings to be achieved with the approximation would outweigh the loss in accuracy. For technical reasons relating to the mathematical form of the exchange potential, it is also far easier to apply the exchange approximation when using a plane wave or a mixed atomic-orbital/ plane-wave basis.

For these two reasons, we are investigating the feasibility of using the local orbitals for polyatomic systems (LOPAS), $\mathrm{ab}$ initio, Hartree-Fock, computer codes of Prof. A. B. Kunz and co-workers of the Univ. of Illinois Materials Research Laboratory. These codes have been successfully applied by those workers to a wide range of insulators and semiconductors and metallic calcium. It is uncertain at this time, however, just how successfully they can be applied to transition metals. and metal hydrides for two reasons: the computer resources required may be too great; and (2) it is not always certain how to choose the constituent atomic subunits of a crystal for the local orbitals program when there is a significant charge transfer involved in the crystal formation. In collaboration with Prof. Kunz, we plan to begin calculations on $\mathrm{TiH}_{2}$ and FeTi. He has kindly supplied us with a copy of his local orbitals code. only minor changes were necessary to make it run on the Control Data Corp. 6600 computers at Wright-Patterson AFB, Aeronautical systems Division, which are being used by Mound Laboratory for this work. This code is to be accompanied by a second part, which is necessary to calculate the electronic band structure. When 1t is implemented on these computers, it will be possible to study the systems of interest to compare the two approaches of approximate Hartree-Fock (SCPWG) and Hartree-Fock (LOPAS).

Still larger efforts during the past six months have been expended on evaluating the feasibility of performing accurate Hartree-Fock (HF), unrestricted HartreeFock (UHF), and generalized valence bond (GVB) calculations on clusters of atoms rather than on perfect crystals. An initial attempt was made to use the Gaussian 70 program obtained from Battelle Laboratory (Columbus). This program was originally developed by Prof. J. A. Pople and co-workers of Carnegie Institute of 
Technology and Mellon Institute. Because of the lack of proper documentation of the version obtained (to which had been added the d-electron package by workers at Battelle), and the sometimes uncertain knowledge of how dependable the code in a particular version was, we decided at Mound to acquire our own version of computer programs that would allow us full control of the package and far more flexibility than the Gaussian 70 package. In addition, we have acquired the consultant services of Dr. F. W.

Bobrowicz of the Univ. of Southern California to combine the BIGGMOLI integrals programs of Dr. R. C. Raffenetti (NASA, Langley) with the GVBTWO general selfconsistent field program written by $F$. W. Bobrowicz (USC), W. R. Wadt (Mound Laboratory), and W. A. Goddard (Caltech). BY the end of July 1976, an unrestricted Hartree-Fock option will also have been added to the package of programs. This program package promises to be a significant advance in the field because of increased efficiency of coding and because of the basis set contraction methods possible with the integrals programs of Dr. Raffenetti. The initial work to be performed with these programs will be $\mathrm{Sc}_{2}$, $\mathrm{SCH}, \mathrm{ScH}_{2}, \mathrm{Sc}_{2} \mathrm{H}_{2}, \mathrm{Ti}_{2}, \mathrm{TiH}, \mathrm{TiH}_{2}$, and $\mathrm{Ti}_{2} \mathrm{H}_{2}$. Parts of this work will be done in collaboration with Dr. Carl Melius of Sandia Livermore for the purposes of avoiding unnecessary duplication of effort and obtaining a maximum acceleration of the program objectives. This collaboration will also provide us with a valuable opportunity to compare the new version of computer codes available at Mound Laboratory to previous versions (namely, those that are used by Dr. Melius for accuracy and possible improved performance). (Jerry L. Ivey and willard R. Wadt)

\section{ELECTRON PARAMAGNETIC RESONANCE STUDIES OF RHODIUM IONS IN LITHIUM HYDRIDE AND LITHIUM DEUTERIDE SINGLE CRYSTALS}

Electron paramagnetic resonance (EPR) studies of transition metal and rare earth ions in diamagnetic metal hydrides, now in progress, should lead to a better understanding of metal-hydrogen chemical bonding. Trends in the covalent contribution to metal-hydrogen bonds are investigated by analyzing magnetic g-factors and hyperfine constants of paramagnetic impurity ions doped in binary and ternary hydrides whose bonding characteristics vary from ionic to metallic.

Lithium hydride was chosen as initial host material for the EPR studies because:
1. Availability of single crystals of LiH and LiD permit evaluation of local symmetry about the paramagnetic impurity and a more direct determination of the anistropic components to the magnetic parameters.

2. Predictions of ab initio quantum mechanical calculations on atomic clusters being developed at Mound Laboratory can be more accurately tested for a transition metal ion in relatively large clusters of $\mathrm{Li}$ and $\mathrm{H}$ atoms.

Although studies by Messer et al. ${ }^{6,7}$ have indicated that several transition metal and rare earth ions are insoluble in LiH, rhodium ( $R$ h) metal can react ${ }^{8}$ with $\mathrm{LiH}$ to form $\mathrm{Ii}_{4} \mathrm{RhH}_{4}$ and $\mathrm{Li}_{4} \mathrm{RhH}_{5}$. This suggests $R h$ could be sufficiently soluble in LiH to permit EPR studies. Single crystals of $\mathrm{LiH}$ and $\mathrm{LiD}$ containing $\sim 100 \mathrm{ppm}$ $R h$ have been grown by $R$. $S$. Carlson of this laboratory. Illumination of these crystals for one minute with ultraviolet light from an unfiltered 100-W mercury lamp produces readily detectable EPR signals associated with paramagnetic $R h$ species. Prior to exposure these signals, when they could be observed, were very weak. Hence, a change in the $\mathrm{Rh}$ oxidation state from a diamagnetic to a paramagnetic ion is occurring. Strong EPR signals are again observed several months after exposure to the ultraviolet light, indicating a relatively stable paramagnetic species.

Following these preliminary results, EPR spectra of $R$ h dissolved in $L i H$ and $L i D$ were investigated in the temperature range $77^{\circ}$ to $325^{\circ} \mathrm{K}$. We used a varian $\mathrm{E}-1$ ine spectrometer operating at about $9.5 \mathrm{GHz}$ in either first ( $100 \mathrm{kHz}$ modulation) or second derivation (100 kHz, $1 \mathrm{kHz}$ double modulation) mode.

With the LiD single crystal we observed spectra for two distinct paramagnetic species, both conforming to a spinHamiltonian $\mathrm{H}=\beta \overrightarrow{\mathrm{H}} \cdot \tilde{\mathrm{g}} \cdot \hat{\mathrm{S}}+\hat{\mathrm{S}} \cdot \tilde{\mathrm{A}} \cdot \hat{\mathrm{I}}$ with $S=1 / 2$ and $I=1 / 2$. The spectra for species A gradually disappeared in the range $125-200^{\circ} \mathrm{K}$, apparently because of line-broadening. Spectra $B$ was stable at all observed temperatures.

Figure 5 shows first derivative spectra of Lid with the magnetic field along a [100] direction at $210 \mathrm{~K}$ and $77 \mathrm{~K}$, respectively. This figure shows clearly the emergence of spectra $A$ at low temperatures. Increasing the microwave power saturates spectra $B$, thus allowing determination of the spectra A parameters 


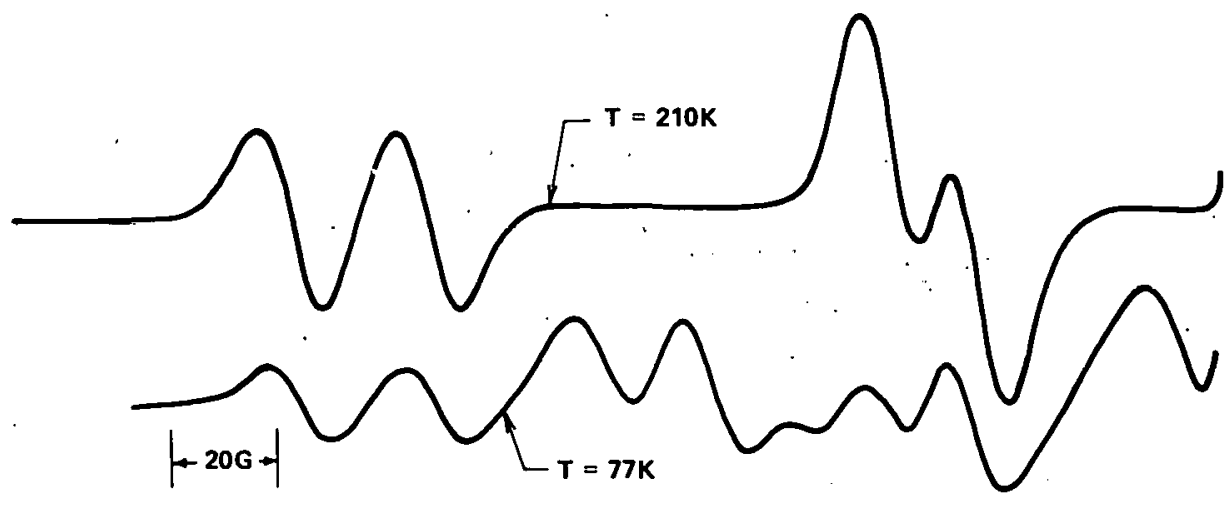

FIGURE 5 - EPR lst derivative absorption curves of a Rh-LiD crystal, recorded with H along a [100] direction. The sharp absorption at the right is DPPH inserted as a gmarker.

Figure 6 shows second derivative spectra at $77 \mathrm{~K}$ of LiD with the magnetic field along the [111] direction. The upper spectrum corresponds to a microwave power level of $100 \mathrm{~mW}$, whereas the other is at $5 \mathrm{~mW}$. This figure shows two resolved doublets indicating magnetic coincidence of the three independent centers (that is, in the cubic LiD crystal, the directions $[100],[010]$ and $[001]$ are all equivalent) for each species.

From the spectra in Figures 5 and 6 , it is possible to deduce that spectra B belongs to a center having axial symmetry, A having orthorhombic symmetry. The principal axes of the $\tilde{g}$ and $\tilde{A}$ tensors of both species appear to coincide with the crystallographic axes of the LiD lattice. Table 4 gives the principal values of the $\ddot{g}$ and $\ddot{A}$ tensors and compares these with results obtained for other host materials doped with Rh.

For LiD, spectra B (that is, the axially symmetric species) can be explained by the conventional approach ${ }^{9}$ developed for strong-field, low-spin d-group ions. In this way we have determined the paramagnetic species responsible for spectra $B$ as elther RhII (4d) or Rho $\left(4 d^{9}\right)$ in a tetragonally-distorted octahedral field. It is experimentally difficult to choose between these two possibilities based on EPR data alone. In either case, the observation $g_{11}>g_{1}>g_{e}$ is evidence that the odd electron occupies primarily a $\mathrm{d}_{\chi^{2}}-\mathrm{y}^{2}$ molecular orbital having lobes aimed directly at the four nearest neighbor deuterons in the $x y-p l a n e$ (perpendicular to the symmetry axis). The formulae 10 for the g-tensor and hyperfine tensor are ac follows:

$$
\begin{aligned}
g_{11} & =2-\frac{8 \lambda}{\Delta_{0}} \\
g_{\perp} & =2-\frac{2 \lambda}{\Delta_{1}} \\
A_{\| 1} & =p\left[-k-4 / 7-\frac{6 \lambda}{7 \Delta_{1}}-\frac{8 \lambda}{\Delta_{0}}\right] \\
\therefore A_{\perp} & =p\left[-k+2 / 7-\frac{11 \lambda}{7 \Delta_{1}}\right] \ldots
\end{aligned}
$$

where $\lambda$ is the spin-orbit coupling parameter ( $\lambda$ less than 0 when the $d$-shell is more than half-filled); $\Delta_{0}$ and $\Delta_{1}$ are energy differences $\left(\Delta_{0} \simeq \Delta_{1}\right)$ between the $t_{2 g}$ and $e_{g}$ manifolds; $P$ is a constant that depends on the nuclear moment of $\mathrm{Rh}$ and on $\left\langle r^{-3}\right\rangle$ where $r$ is the instantaneous 


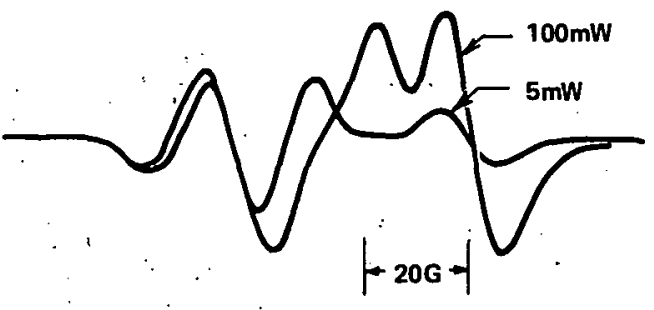

FIGURE 6 -EPR 2nd derivative absorption curves of a Rh-LiD crystal, recorded with $H$ along $[111]$ at $77 \mathrm{~K}$.

Table 4

EPR DATA FOR VARIOUS PARAMAGNETIC RHODIUM SPECIES

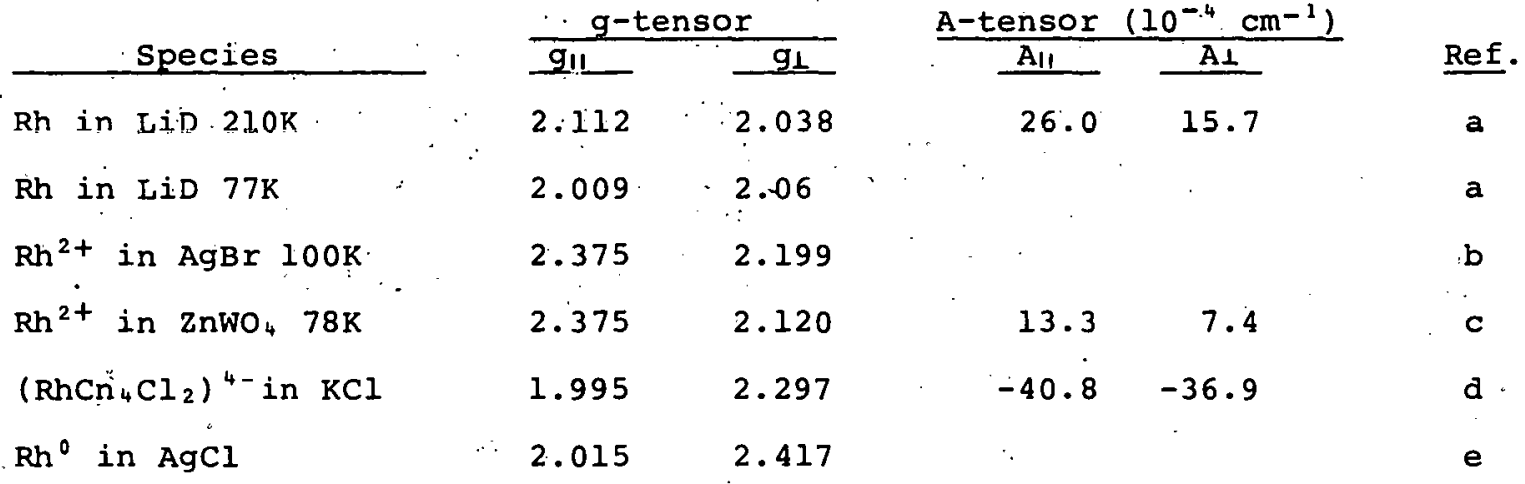

ahis work:

${ }^{b}$. S. Eachu and R. E. Graves, J. Chem. Phys., 61, 2860 (1974).

CM. G. Townsend, J. Chem. Phys.; 41, 3149 (1964).

${ }^{d}$ R. P. A. Muniz, N. V. Vugman and J. Danon, J. Chem. Phys., 54, 1284 (1971).

e J. Wilkens, D. P. De.Graag and J.N. Helle, Phys. Lett., 19, 178 (1965). 
position of the paramagnetic electron relative to the $\mathrm{Rh}$ nucleus; and $\kappa$ is the core-polarization parameter. 11 The latter two quantities are usually treated as parameters to be determined by experiment. The values we obtain are consistent with past experience and are indicative of covalent bonding with the ligand atoms.

The effects of covalent bonding are immediately apparent in the spectra of LiH doped with $\mathrm{Rh}$. The spectra from species $B$ now contain additional lines (called superhyperfine or simply shf) that can only be caused by bonding interactions of the paramagnetic electron with nearest-neighbor protons (the nuclear moment of ${ }^{2} \mathrm{H}$ is insufficient to permit observation of these lines in LiD).
These shf lines, in addition to associated satellite lines from the relative magnitude of the nuclear Zeeman term, allow a clear resolution of the spectrum only when the magnetic field is either parallel or perpendicular to the symmetry axis. We show the spectrum for each of these orientations in Figure 7. The temperature is $210 \mathrm{~K}$, thus eliminating signals from species $I$. Note that in the parallel position the shf lines are not resolved.

These results are being analyzed in terms of ligand-field theory and are expected to provide quantitative information about the extent of covalent bonding in the $\mathrm{Rh}-\mathrm{H}_{4} \quad \mathrm{~d}_{\mathrm{x}}{ }^{2}-\mathrm{y}^{2}$ molecular complex.

(George $C .^{-y}$ Abell and Robert C. Bowman,Jr.)

FIGURE 7 - EPR lst derivative adsorption curve of a Rh-LiH crystal, recorded with $H$ along a [100].direction at $210 \mathrm{~K}$ (compare with Figure 5).

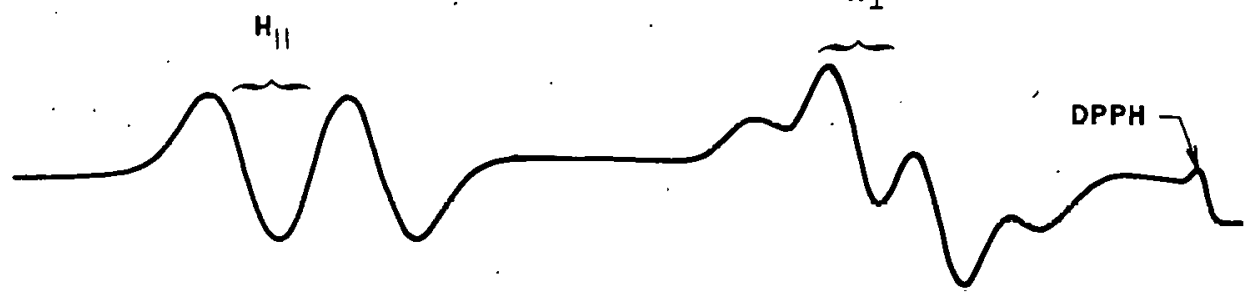


Studies of TiFeH $_{x}$

The intermetallic compound titanium-iron (TiFe) will react directly with hydrogen gas to form, in succession, hydrides of . composition TiFeH and $\mathrm{TiFeH}_{2}$.. Reilly and Wiswali 2 have measured the dissociation pressures as well as other properties: of these hydrides and concluded $\mathrm{TiFeH}_{\mathrm{x}}$ is a promising candidate for both mobile and stationary hydrogen storage applications. ${ }^{13}$ The phase diagram for the TiFeH ${ }_{x}$ system as determined by Reilly and Wiswall is shown in Figure 8 . The characteristics of the three known $\mathrm{TiFeH}_{\mathrm{x}}$ phases are presented in Taole 5 (the lattice parameters $a$ and $c$ were determined at Mound). Unfortunately, many important physical properties such as crystal structure, hydrogen occupancy sites, electronic structures, and hydrogen mobility have not been determined for the TiFeH $x$ phases. Since nuclear magnetic resonance (NMR) can provide detailed information on the physical states of hydrogen atoms, a comprehensive investigation using pulse NMR techniques has been undertaken to evaluate the fundamental physical properties of the $\mathrm{TiFeH}_{\mathrm{x}}$ system.

Samples of $\mathrm{TiFeH}_{1.1}$ and $\mathrm{TiFeH}_{1.7}$ were prepared from two batches of TiFe compound. One batch was prepared at Mound by arcmelting a stoichiometric mixture of pure metal powders under argon; whereas the second batch was purchased from Alfaventron. Both TiFe batches were reasonably pure with the exception of about 0.3 wt ox oxygen. The TiFe powders were reacted with 1000 psi hydrogen gas following the general procedures described by Reilly and Wiswall. ${ }^{2}$ The offgassing of hydrogen from the TiFeH:x samples was reduced by exposing the samples to air at low temperatures as suggested by Reilly and wiswall. Subsequent $x$-ray diffraction analyses verified the presence of $\beta$-phase for $\mathrm{TiFeH}_{1.1}$ and $\gamma$-phase for TiFeH 1.7 .

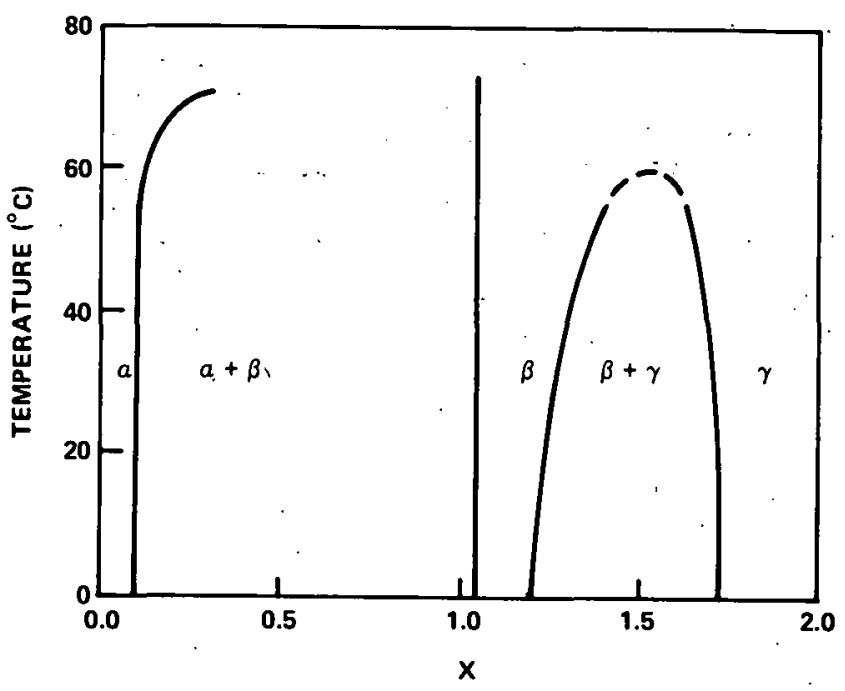

FIGURE 8 - Phase diagram of FetiHX (after Reilly \& Wiswall).

During the initial studies ${ }^{14}$ on the $\mathrm{TiFeH}_{\mathrm{x}}$ samples, no free induction decay (FID) proton signals were detected following a single $\pi / 2$-pulse. However, an extremely sharp (that is, $\mathbf{T}_{2} *<5$ sec) proton spin echo is observed when a $\pi / 2-t^{\prime}-\pi / 2$ pulse sequence (with $t^{\prime}<50 \mu \mathrm{sec}$ ) is applied. Since the electronic recovery time of the pulse spectrometer is $\sim 8-10 \mu \mathrm{sec}$, the proton FID decays too rapidly, for detection after a single pulse. The proton lineshapes for both $\mathrm{TiFeH}_{\mathrm{x}}$ phases are approximately Gaussian (a.lthough there are in-, dications of some more slowly decaying contributions).

Table 5 .

\section{IRON-TITANIUM HYDRIDES $\left(\right.$ FeTiH $\left._{x}\right)$}

\begin{tabular}{clc} 
Phase & & $\begin{array}{c}\text { Lattice } \\
\text { Parameters }\end{array}$ \\
\cline { 3 - 3 }$\alpha$ & & $a=2.977 \pm 0.003$ \\
$\beta$ & $a=3.17 \pm 0.02$ \\
& $\quad c=8.76 \pm 0.03$ \\
$\gamma$ & $a=6.61 \pm 0.03$
\end{tabular}

Structure $\frac{\begin{array}{c}\text { Structure } \\ \text { Type }\end{array}}{\text { Cubic }} \quad \frac{\text { CsCl }}{\text { Cscla }}$

Tegragonal Unknown

Cubic

Unknown
Composition Range e $298 \mathrm{~K}$

$$
x \leqslant 0.1
$$

$1.04 \leqslant x \leqslant 1.22$

$x \geqslant 1.7$ 
The line width relaxation time $\left(T_{2} *\right)$ is defined as the time required for the proton signal to decay to $1 / e$ of its maximum value.

The resonance frequency (or, equivalently, magnetic field strength) dependence for $\mathrm{T}_{2}{ }^{*}$ and the spin-lattice relaxation time $\mathrm{T}_{1}$ at room temperature are given in Table 6. The decrease in $T_{2} *$ as the resonance frequency increases implies the echo is inhomogeneously broadened (that is, $T_{2}$ * is not only caused by field-independent spin dipolar interactions but also has inhomogeneous magnetic contributions). The independence of $\mathrm{T}_{1}$ to magnetic field strength indicates the major relaxation mechanism is probably caused by interactions with conduction electrons and not hydrogen diffusion.

\section{Table 6}

NMR PARAMETERS FOR FeTiH AT ROOM -TEMPERATURE

\begin{tabular}{|c|c|c|c|c|}
\hline \multirow[b]{2}{*}{$\begin{array}{c}\nu \\
(\mathrm{MHz}) \\
\end{array}$} & \multicolumn{2}{|c|}{ FeTiH $_{1.1}$ ( $\beta$-phase) } & \multicolumn{2}{|c|}{ FeTiH ${ }_{1.7}$ ( $\gamma$-phase } \\
\hline & $\begin{array}{c}\mathrm{T}_{2}{ }^{\star} \\
\text { (usec) }\end{array}$ & $\begin{array}{c}\mathrm{T}_{1} \\
\text { (msec) }\end{array}$ & $\begin{array}{l}T_{2}{ }^{*} \\
(\mu \text { sec })\end{array}$ & $\begin{array}{c}\mathrm{T}_{1} \\
\text { (msec) }\end{array}$ \\
\hline 45.7 & - & - & 2.4 & 23 \\
\hline 34.5 & 3.3 & 6.5 & 2.6 & 23 \\
\hline 23.3 & - & - & 3.0 & 25 \\
\hline 16.0 & 4.8 & 6.6 & 3.8 & 24 \\
\hline
\end{tabular}

The spin-spin relaxation times $T_{2}{ }^{\prime}$ were determined from the dependence of the spin echo maxima on the pulse spacings between the two $\pi / 2$ pulses. The echoes obeyed a Gaussian relation for at least 708 of their decay. Since the spin echo deray shnild be unaffected by field inhomogeneities, the nearly Gaussian behavior is very significant. If the hydrogen atoms in the $\mathrm{TiFeH}_{\mathrm{x}}$ were very mobile, the echo decay is expected to be exponential.15 However, dipolar interactions among rigid atoms normally yield a nearly Gaussian time dependence. Hence, the hydrogen atoms in both $\mathrm{TiFeH}_{\mathrm{x}}$ phases are apparcntly rigidly located on their lattice sites (that is, hydrogen mobility is insufficient to produce an exponential dependence $^{15}$ for the dipolar interaction). The temperature dependence of $\mathrm{T}_{2}{ }^{*}$ and $\mathrm{T}_{2}$ ' for $\mathrm{TiFeH}_{1.0}$ and $\mathrm{TiFeH}{ }_{1.7}$ prepared from the Alfa-Ventron metal is presented in Figure 9. Four observations can be made:

1) $\mathrm{T}_{2}{ }^{\prime} \gg \mathrm{T}_{2}$ * for both $\mathrm{TiFeH}$ phases.
2) $\mathrm{T}_{2}$ * decreases as the temperature is lowered whereas $T_{2}$ ' is essentially temperature independent.

3) $\mathrm{T}_{2}$ * is significantly shorter for $\gamma$-phase TiFeH $_{1.7}$ than for $\beta$-phase TiFeHi.o.

4) $\mathrm{T}_{2}$ ' is not very different (within experimental uncertainty) for the two TiFeH ${ }_{x}$ phases.

The large temperature dependent inhomogeneous contribution to $\mathrm{T}_{2}$ * probably arise from both magnetic impurities (that is, free iron, iron oxides, etc.) and the intrinsic magnetic susceptibilities ${ }^{16}$ of the $\mathrm{TiFeH}_{\mathrm{x}}$ powder samples: $\mathrm{T}_{2}{ }^{\prime}$ probabl.y represents the dipolar interactions between protons for both $\mathrm{TiFeH}_{\mathrm{x}}$ phase. The temperature independence of $\mathrm{T}_{2}$ ' confirms the previous suggestion that the hydrogen diffusion rate is fairly slow (that is, $D \leqslant 10^{-11} \mathrm{~cm}^{2} / \mathrm{sec}$ ) in both phases. In principle, the $\mathrm{T}_{2}$ ' data could be used to determine 7 the probable lattice sites occupied by the hydrogen atoms in both TiFeH ${ }_{x}$ phases. Unfortunately, since the crystal structures of the TiFeH $x$ phases are unknown, this calculation cannot be performed. However, it appears the average separation between hydrogen atoms is not very different for the $\beta$ and $\gamma$ phases since the $T_{2}{ }^{\prime}$ values are nearly equal.

The large contributions of magnetic impurities to the proton NMR line widths in $\mathrm{TiFeH}_{\mathrm{x}}$ has been verified by measurements on a sample of $\mathrm{TiFeH}_{1.1}$ provided by Dr. L. H. Bennett of the National Bureau of standards (NBS). Crude tests with a rare-earth magnet indicate the NBS material has a significantly weaker magnetic susceptibility (that is, smaller concentration of magnetic impurities) than any TiFeHx sample prepared at Mound. The room temperature value for $T_{2}$ * at $34.5 \mathrm{MHz}$ was $7.0 \mu \mathrm{sec}$ for the NBS sample compared to 3-5 $\mu \mathrm{sec}$ for $\mathrm{TiFeH}_{\mathrm{x}}$ samples prepared at Mound. The longer $T_{2}$ * for the NBS sample is exactly as predicted for less magnetic impurities. Although pulse NMR and $x$-ray diffraction measurements at Mound indicate the NBS TiFeH ${ }_{1.1}$ is inhomogeneous and comprised of the $\alpha, \beta$, and $\gamma$ phases, its ' $_{1}{ }_{1}$ and $T_{2}{ }^{\prime}$ values roughly agree with the corresponding values for $\mathrm{TiFeH}_{\mathrm{x}}$ prepared at Mound.

The spin-lattice relaxation rates $\left(1 / T_{1}\right)$ for both $\mathrm{TiFeH}_{\mathrm{x}}$ phases are given in Figure 10. $T_{1}$ for $\gamma$-phase $\mathrm{TiFeH}_{1.7}$ obeys the Korringa relation:

$$
T_{1} T=K \text {, }
$$




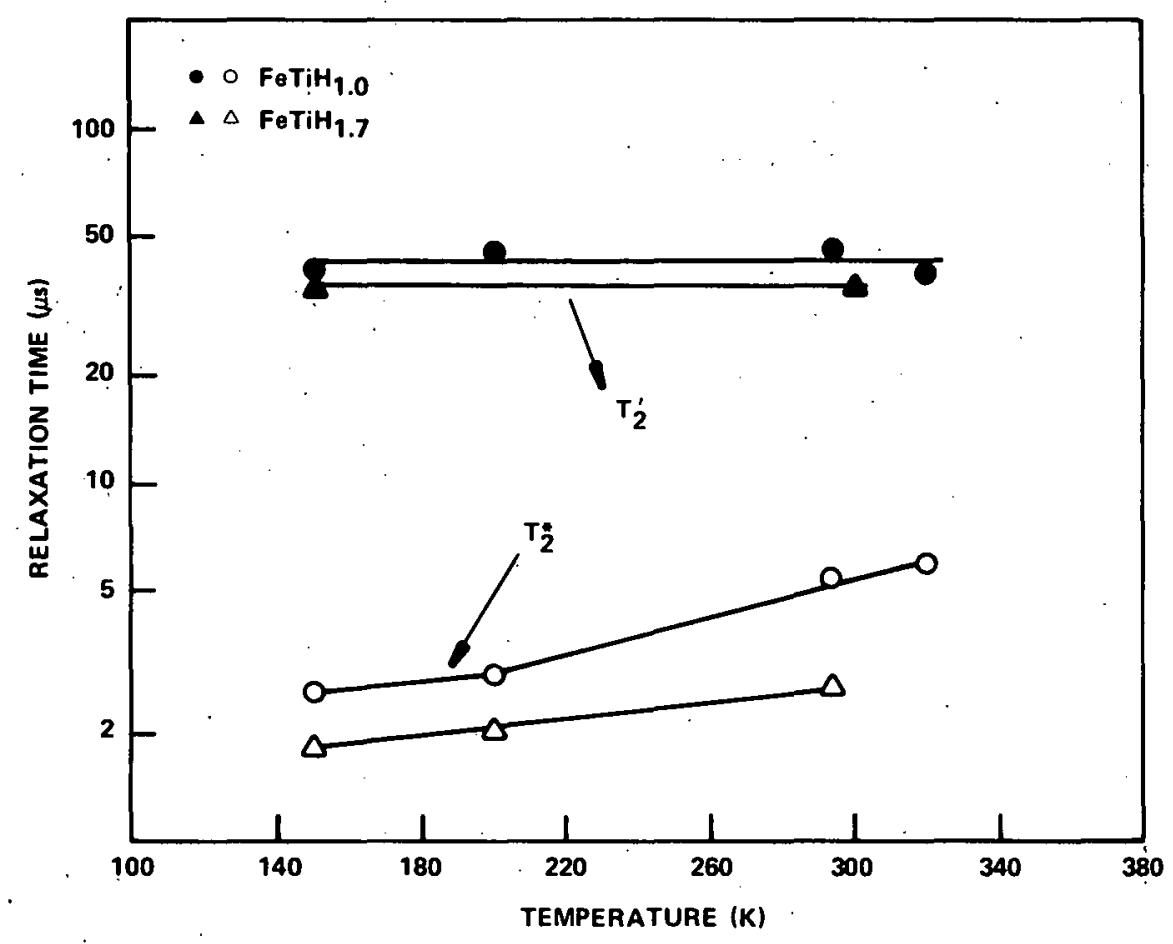

FIGURE 9 - spin-spin relaxation times.

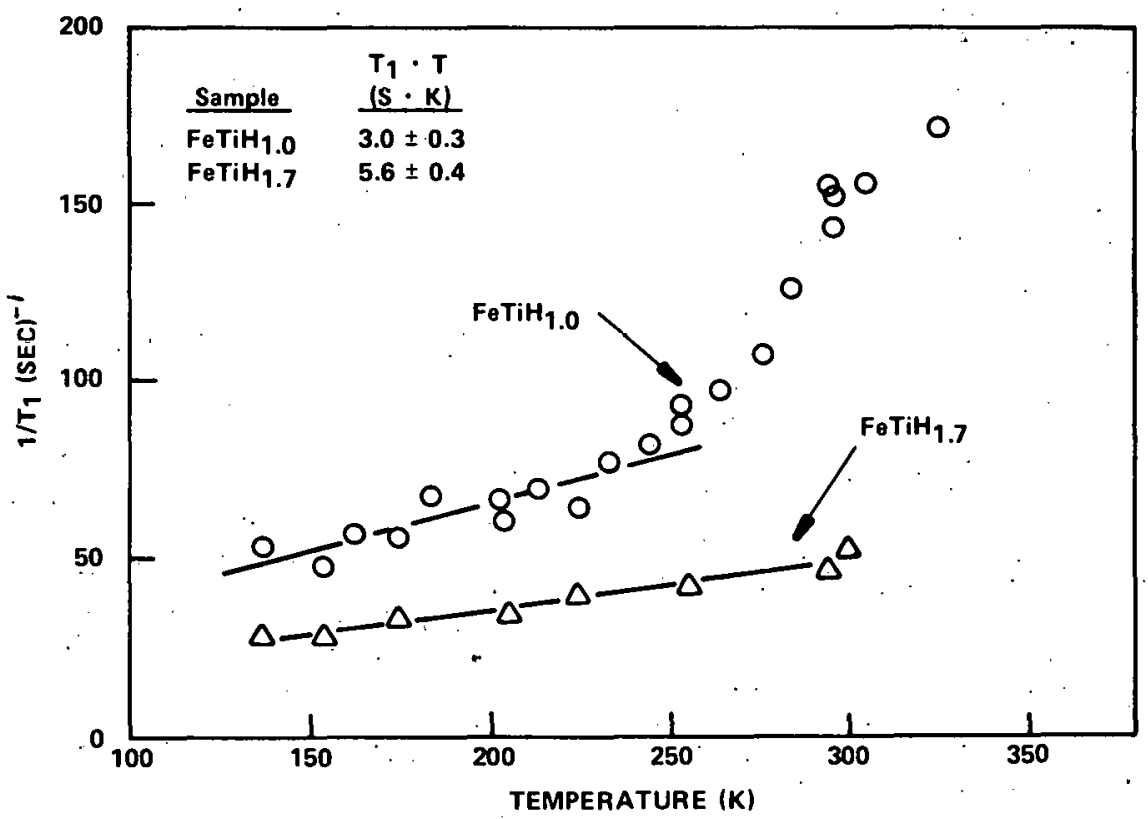

FIGURE 10 - Proton spin-lattice relaxation times. 
throughout the measured temperature range. Here, $T$ is the absolute temperature and $K$ is a constant related to the density of states at the Fermi level. The $T_{1}$ data for $\beta$-phase TiFeH 1.0 exhibits Korringa behavior at low temperature but changes above $\sim 250 \mathrm{~K}$. "From the $\mathrm{T}_{2}$ ' data it seems unlikely the $T_{1}$ values in the $\beta$-phase have large diffusion contributions. Hence, it is tentatively believed that a change in the electronic structure is occurring. in the $\beta$-phase which alters the density of states. Until additional information is available on the crystal structures of the $\mathrm{TiFeH}_{x}$, the $\mathrm{T}_{1}$ data cannot be quantitatively explained. Nevertheless, the values for the Korringa constants given in Figure 10 indicate significant differences in the electronic structures between $B$ and $\gamma$ phase $\mathrm{TiFeH}_{x}$.
Although the current NMR studies have been hampered by the extremely short FID signals that make quantitative measurements very difficult, two approaches are being made to improve the results. First, new batches of TiFe with lower oxygen and magnetic impurity contents will be used to prepare the hydrides. Secondly, the pulse NMR equipment is being modified to provide more intense rf-pulses with short recovery times. These changes, along with improved operating techniques, should permit a more detailed evaluation of the properties of $\mathrm{TiFeH}_{\mathrm{x}}$. (Robert C. Bowman,Jr., Albert Attalla, and Wayne E. Tadlock) 


\section{Separation Chemistry}

PROBLEMS IN PLUTONIUM CHEMISTRY (II-I): CONDITIONS OF EQUILIBRIUM AND

KINETIC VALENCE STATE DISTRIBUTIONS IN LABORATORY AND

ENVIRONMENTAL CIRCUMSTANICES

An interesting phenomenon in recent times is the increased interest in the study of the rates of reactions of plutonium in aqueous solutions. ${ }^{8}$. In comparison, the statics of plutonium solutions have not appeared to elicit much interest. Both areas of study share some elementary conditions which, while not ordinarily the focus of attention, may nevertheless prove occasionally useful. A brief consideration of these conditions might take the following form. ( $w$ = trivalent plutonium, $\mathrm{X}=$ tetravalent plutonium, $\mathrm{Y}=$ pentavalent plutonium, $\mathrm{z}$ = hexavalent plutonium, and $A W, A Y$, and $A Z$ are the respective alpha coefficients for these oxidation states.)

A solution contains only plutonium. At equilibrium, the sum of the fractions of all valence forms must be equal to unity. This represents the conservation of mass. Otherwise stated, the sum of the amounts of all valence forms must be equal to the initial amount of plutonium. The plutonium average oxidation number (N) of the final valence state distribution must be equal to the average oxidation number of the initial plutonium. Exceptions to the constancy of the average oxidation number are few and well defined, for example, solvent decomposition via a nonequilibrium form of the plutonium such as heptavalent plutonium or plutonium metal, and the effects of valence wandering produced by the internal alpha radiations of the various plutonium isotopes.19. In other words, charge conservation applies except in special circumstances. It applies because no electrons are transferred into or out of the vessel containing the plutonium. ${ }^{20}$ If at equilibrium, the products and quotients of the uncomplexed concentrations of oxidation states must be such that $\left(W Y H^{4} / X^{2}\right)=K_{1}$ and ( $\left.W Z / X Y\right)$ $=K_{2}$, where $K_{1}$ and $K_{2}$ are equilibrium constants whose numerical values are appropriate for the ionic strength at hand ( $\mathrm{H}=$ equilibrium acidity).
Even if not at equilibrium, mass conservation still maintains, the average oxidation number remains unchanged, and charge conservation applies. Thus, valence state distributions which occur during the disproportionation of $\mathrm{Pu}(\mathrm{IV})$, are always subject to charge conservation: $W=$ $Y+2 Z$, or, where complexation occurs $(W)(A W)=(Y)(A Y)+2(\mathrm{Z})(\mathrm{AZ})$. If not at equilibrium, equilibrium constants do not apply, and valence state distributions will not usually yield quotients that are numerically equal to $K_{1}$ and $K_{2}$. Valence state distributions which are not reported to have been perturbed by reaction of the plutonium with other elements, by electrolysis, or by the effects of internal radiations, and for which charge conservation does not apply, should be carefully regarded.

A plutonium solution contains an element which reacts with the plutonium by an oxidation or reduction process.

If at equilibrium the initial $\mathrm{N}$ is not equal to the final $\mathrm{N}$, but the "overall" average oxidation number of all. the elements remains unchanged. Charge conservation for all the elements applies. $21.22 K_{1}$ and $K_{2}$ apply, as does mass conservation for plutonium and the other element. An equilibrium constant connects the plutonium valence state distribution with the distribution of valence states of the other element.

If not at equilibrium, mass conservation still applies. $K_{1}$ and $K_{2}$ do not apply, but the charge conservation statement for the whole reaction of plutonium and the other element applies.

There is nothing about statements of mass or charge conservation which restrict them either to equilibrium or nonequilibrium conditions. In one form or another, they always apply (this is also true for other conservation statements such as charge balance). Since statements of mass conservation and charge conservation apply equally well to equilibrium and nonequilibrium "kinetic" circumstances, they are very useful when examining reported valence state distributions. 
When considering plutonium valence state distributions, it would be very desirable to have available a method for accurately computing the numerical values of $K_{1}$ and $\mathrm{K}_{2}$ over wide ranges of ionic strength. Costanzo, Biggers, and Bell have suggested a method of determining activity coefficients which they believe yield accurate and trustworthy results. 23 Newton also offers a method of correcting constants by means of an extended DebyeHueckel approach. ${ }^{24}$ The equation of Costanzo, Biggers, and Bell appears to differ from the equation of Newton; and it is not clear which approach is the better of the two or if either approach constitutes a satisfactory answer to the problem of activity coefficient evaluation for plutonium ions. Newton, however, reports deviations between experimental and theoretical results of about $8 \%$ are common with his equation, and much larger deviations may also be observed. ${ }^{4}$ The equation which Newton suggests did not seem to work well when used for determining various parameters of the actinide ions. ${ }^{5}$ Bell, Friedman, and Billings have suggested what appears to be a third method of computing activity coefficients, and have used this method to correct equilibrium constants for ionic strength effects. 26

An uncommon interpretation of the radiation induced autoreduction of hexavalent plutonium involves computation of an equilibrium valence state distribution for each value of the plutonium average oxidation number obtained during the reduction process. In so far as valence state distributions are concerned, 27 the "kinetics" so obtained appear to approximate experiment.

In natural systems, where plutonium concentrations are likely to be very low, the product of the concentrations of two plutorilum speries is also likely to be a very low number; and this product is likely to remain a low number even when multiplied by a disproportionation reaction rate constant. Disproportionation reactions are likely to be rather slow, perhaps vanishingly slow, under environmental circumstances. But the probable slowness of disproportionation under natural conditions does not nccessarily prohibit attainment, even rapid attainment, of the same valence state distribution as might have been derived by disproportionation. ${ }^{28-31}$ Disproportionation represents only one path for the generation of the various plutonium ions. Natural systems ordinarily contain a multitude of oxidation-reduction agents of biological and mineral origin, and these agents can probably react with plutonium in such a manner that the equilibrium valence distribution is more rapidly attained than might be possible in systems where disproportionation is the only means of rearranging valence states. (Gary L. Silver)

PROBLEMS IN PLUTONIUM CHEMISTRY

(IV): IS A BATTERY A USEFUL TOOL FOR STUDYING

DISPROPORTIONATION KINETICS?

As plutonium is capable of existing in dilute aqueous acids in four oxidation states, it provides opportunities for the study of chemical phenomena that may not easily be studied or easily imagined in other chemical systems. One such phe-. nomenon may be the preparation of simple plutonium concentration cells for the trainsformation of thermal energy into electrical energy. Thus, a battery can be imagined that consists of two wet halfcells connected by a salt bridge or other suitable means for ion transport. Into each half-cell are placed identical solutions of tetravalent plutonium (that is, identical concentrations of plutonium and acid). When equilibrium has been reached in each half-cell, there will be no potential difference between the two halves of the battery, and no current will flow. Now suppose that the salt bridge connecting the half-cells is a few centimeters long such that one half of the battery may be placed in warm sunlight, and the other half in a shaded area. As one halfcell warms, the distribution of plutonium valence states within this half-cell may change since the disproportionation equilibrium of plutonium(IV) is temperaturesensitive. ${ }^{3}$ This changing distribution of valence states may induce a small voltage between the two halves of the battery, current may flow until equilibrium is reestablished, and power may be generated. After equilibrium has been reached, the battery may be rotated so that the portion that was in the sumliylı will now be shaded. Reversing the battery in this manner again allows the generation of electrical power. of course, there is no point in building such a battery, for it would be very, very inefficient.

Suppose, however, that tetravalent plutonni.um is introduced into the two halfcells of the battery at different times, such that the plutonium in one half-cell was closer to disproportionation equilibrium than the plutonium in the other halfcell. Now a voltage may also be induced between the two wet half-cells. Connecting the half-cells to allow the passage of current may cause the plutonium in one half-cell to be oxidized above average oxidation number four, whereas the 
plutonium in the other half-cell may be reduced below average oxidation number four. of course, the average oxidation number of all of the plutonium in the battery remains unchanged at 4.00 . As time passes and the plutonium in both cells proceeds toward disproportionation equilibrium, a time may come when the polarity of the battery may reverse so that the previously oxidized plutonium on one side of the battery may begin to oxidize the previously reduced plutonium on the other side of the battery. The time for this polarity reversal depends upon several parameters: the disparity between the solutions at the start of the experiment; the amount of charge which the cell may pass during a given time (the "cell constant") and the kinetic rate constant for the slow reaction:

$$
2 \mathrm{Pu}^{4+}+2 \mathrm{H}_{2} \mathrm{O}=\mathrm{Pu}^{3+}+\mathrm{PuO}_{2}^{+}+4 \mathrm{H}^{+} \text {. }
$$

Hence, a method of estimating the kinetic rate of Eq. 1, since the kinetics of the reaction

$$
\mathrm{Pu}^{4+}+\mathrm{PuO}_{2}^{+}=\mathrm{Pu}^{3+}+\mathrm{PuO}_{2}^{2+}
$$

are perhaps fast enough to cause no appreciable delay in the time required to reach polarity reversal, might be to build a battery consisting of two wet cells to measure the time required for polarity reversal. As there is at the present time considerable interest in oscillating chemical systems, ${ }^{3} 3$ the possibility that the polarity of such a battery might display oscillations is immediately suggested. Of course, halfcells could doubtless be constructed such that any oscillation would be immediately damped out, but there is the possibility that this system might represent a new example of electrical potential oscillation in a chemical system. The battery method of studying the kinetics of disproportionation is interesting in that it does not require all of the chemical measurements usually required in the study of kinetic systems. The "cell constant" and the concentrations of plutonium (present initially in the tetravalent state) and acid may be all that is required for such a study. (Gary L. Silver)

\section{STUDY OF THE REACTIONS OF BONE CHAR WITH PLUTONIUM AND URANIUM}

Experimental work in the adsorption of plutonium and uranium from alkaline and neutral aqueous solutions has continued. The use of isotherms to describe adsorption behavior of plutonium onto bone char is being developed. From these isotherm tests, it will be determined whether or not a particular degree of plutonium removal can be effected by adsorption alone. Also, it will show the approximate adsorptive capacity of the bone char for the particular application. In addition, isotherm tests afford a convenient means of studying the effects of $\mathrm{pH}$ and temperature on adsorption. In order to measure the adsorption capacity of plutonium on bone char, a series of experiments were conducted. Equilibrium tests were run using varying concentrations of bone char along with a constant concentration of plutonium-238 isotope. The solutions were buffered at $\mathrm{pH} 10\left(\mathrm{NH}_{3}\right.$ buffer), at pH 8 (the natural buffering capacity of bone char), and at $\mathrm{pH} 7$ (acetate and a trace of $\mathrm{NH}_{4} \mathrm{OH}$ ). The forms of the plutonium in solution were polymeric $2{ }^{8} \mathrm{Pu}(\mathrm{IV})$ and ${ }^{2}{ }^{8} \mathrm{Pu}(\mathrm{VI})$. Indications are that the intensity of adsorption, as measured by the slope of the isotherm, is less than that exhibited by uranium adsorption reported in previous reports. Also, because of polymerization, the high correlation achieved with uranium was not repeated. Correlations were reasonable but not as high as expected.

Further results are being compiled. These results should be available for publication in a final report scheduled for publication in September 1976. (John Koenst)

\section{STUDY OF THE REACTION OF} PLUTONIUM WITH BONE CHAR

Bone char, a material commercially prepared from the bones of cattle, shows considerable ability to adsorb various species from solution. In particular, bone char shows a pronounced ability to concentrate such metal ions as plutonium ions. For this reason, bone char is under investigation as an adsorbent for plutonium in waste streams. previous studies have indicated that bone char affects its aqueous environment by exerting a $\mathrm{pH}$ buffering and a potential modifying effect on the aqueous environment. ${ }^{3}{ }^{4}$ These effects cannot be overlooked when considering the bone char-plutonium reaction. Previous studies have also indicated that tetravalent plutonium polymer is adsorbed by bone char in a manner that depends upon the $\mathrm{pH}$ of the medium from which adsorption occurs. The pH of maximum polymer adsorption was shown to be near $\mathrm{pH} 7$.

Further experimentation on the adsorption of tetravalent plutonium polymer by bone char has confirmed that the adsorption process is $\mathrm{pH}$ dependent and that the adsorption is maximizea near $\mathrm{pH} 7$. A typical adsorption study for the plutonium(IV) polymer is shown in Figure 11, which plots 


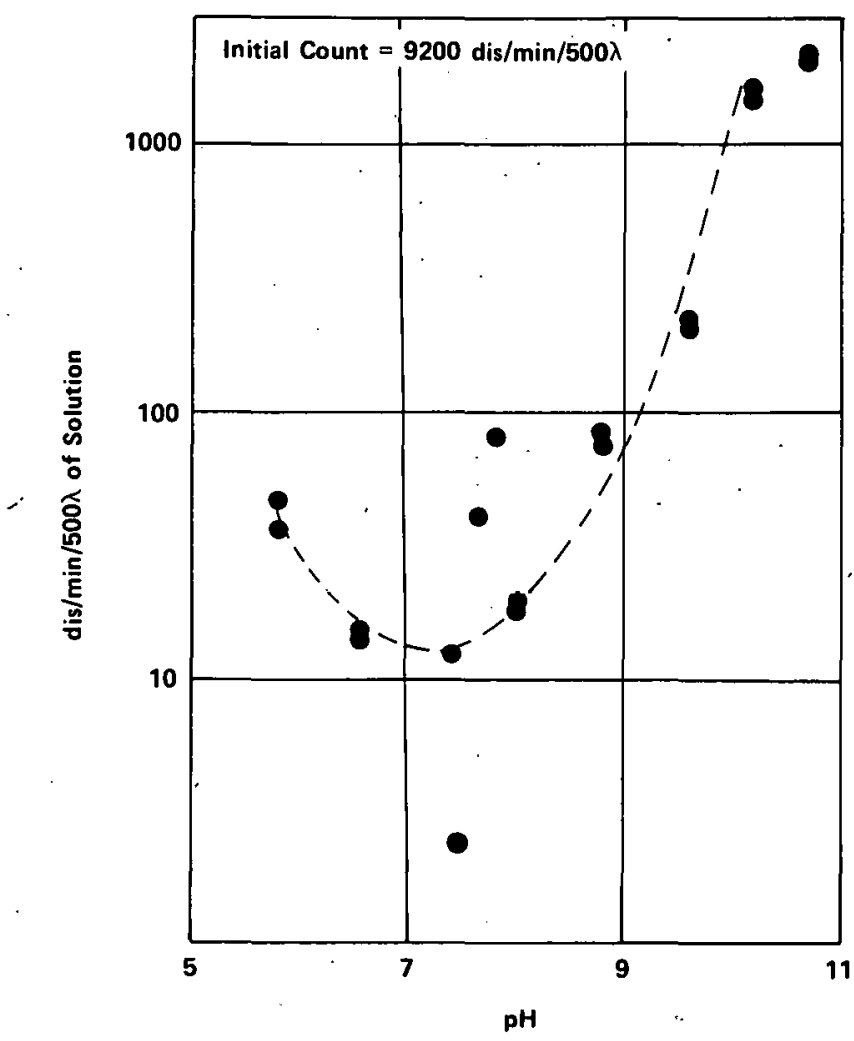

FIGURE 11 - Adsorption of plutonium(IV) polymer by bone char as a function of $p H$.

residual solution activity in a $100 \mathrm{ml}$ flask (that contains $1 \mathrm{~g}$ bone char) buffered with ethylenediamine hydrochloride and ammonium chloride. As can be seen from Figure 1l, the point of maximum polymer adsorption is near $\mathrm{pH} 7$; and adsorption decreases as $\mathrm{pH}$ increases or decreases from 7. The plot shows typical data points with typical scatter in the count rate of solutions of very low levels of radioactivity, a phenomenon which as frequently been observed with plutonium and other radiotracers. Figure 12 shows the results of a similar experiment with a higher initial concentration of plutonium. The shape of the curve is similar to the curve in.Figure 11 , although the minimum corresponds to a higher final concentration of the plutonium $\left(808^{23.8} \mathrm{Pu}, 208^{239} \mathrm{Pu}\right)$.

Plutonium may conceivably occur in waste streams in a variety of forms:

trivalent plutonium, and complexeg thereof; tetravalent plutonium, and complexes thereof; pentavalent plutonium, and complexes thereof; hexavalent plutonium, and complexes thereof; colloidal tetravalent plutonium "polymer"; insoluble hydrous oxides such as plutonium(IV) hydroxide; plutonium sorbed by particulate

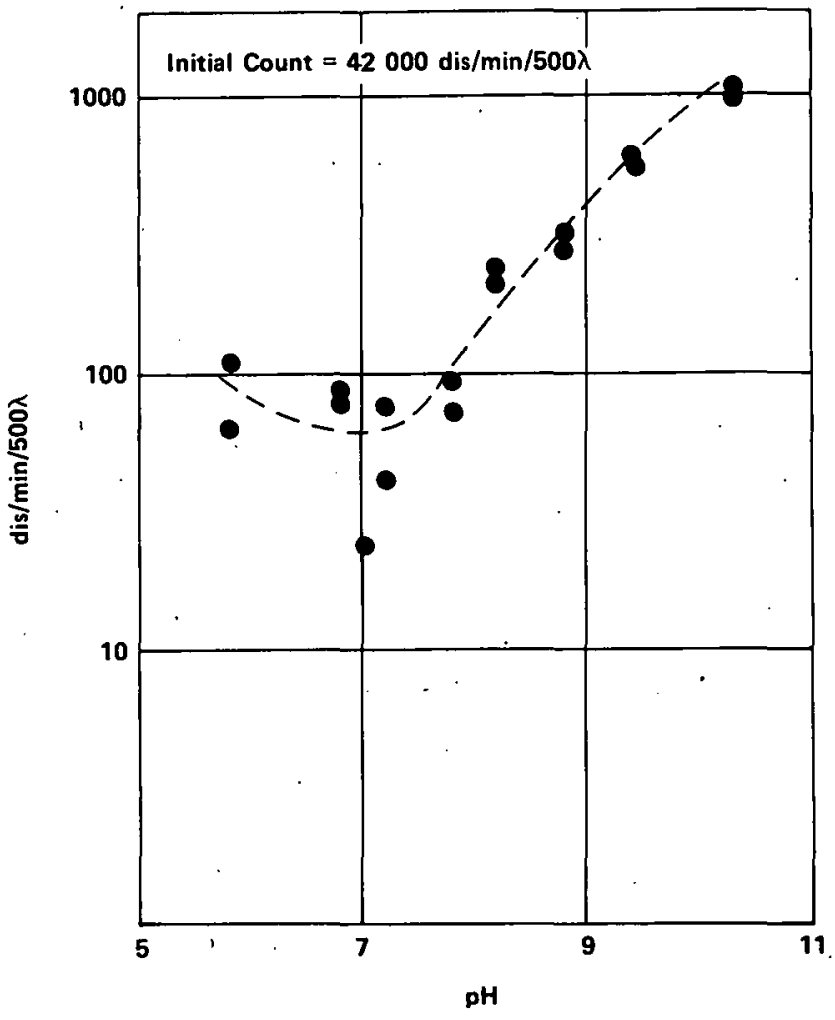

FIGURE 12 - Apparent reaction of plutonium polymer with bone char.

matter in the waste stream; and insoluble compounds of plutonium formed with waste stream constituents.

Since it has been repeatedly shown that a pH value near pH 7 maximizes the adsorp, tion of plutonium on bone char in controlled studies, examination of another form of plutonium seemed appropriate. Examination of a potential-pH diagram ${ }^{3}$ for plutonium suggests that, after tetravalent plutonium polymer, some form of hexavalent plutonium or pentavalent plutonium may be the most likely soluble plutonium species to occur in neutral or alkaline waste solutions. To this end a solution of hexavalent plutonium has been prepared by oxidation of plutonium(IV) with divalent silver oxide. The visible spectrum of the solution revealed that the plutonium in the solution was hexavalent plutonium, and the presence of other oxidation states was not discerned.

The adsorption behavior of hexavalent plutonium was examined in the same manner as was used for studying the adsorption of tetravalent plutonium polymer by the bone char. It was quickly apparent, however, that hexavalent plutonium behaved in a manner strikingly different from tetravalent plutonium. Six experiments 
revealed that this behavior is erratic and not subject to easy interpretation. Figure 13 shows the steady state count rate per minute of half $\mathrm{ml}$ samples of a solution of hexavalent plutonium that was allowed to equilibrate with bone char for about one week (Figures 13, 14 and 15 each contain the results of two experiments). The data appear even more scattered than those data obtained from studies with plutonium(IV) polymer and only suggest the possibility of a minimum count rate near $\mathrm{pH} 9$. Solutions containing higher initial concentrations of hexavalent plutonium also contained higher equilibrium concentrations of plutonium, in this manner they are similar to solutions of plutonium(IV) polymer. This appears to be the only unambiguous conclusion that can be drawn from Figures 13-15. In each experiment, a maximum in the adsorption of the plutonium near $\mathrm{pH} 9$ is suggested (A maximum in the adsorption of plutonium corresponds to a minimum in the steady state count rate). Unfortunately, this minimum cannot be unambiguously assigned because of the considerable, and surprising, scatter in the data. Figures 13 and 14 contain dashed lines which are drawn to illustrate the suggested minima in the plutonium concentration near pH 9. These lines are visual aids drawn only to

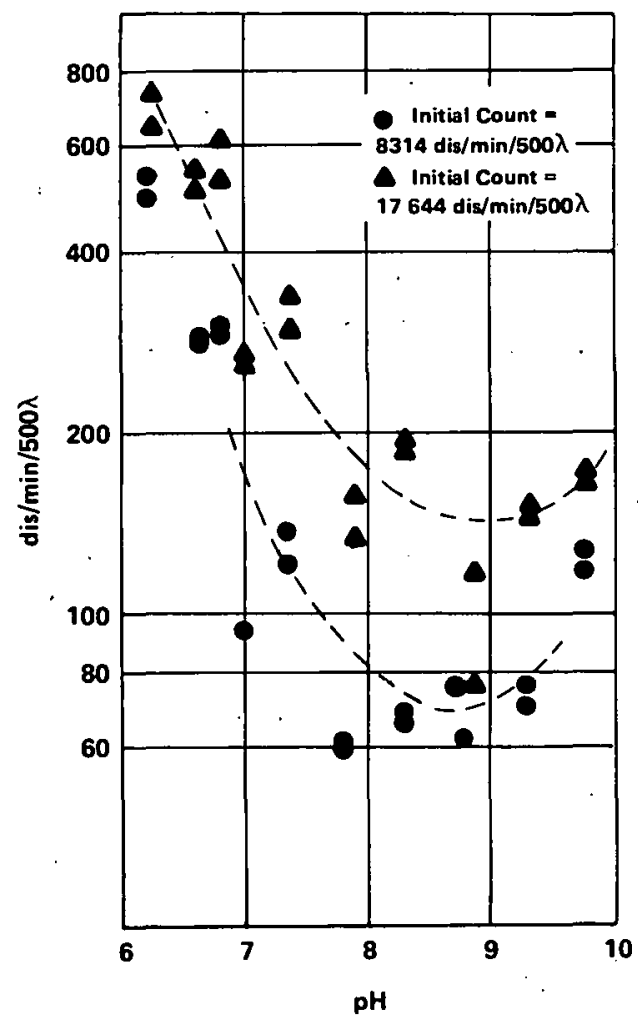

FIGURE 14 - Adsorption of hexavalent plutonium by bone char in ethylene diammine ammonia buffer.

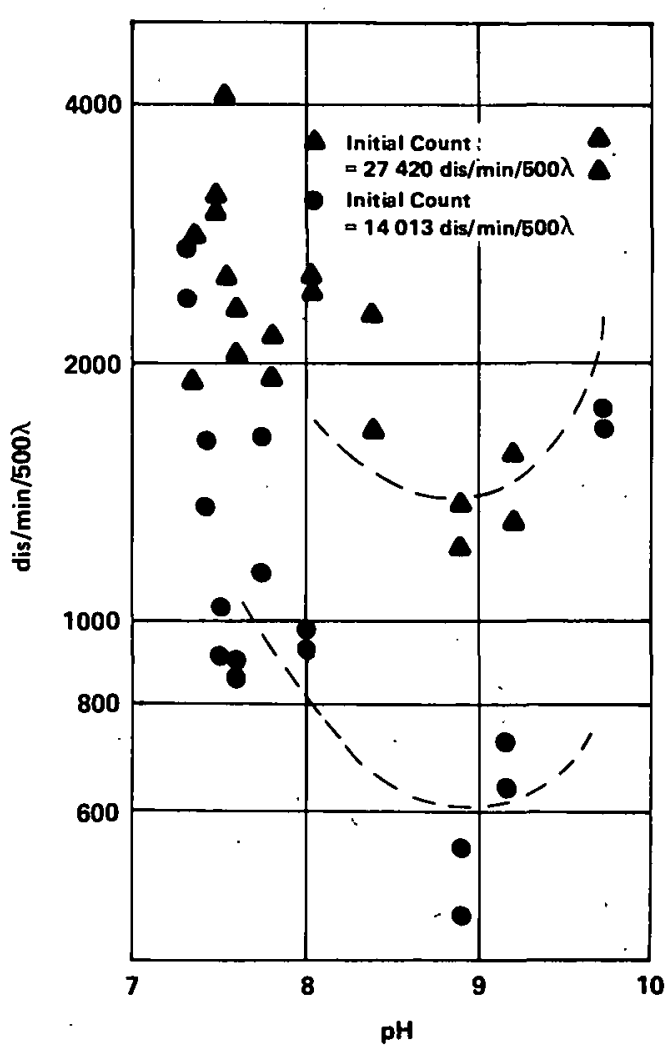

FIGURE 13 - Adsorption of hexavalent plutonium by bone char in ethylene diammine ammonia buffer.

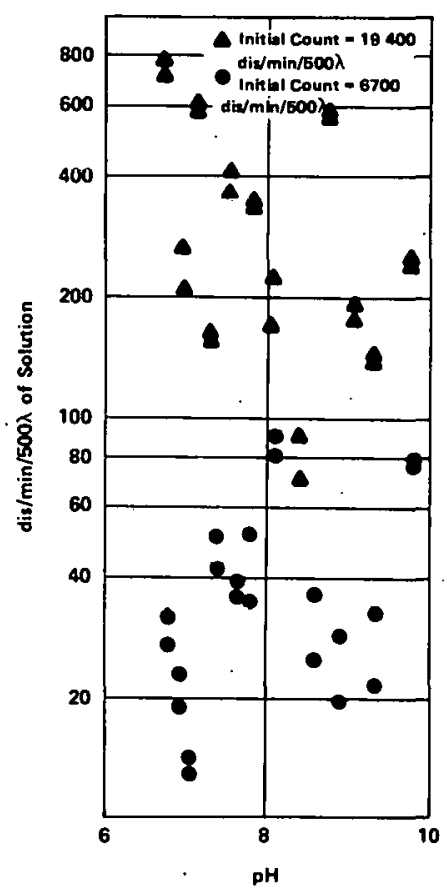

FIGURE 15 - Adsorption of hexavalent plutonium. by bone char in ethylene diammine ammonia buffer. 
illustrate this suggested minimum. Figure 15 contains no such 1 ines because the data are too scattered to suggest this minimum unambiguously. Careful examination of Figures $13-15$ also suggests the possibility of another adsorption maximum near $\mathrm{pH} 7$, but this possible maximum in the adsorption is not emphasized with dashed lines.

It is of interest to speculate on the pronounced difference in the behavior of these two different oxidation states of plutonium. In comparison to hexavalent plutonium, the polymer is relatively "inert"; that is, many reactions of the polymer, such as depolymerizattion to $\mathrm{Pu}^{4}+$ cations, oxidation, or reduction, are generally slow except under extreme conditions. The polymer, so far as is known, forms no "complexes" such as might be formed by simple plutonium cations. Hexavalent plutonium in contrast, forms a wide variety of complexes, and is guite reactive as an oxidizing agent. That is, there are many circumstances under which hexavalent plutonium is subject to facile reduction to the pentavalent, tetravalent, or trivalent oxidation states.

The general problem of the equilibrium distribution of valence states of plutonium may be solved in terms of the plutonium ion alpha coefficients and two other variables such as solution $\mathrm{pH}$ and redox potential. The potential behavior of solutions in contact with bone char has been examined in prior reports. Although nothing is known about the plutonium alpha coefficients which are appropriate for the bone char-water system, it may nevertheless be instructive to examine the behavior of valence state distributions at the $\mathrm{pH}$ and potential values of such systems assuming no complexation. Computations can be made that yield a model of the equilibrium valence state distribution of the uncomplexed plutonium as well as the molar concentration of all of the soluble plutonium. For example, a $\mathrm{pH}=7$ and $E=+0.20 \mathrm{~V}$, trivalent plutonium is the predominant species and the total soluble plutonium concentration is about $0.17 \mathrm{E}-14 \mathrm{M}$. At $\mathrm{pH} 7$, and $\mathrm{E}=0.30,0.40$, and $0.50 \mathrm{~V}$, pentavalent plutonium is the predominant plutonium species and the molar concentration of the uncomplexed plutonium is about $0.2 \mathrm{E}-14 \mathrm{M}, 0.99 \mathrm{E}-13 \mathrm{M}$, and $0.48 \mathrm{E}-11 \mathrm{M}$, respectively. $=$ At $\mathrm{pH} 9, \overline{a n d} \overline{\mathrm{E}}=0.20,0.3 \overline{0}$, $0.40,0.50 \mathrm{~V}$, pentavalent plutonium is always predominant, and the soluble, uncomplexed plutonium concentration is about $0.14 \mathrm{E}-16 \mathrm{M}, 0.20 \mathrm{E}-14 \underline{\mathrm{M}}, 0.99 \mathrm{E}-13 \mathrm{M}$, and $0.48 \mathrm{E}-1 \mathrm{lM}$, respectively. For these Calculations, the solubility product of $\mathrm{Pu}(\mathrm{OH})_{4}$ was taken as $1 E-56$ and only the first hydrolysis of $\mathrm{Pu}^{1+}$ was considered $\left(\mathrm{Pu}^{4 \cdot}+\mathrm{HOH}=\right.$
$\left.\mathrm{PuOH}^{3+}+\mathrm{H}^{+} ; \mathrm{KH}=0.03\right)$. At the higher EMF values, where $\mathrm{Pu}(\mathrm{V})$ predominates, the solubility of the plutonium is approximately independent of acidity:

$$
\mathrm{Pu}(\mathrm{OH})_{4}=\mathrm{PuO}_{2}^{+}+2 \mathrm{HOH}+\varepsilon
$$

Typically, the initial concentration of the plutonium in bone char experiments is about $20,000 \mathrm{dis} / \mathrm{min} / 500 \lambda$. Also, the final concentration is about $20 \mathrm{dis} / \mathrm{min} / 500 \lambda$. Thus this final equilibrium concentration is not likely to be more than about $3 E-12 M$, which is a value that approximates those solubility values calculated above for various conditions of $\mathrm{pH}$ and potential. What is more interesting, however, is the observation that calculation suggests the equilibrium concentration of soluble plutonium to be much less than the initial concentration; and that this reduction in solubility occurs through the formation of plutonium polymer. Hence, in the bone char-water system, most of the initial plutonium is reduced to polymer. But the nature of the plutonium polymer is highly dependent upon the conditions of formation, at least in the experimental systems studied so far, and there is no reason to suppose that the properties of the polymer (such as size, charge, molecular weight, and degree of hydration) prepared by bone char reduction should not also depend upon the particulars of the reducing environment, such as potential and $\mathrm{pH}$. Measurement of the adsorption of hexavalent plutonium upon bone char thus represents the measurement of more than one phenomenon:

the intrinsic adsorption behavior of hexavalent plutonium on bone char, the intrinsic behavior of pentavalent plutonium upon bone char, the intrinsic behavior of the adsorption of complexes of plutonium(V) and plutonium(VI), and the intrinsic behavior of plutonium polymer upon bone char.

It seems very likely that the last parameter is a function of the type of colloidal polymeric particles produced, and is thus a function of potential, $\mathrm{pH}$, and perhaps, ionic strength.

Hexavalent plutonium prepared as described above does not appear to be strongly adsorbed by glass. During the course of a month, a solution at $\mathrm{pH} 6.60$ (containing originally $13,111 \mathrm{dis} / \mathrm{min} / 500 \lambda$ ) decreased at most to $12,740 \mathrm{dis} / \mathrm{min} / 500 \lambda$. Similar behavior was shown by solutions of $\mathrm{pH}$ $6.90,7.20,7.67,8.05,8.52$, and 8.92. since \pm 2 standard deviations in this count rate is about $\pm 230 \mathrm{dis} / \mathrm{min}$, this represents little adsorption. However, solutions of plutonium(VI) at $\mathrm{pH}$ values 
of $9.23,9.58$ and 9.92 showed slightly more adsorption. (Gary L. Silver)

\section{THOR IUM- 229}

A total of $21.40 \mathrm{mg}$ thorium-229 has been extracted and purified during FY-1976. The following table gives the run number and the quantity for the FY-76 shipments.

\begin{tabular}{ll}
$\begin{array}{c}\text { Run } \\
\text { Number }\end{array}$ & $\begin{array}{l}229 \mathrm{Th} \\
(\mathrm{mg})\end{array}$ \\
\hline HP -1 & 5.42 \\
HP -2 & 2.61 \\
HP -3 & 4.43 \\
HP -4 & 4.37 \\
LP -2 & 4.57
\end{tabular}

The designation HP indicates high purity from material previously processed. LP indicates low purity or material not previously processed.

Mass spectrometer analysis for thorium was made available during this period, and the following table shows the results that were obtained.

\begin{tabular}{|c|c|}
\hline $\begin{array}{c}\text { Run } \\
\text { Number }\end{array}$ & $\begin{array}{l}229 \mathrm{Th} \\
(\text { at. } 8 \text { ) }\end{array}$ \\
\hline $\begin{array}{l}\mathrm{HP}-2 \\
\mathrm{HP}-3 \\
\mathrm{HP}-4\end{array}$ & $\begin{array}{r}98.96 \\
98.92 \\
98.90\end{array}$ \\
\hline
\end{tabular}

The mass analysis on LP- 2 has not been determined yet. Also, HP-1 was shipped prior to the availability of the thorium mass analysis at Mound Laboratory.

In order to obtain the maximum quantity of thorium-229 per batch, the extraction equipment was increased in volume to accommodate $1000 \mathrm{ml}$ of solution, which contained not more than $200 \mathrm{~g}$ uranium-233. This doubling of the volume of the extraction equipment has resulted in an approximate 208 increase in the thorium-229 processing rate. With the current "cow", approximately $5 \mathrm{mg}$ of thorium-229 can be obtained from this amount of uranium-233. (William s. Stringham)

\section{THORIUM-230 AND PROTACTINIUM-231}

Mound Laboratory is recovering thorium-230 and protactinium-231 from a uranium mill by-product known as cotter concentrate and ships the products to the Heavy Elements Isotope Pool at ORNL. Previous reports ${ }^{36-39}$ contain detailed descriptions of the origin and character of cotter concentrate, the facilities, and the development of the current recovery and purification process. Briefly, the process consists of leaching approximately 20-liter batches of the solids with hot, concentrated nitric acid, diluting, and filtering off the insoluble residue. Uranium is removed from the 90-liter batches of filtrate by liquid-liquid extraction with $10 \% \mathrm{DSBPP} / \mathrm{CCl}_{4}$ (di-secbutylphenyl phosphonate in carbon tetrachloride) after which it is stripped from the organic with $0.005 \mathrm{M}$ nitric acid. Thorium is extracted from the filtrate by multiple contacts with $0.1 \mathrm{M}$ TOPO/ $\mathrm{CCl}_{4}$ (tri-n-octyl phosphine oxide in carbon tetrachloride), with each contact followed by an $0.3 M$ sulfuric acid strip. After the thorium hàs been removed from the filtrate, further contacts with TOPO/CCl 4 , each followed by an $0.5 \mathrm{M}$ oxalic acid strip, result in recovery of the protactinium. Uranium strip solutions are precipitated with ammonia and the precipitate collected for eventual return to the uranium processor. The thorium strip solutions are purified by an oxalate precipitation and then calcined to the oxide. Protactinium strip solutions are concentrated by evaporation after which they are purified by a series of precipitation steps. The process is summarized in a process flow diagram that is shown in Figure 16 .

Since the last semiannual report, ${ }^{39} 17$ additional batches of cotter Concentrate have been processed from Drum Nos. 177 , 176, and 179. A shipment of $62.0 \mathrm{~g}$ of purified thorium-230 was made on May 3 , 1976 to the Heavy Elements Isotope Pool at ORNL, thus completing the FY-1976 inventory program quota. In addition, 17.4 $g$ of partially purified thorium-230 are on hand from recent production.

The thorium-230 shipment assay value was based on calorimetry using a half-life value of $80,000 \mathrm{yr}$. A thorium-230/total thorium atom ratio of 0.03132 was determined by mass spectrometry. Impurities, determined by emission spectrographic analysis, were: Sc $(0.88)$, Zr(less than $0.1 \%), \mathrm{Si}(0.08 \%)$, with, in descending order, $\mathrm{B}, \mathrm{Fe}, \mathrm{Mo}, \mathrm{Al}, \mathrm{Mn}, \mathrm{Pb}, \mathrm{Mg}, \mathrm{Cr}, \mathrm{Ni}$, $\mathrm{V}$, and $\mathrm{Cu}$ all detectable but each present at less than 0.018 concentration.

Unpurified protactinium-231 recovered from the 17 batches is estimated by gamma spectrum analysis to be approximately $130 \mathrm{mg}$.

The only change in processing methods during the period was the complete changeover from the previous batch solvent extraction to the use of a 3 in. diam Karr reciprocating plate liquid-liquid extraction 


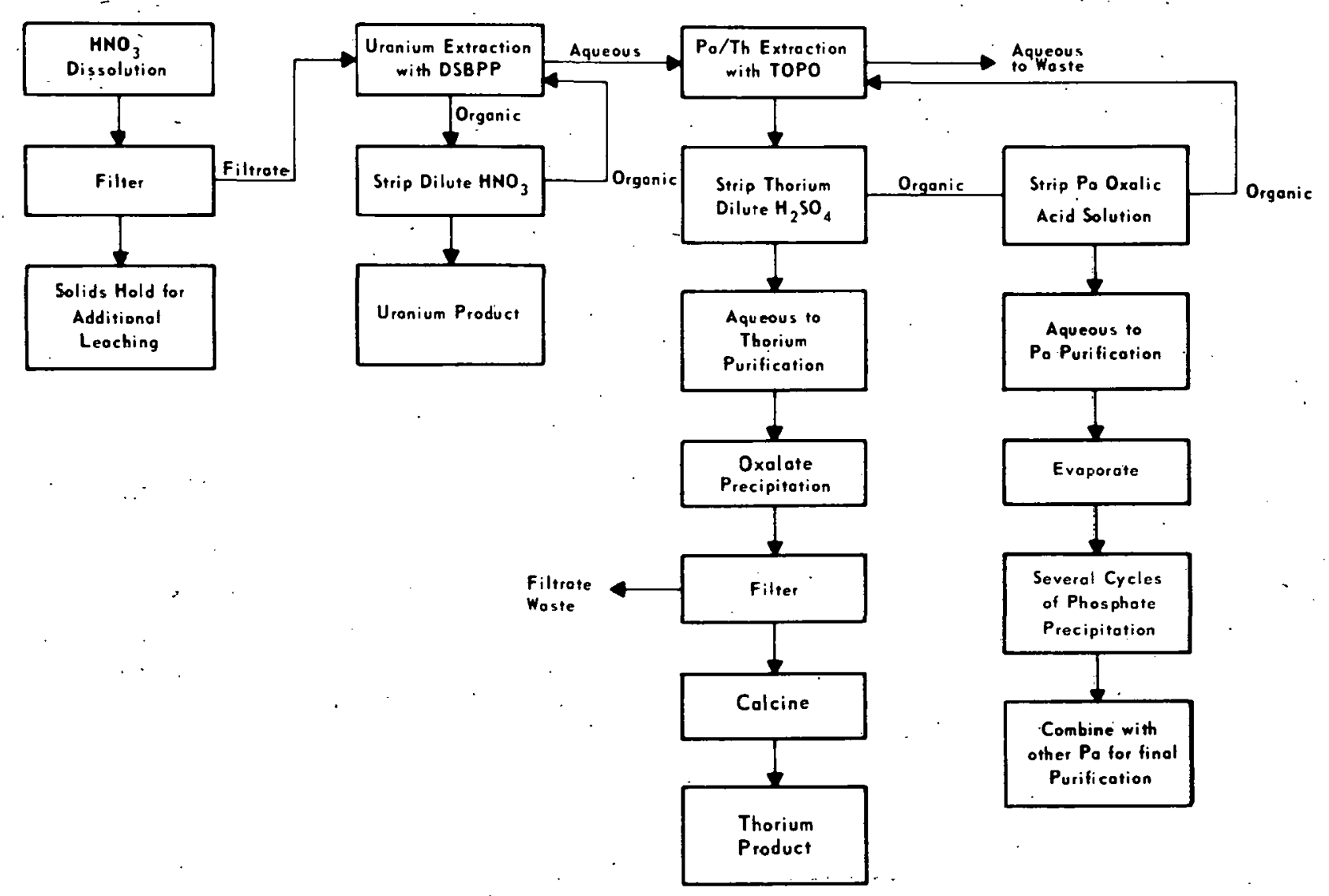


column for extraction and stripping of the uranium from the "filtered feed" batches prior to batch extraction of the thorium and protactinium. This resulted in doubling the productivity of the personnel involved in the concentration process. A second Karr column was tested for the thorium and. protactinium extraction steps but the operating parameters have not yet been fully worked out.

Mound Laboratory received approximately one gram protactinium-231 from the Heavy Elements Pool at ORNL. The $\mathrm{Pa}$ was in the form of the double salt $\mathrm{K}_{2} \mathrm{PaF}_{7}$. This was to be converted to the oxide, and removal of 'heavy metal' impurities was desired.

A calorimetric determination of the heat of radioactive decay on Jan. 15, 1976 gave a value of $354 \mu \mathrm{W}$. The reported content was $1.121 \mathrm{~g} \mathrm{~Pa}$, and calculations showed that this amount of $\mathrm{Pa}$ would have the observed heat after 5.85 yr (purification date-Feb. 1970). For comparative purposes, it was calculated that $1.000 \mathrm{~g} \mathrm{~Pa}$ would have the observed heat value after $7.30 \mathrm{yr}$ (purification date--Sept. 1968). In an attempt to determine the age, the gamma spectrum of the $\mathrm{Pa}$ was compared with gamma spectra of $\mathrm{Pa}$ samples of known age. This effort was hampered by the lack of proper standards and counting capabilities, but it did suggest ages consistent with the calculations from calorimetric data. Without an accurate value of the age, it was not possible to determine the amount of $\mathrm{Pa}$ from the data.

After opening the shipping capsules, a white granular powder (the $\mathrm{K}_{2} \mathrm{PaF}$ ) was transferred to a beaker containing $0.70 \mathrm{~g}$ $\mathrm{H}_{3} \mathrm{BO}_{3}$ (to assist in the removal of fluoride), sulfuric acid was added, and the slurry heated to fumes of $\mathrm{SO}_{3}$. Although $\mathrm{Pa}$ is relatively insoluble in concentrated sulfuric acid, it was felt that this treatment would remove the fluoride (evolution of $\mathrm{BF}_{3}$ and evaporation of $\mathrm{HF}$ ). After removal of the excess sulfuric acid (and addition of water), the $\mathrm{Pa}$ should dissolve in the resulting dilute sulfuric acid. Actually, only a small percentage of the $\mathrm{Pa}$ dissolved, under these conditions, and a number of other treatments were tried. Sodium hydroxide metathesis of the solids was not very successful in "unlocking" the $\mathrm{Pa}$. Ammonium hydroxide precipitation of the dilute sulfuric acid solutions was used in an effort to remove impurities such as $\mathrm{K}$ and $\mathrm{Na}$. Repeated cycles of sulfuric acid purification (evaporation to $\mathrm{SO}_{3}$ fumes, removal of supernate and leaching with dilute sulfuric) eventually resulted in dissolution of the $\mathrm{Pa}$ and separation of solids, containing relatively little $\mathrm{Pa}$, but a fair amount of 'daughter' activity.
Originally, the intent was to determine total $\mathrm{Pa}$ and the age (amount of daughter activity) from alpha mounts representing the entire Pa material. However, by the time all the $\mathrm{Pa}$ had been dissolved, the original material had been split into many fractions; and the original plan was abandoned. Progress of the dissolution steps had been followed by LEPS counting of small aliquots, using the 27 $\mathrm{keV}$ peak as a quantitative measure of the protactinium-231 content, the $50.1 \mathrm{keV}$ peak as a semiquantitative indicator of the thorium-227 content, and the 81.1 and $83.9 \mathrm{keV}$ peaks of bismuth-21l as semiquantitative indicators of the radon-223 content. Errors and inaccuracies in the LEPS counting procedure and the sampling prevented an accurate determination of total Pa, but the method worked well for process control.

During the dissolution steps, it was observed that the sulfuric acid purification cycle was relatively efficient in separating radon-223 and daughters, but provided relatively little separation of thorium-227. A good separation of the thorium-227 was achieved inadvertently when a dilute acid solution was incompletely precipitated with ammonium hydroxide. The Pa left in the hydroxide supernate and in the concentrated sulfuric acid supernatant solutions was recovered by DIBC (di-iso-butyl carbinol) extraction, after adjusting to the proper conditions.

The final purified $\mathrm{Pa}$ solution was assayed by alpha counting. Negligible amounts of daughter activity were found in an alpha pulse height analysis. The Pa was precipitated with ammonium hydroxide and collected on filter paper. After drying and ashing the paper, the sample was calcined at $700^{\circ} \mathrm{C}$. Final weight of the oxide was $1.118 \mathrm{~g}$, which calculates to be $0.953 \mathrm{~g}$ of $\mathrm{Pa}$ as $\mathrm{Pa}_{2} \mathrm{O}_{5}$. Correcting the alpha count value for losses occurring in the conversion to oxide, the final value (based on alpha counting data) was 0.937 g. The Pa has been shipped back to the Heavy Elements Pool at ORNL.

A sample of the final purified $\mathrm{Pa}$ solution, submitted for impurity analysis by emission spectrographic analysis, showed the presence of a number of elements. However, the accompanying blank sample showed the same elements at the same levels, and the results are judged to be inconclusive. A sample was also submitted for analysis by mass spectrometry. From the lack of peaks in the 'heavy metal' range, it was concluded that the $\mathrm{Pa}$ was quite pure; but additional work would be required before this method could be used quantitatively, 
or the lower limits of detectability determined.

$\mathrm{Pa}$ derived from cotter Concentrate processing, and partially purified previously, was converted to a sulfuric acid medium and extracted into DIBC. After stripping, this material was treated by one cycle of the sulfuric purification cycle. This material, which contains about $160 \mathrm{mg} \mathrm{Pa}$, is in the final stages of conversion to oxide and will be shipped to the Heavy Element Pool at ORNL. (Martin R. Hertz and Paul E. Figgins)

\section{URAN I UM- 234}

Mound Laboratory has been separating and recovering high isotopic purity uranium234 from aged plutonium-238 materials for several years. The general chemical procedures for separating and purifying the uranium have been described previously. ${ }^{40}$

Preparation of solution Al0-P for the initial purification step (oxalate precipitation of plutonium) was described in the last report. ${ }^{4}$ The bulk of the plutonium ( $11.4 \mathrm{~g}$ ) has been precipitated with dimethyl oxalate in the presence of $\mathrm{H}_{2} \mathrm{O}_{2}$ to keep the plutonium reduced. The plutonium oxalate was set aside for eventual calcination and storage as "cow" material. The uranium-rich filtrate, containing an estimated four grams of uranium-234, was evaporated to destroy the oxalate and to concentrate the volume. Solution Al0-P is now awaiting preparation for the intermediate purification step; namely, anion exchange in nitrate media.

Initial preparation of solutions $U-8, U-9$, and $U-10$ for the intermediate purification step was described in thc last report. 41 This preparation was completed by salting of the solutions to $1.6 \mathrm{M}$ with $\mathrm{Al}\left(\mathrm{NO}_{3}\right)_{3}$ in $0.3 \mathrm{M} \mathrm{HNO}_{3}$. These three solutions, containing an estimated three grams of uranium-234, are now awaiting intermediate purification.

Special initial processing of approximately 100 liters of waste solution in the plutonium recovery operations was describcd in tho last report. ${ }^{4} 1$ The uranium-rich solution from this material, now designated batch $A 15$, contained five grams of plutonium-238 by total alpha analysis, measured $9200 \mathrm{ml}$ in volume and was $5.5 \mathrm{M}$ $\mathrm{HNO}_{3}$. Alpha pulse height analysis indi= cated approximately $50 \mathrm{~g}$ uranium-234, whereas a mass spectrographic analysis indicated $42 \mathrm{~g}$ uranium-234. About one-half of the Al5 solution was eventually prepared in one liter units as feed to the intermediate purification step. This part of Al5 was expected to provide $20 \mathrm{~g}$ of uranium-234 product, to meet $F Y-76$ requirements, when taken through final purification. These feed units were salted to 1. $6 \mathrm{M}$ with $\mathrm{Al}\left(\mathrm{NO}_{3}\right)_{3}$ and adjusted to $0.3 \mathrm{M}$ acid concentration with addition of concentrated $\mathrm{NH}_{4} \mathrm{OH}$.

For the intermediate purification step, the prepared feed is normally loaded onto a column of Dowex $1 \times 4$ anion exchange resin (nitrate form) and followed with a wash of $1.6 \mathrm{M} \mathrm{Al}\left(\mathrm{NO}_{3}\right)_{3} / 0.3 \mathrm{M} \mathrm{HNO}_{3}$. Next, the uranium is eluted with $7 \mathrm{M} \mathrm{HNO}_{3}$, and then, the plutonium is eluted with $0.35 \mathrm{M} \mathrm{HNO}_{3}$, which contains hydroxlamine nitrate as a reductant. Five runs, each using two liters of the prepared feed, were anticipated for the intermediate purification.

The first anion exchange run (nitrate media) proceeded as expected, but column flow effectively stopped before $500 \mathrm{ml}$ of feed was loaded for the second run. This "plugging" of the column continued to be a problem, and ten runs were required to complete the intermediate purification. In some runs, the resin had to be removed from the column after loading as much feed as possible; and the run was completed in a batch mode. This batch mode used a beaker for contacting the resin with the appropriate solution, and a vacuum flask and coarse fritted Buchner funnel to separate the solution after contact with the resin. Several adjustments were made as the intermediate purification progressed, but none had any effect upon the flow problem. These adjustments are 1 isted and briefly discussed here.

1. The resin was replaced after the second run.

2. The coarse glass frit that supports the resin bed in the column was leached with $\mathrm{HNO}_{3}$ each time the column was emptied. There was never any visual evidence that insolubles were plugging the frit.

3. The acid concentration of the feed was increased from 0.3 to $0.6 \mathrm{M}$ after the second run in case any undissolved hydroxides might be present. However, several of the feed solutions were easily passed through a coarse glass filter; and no insolubles were removed from the solutions.

4. In case oversalting might be the problem, the feed was diluted with $0.35 \mathrm{M} \mathrm{HNO} \mathrm{HN}_{3}$ by 15 to $30 \%$ from the 
third through the final run. The Al5 solution contained an unknown quantity of $\mathrm{Al}\left(\mathrm{NO}_{3}\right)_{3}$ from the special processing, and this was ignored in the salting to $1.6 \mathrm{M}$. A sample of prepared feed was evaporated to dryness and found to contain $38 \%$ more solids than a similarly evaporated $1.6 \mathrm{M}$ $\mathrm{Al}\left(\mathrm{NO}_{3}\right)_{3} / 0.3 \mathrm{M} \mathrm{HNO}_{3}$ solution. Oversalting woul $\bar{d}$ not be expected to adversely effect the operation as long as there was no "salting out" taking place. There was never any visual evidence of "salting out" in the solution or on the resin.

5. The feed for the eighth run was specially prepared using analytical grade $\mathrm{Al}\left(\mathrm{NO}_{3}\right)_{3}$. Technical grade was used to salt feed for all other runs, which was a deviation from previous batches.

Alpha pulse height analyses of the uranium fractions from the 10 intermediate purification runs indicated a total of $25.3 \mathrm{~g}$ uranium-234 with $36 \mathrm{mg}$ plutonium238. The fractions, totaling 16 liters, were combined and concentrated by evaporation to a one liter volume. The concentrated uranium solution was converted from nitrate to chloride form in preparation for the final purification step; namely, anion exchange in chloride media. The uranium was precipitated twice with $10 \mathrm{M} \mathrm{NaOH}$ and dissolved each time in 9M HCI. Final volume was $800 \mathrm{ml}$.

For the final purification of the Al5 material, the 9M uranyl chloride solution was loaded onto a column of Dowex $1 \times 4$ anion exchange resin (chloride form). Plutonium was eluted with $9 \mathrm{M} \mathrm{HCl}$, which contained $0.05 \mathrm{M} \mathrm{NH}_{4} \mathrm{I}$ as reductant for the plutonium, and the column washed with $9 \mathrm{M}$ $\mathrm{HCl}$. Then, it was intended to elute neptunium-237 (follows uranium to this step) with $4.5 \mathrm{M} \mathrm{HCl} / 1.0 \mathrm{M} \mathrm{HF}$. This scheme for the anion exchange (chloride media) was a change from the previous year's operations, and it was reported ${ }^{4 \frac{1}{2}}$ as a specific procedure for separating plutonium, neptunium, and uranium. This change was prompted by the difficulties reported ${ }^{4}$. last year when HI was used as the reductant.

The first two of four purification runs made on the Al5 material proceeded without apparent problems. Upon loading of the third run, it became evident that the HF used in the eluants for neptunium and uranium had attacked the glass frit that supports the resin bed in the column. The frit finally broke away from the wall of the column. The resin was transferred to a new column, and the third and fourth runs were completed without the use of HF in the eluants. Observation of the effluent during column operations indicated. no differences with or without the inclusion of $\mathrm{HF}$ in the eluants. However, the effectiveness of this procedure cannot be fully evaluated until all analyses on the final product are completed.

Alpha pulse height analyses of the uranium fractions indicate a total of $21.8 \mathrm{~g}$ uranium-234. The uranium in these fractions has been precipitated as the hydroxide with $\mathrm{NH}_{4} \mathrm{OH}$, and is being calcined to the oxide. The uranium fractions were combined and mixed prior to precipitation to ensure a uniform product from six individual precipitations. Final analyses and characterization of the product, which will be designated Al5-1, will be reported when completed. (Perle L. Keister) 


\section{Separation Research}

\section{CHLORINE ISOTOPE SEPARATION}

In a previous report ${ }^{4} 4$ data were given regarding the relative merits of 1-chloropropane and chlorobenzene as working fluids for chlorine isotope separation by liquid phase thermal diffusion. It was found that chlorobenzene gave a somewhat higher equilibrium (total reflux) separation factor, but 1-chloropropane had a significantly higher initial transport coefficient. on the basis of these characteristics, the start-up time was predicted to be shorter; and the chlorine isotope production rate was predicted to be much larger with Ichloropropane than with chlorobenzene. Accordingly, 1-chloropropane was chosen as the working fluid for the initial work with chlorine.

A 14-column cascade for chlorine isotope separation was started up on October 21 , 1975. The total length of the cascade, was $14.5 \mathrm{~m}$ comprised of liquid thermal diffusion columns with spacings between the hot and cold walls that ranged from 300 to 180 $\mu \mathrm{m}$. The system was designed for the simultaneous separation of chlorine-35 and chlorine-37 at $90 \%$ or higher enrichment. The 1-chloropropane separation experiment, the progress of which is shown in Figure 17, was continued for 127 days. The observed chlorine isotope concentrations remained in good agreement with theory for a short time after start-up of the cascade. After the sixth day of operation, a variety of experimental problems were encountered, that resulted in slow progress of the separation. The experimental problems fell into three categories: 1) leaks, 2) failure of interstage pumps, and 3) plugged capillary interconnecting lines. The pump failures and plugged lines were thought at that time to result from accumulation of residue in the system from the previous sulfur34 separation experiment.

Starting at day 29 of the experiment, fluid was regularly withdrawn from the top of the cascade at a rate of $25 \mathrm{mI}$ per week. The withdrawals were intended to increase the rate of chlorine-37 accumulation in the cascade and to remove the small

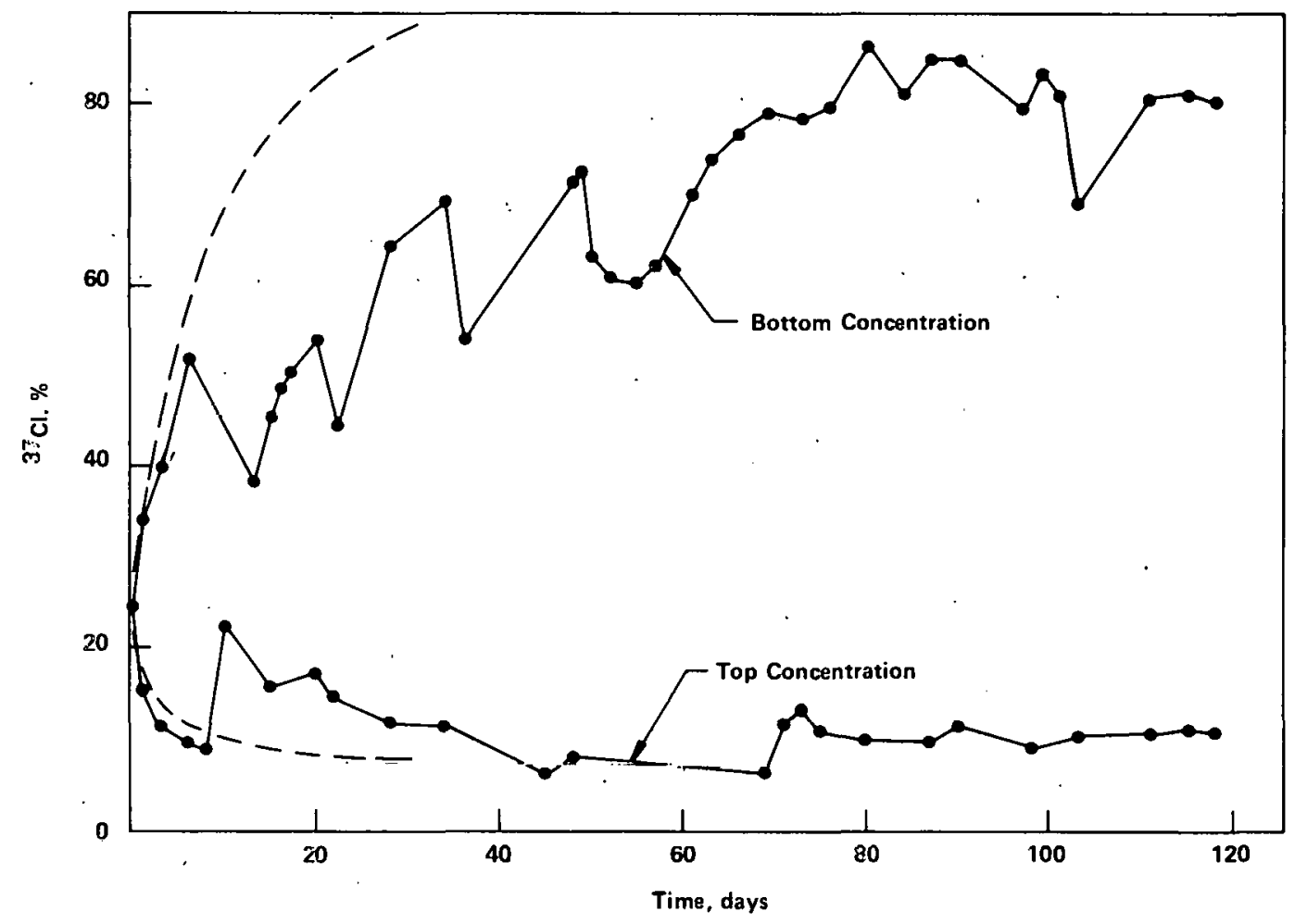

FIGURE 17 - Performance of the l-chloropropane liquid thermal diffusion cascade (the dashed lines are calculated from theory). 
quantity of gas that tended to concentrate at the top of the system. No attempt was made to control the isotopic concentration; however, material which exceeded the desired $90 \%$ enrichment of chlorine-35 was retained separately.

Near the end of the experiment a nearly complete obstruction occurred in one of the $0.8 \mathrm{~mm}$ i.d. capillary lines attached to a column in the middle of the cascade. Process fluid was removed from the column and several solvents were tested to remove the obstruction. When acetone was injected into the column, a dark brown solution was recovered. The solute was subsequently identified as $\mathrm{FeCl}_{3}$ resulting from a slow reaction between the 1-chloropropane and the hot surfaces of the thermal diffusion system. The experiment was immediately terminated. The cascade was emptied, and several batches of enriched material were recovered. Amounts and compositions of these are given in Table 7 . These quantities total $9.6 \mathrm{~g}$ of chlorine-35 at $90.7 \%$ enrichment and $14.9 \mathrm{~g}$ of chlorine-37 at enrichments ranging from 56.8 to 73.38 . The empty system was thoroughly rinsed with acetone, and the total quantity of soluble iron was determined to be $1.2 \mathrm{~g}$. If it is assumed that corrosion was confined to the hot walls of the columns, this would be equivalent to surface removal at a rate of $1 \times 10^{-5} \mathrm{~cm} / y \mathrm{r}$. A rate this small could not have been detected in the 10 day accelerated materials compatibility and corrosion test that was conducted prior to the start of the separation experiment.

\section{Table 7}

ENRICHED 1-CHLOROPROPANE MATERIALS PRODUCED DURING THE FIRST CHLORINE ISOTOPE SEPARATION EXPERIMENT

\begin{tabular}{lrrr}
\multicolumn{1}{c}{ Source } & $\frac{\begin{array}{c}\text { Net } \\
\text { Weight } \\
(g)\end{array}}{\frac{{ }^{37} \mathrm{Cl}}{(8)}}$ & $\frac{(8)}{9.7}$ & 9.3 \\
Top Product & & 7.7 & 73.3 \\
Column 14 Holdup & & 36.1 & 56.8 \\
Columns 11-13 Holdup & & 10.1 & 61.0 \\
Sample Purge & &
\end{tabular}

An evaluation of analytical data taken during the separation experiment with 1-chloropropane revealed that a small amount of isomerization to 2-chloropropane took place in the system. Although the feed material was found to be essentially free of 2-chloropropane (less than 0.5\%), concentrations up to 5\% were found in the cascade. The effect that this might have had on the isotope separation process is unknown.

\section{Chlorobenzene}

Chlorobenzene was selected as an alternate working fluid for chlorine isotope separation, and a 15 column cascade was set up for a second separation experiment. Figure 18 shows the profile of the 15 column cascade superimposed on that of an ideal cascade for separating $98 \%$ chlorine-35 at the top and $95 \%$ chlorine -37 at the bottom. The profile is a plot of the relative initial transport coefficient of the columns as a function of $\mathrm{Y}$, where $\dot{\mathrm{Y}}=$ en $\mathrm{q}_{e}$, and $\mathrm{q}_{e}$ is the equilibrium separation factor of the column defined by

$$
q_{\epsilon}=\frac{\left(w_{1} / w_{2}\right)_{B}}{\left(w_{1} / w_{2}\right)_{T}},
$$

where $w_{1}$ and $w_{2}$ are the mass fractions of the isotopic components, and the subscripts $T$ and $B$ refer to the top and bottom of the column, respectively.

The characteristics of the individual columns depend on the spacing between the hot and cold walls, the annular diameter, and the length. Table 8 gives the appropriate data for the six types of column that comprise the system.

Table 8

CHARAC'IERIS'ILSS OF LIQUỦID THERMAL DTFFUSTUN CULUMNS USED IN THE 15 COLUMN CHLOROBENZENE CASCADE

\begin{tabular}{|c|c|c|c|}
\hline $\begin{array}{l}\text { Column } \\
\text { Type }\end{array}$ & $\begin{array}{l}\text { Length } \\
\text { (m) }\end{array}$ & 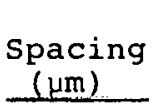 & $\begin{array}{l}\text { Annular } \\
\text { Diameter } \\
\text { (mm) }\end{array}$ \\
\hline A & 2.4 & 300 & 25 \\
\hline B & 1.2 & 250 & 25 \\
\hline C & 0.76 & 250 & 25 \\
\hline D & 0.6 & 250 & 25 \\
\hline$E$ & 0.6 & 250 & 19 \\
\hline $\mathrm{F}$ & 0.9 & 180 & 19 \\
\hline
\end{tabular}

The second chlorine isotope separation experiment was started on February 24 , 1976 with 11 of 15 columns in operation. Upon completion of cleaning operations, four additional columns were added on the sixth day of the experiment. 


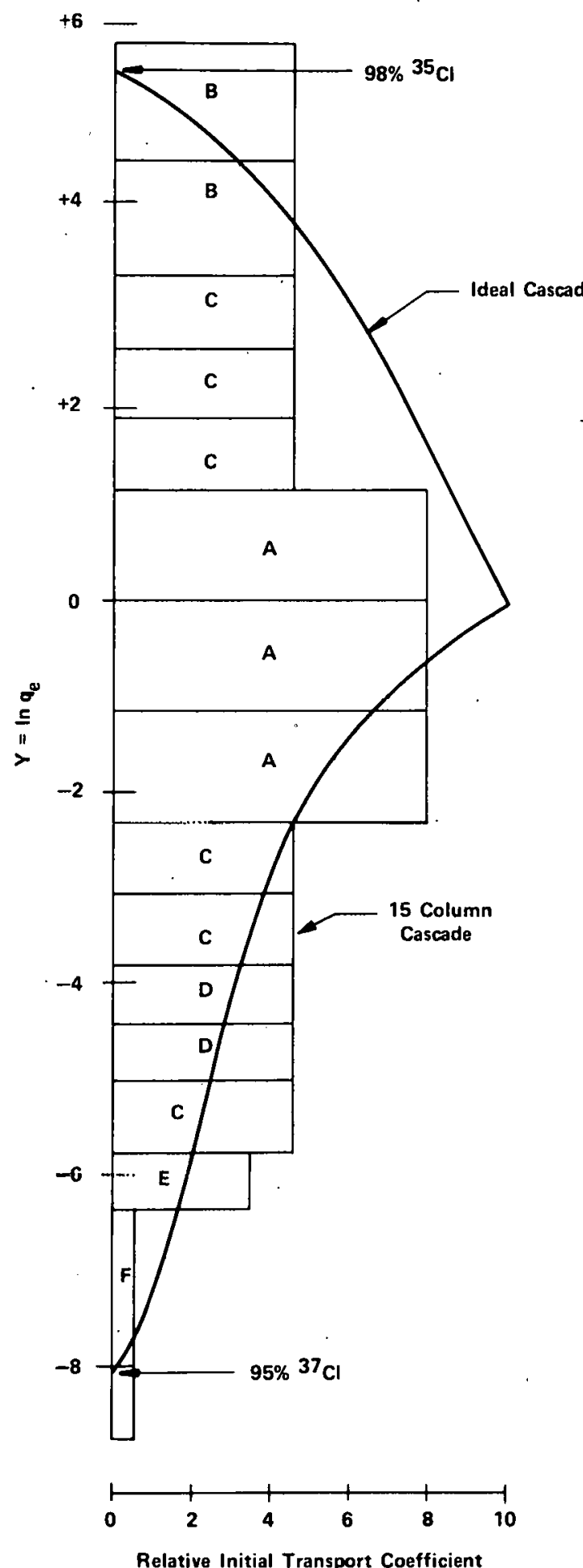

FIGURE 18 - Initial transport profiles for chlorine isotope separation with chlorobenzene as the working fluld.
The separation proceeded in reasonable agreement with theory (Figure 19) for a short time; however, a problem developed in the chlorine-35 section of the cascade and the chlorine-35 concentration at the top began to drop. This led to the first of a number of column replacements and rearrangements in the upper cascade.

After 30 to 40 days of operation, the performance of the system began to show a steady departure from the calculated performance; however, a desired interim goal of 958 chlorine-35 was reached and product withdrawal was started on day 85 of the experiment. To date, approximately $10 \mathrm{~g}$ of chlorobenzene have been collected at that isotopic concentration.

Although the cascade is long enough in theory to reach concentrations exceeding 958 chlorine-37, it has not been possible as yet to go above $87 \%$. The reasons for this are not clear, and an evaluation of individual separation units in the lower part of the cascade is now in progress. The results of these tests should indicate the source of the difficulty.

(William M. Rutherford)

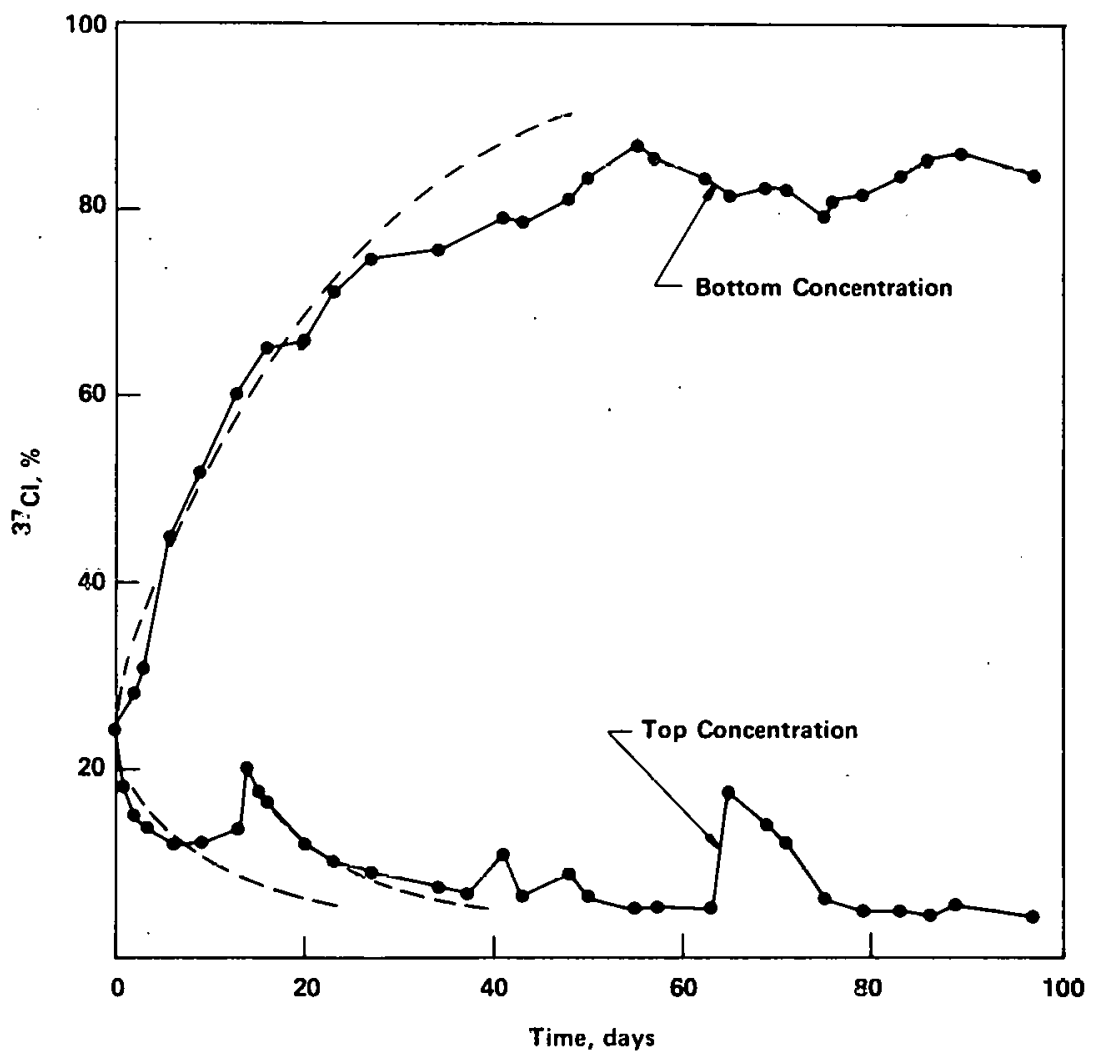

FIGURE 19 - Performance of the chlorobenzene liquid thermal diffusion cascade (the dashed lines are calculated from theoryl. 


\section{MOLECULAR BEAM SCATTERING}

\section{Total Scattering Cross Sections}

The measurements of the total scattering cross sections of the argon-krypton system in the low relative velocity range of 3 to $7\left(x 10^{4}\right) \mathrm{cm} / \mathrm{sec}$ have been completed. These determinations were made by passing a supersonic beam through a target cell containing the scattering gas at known pressures. Details of the experimental components and pressure calibration method have been given in earlier reports in this series. $45 \mathrm{a}-\mathrm{d}$ ' Both $\mathrm{Ar}$ and $\mathrm{Kr}$ were used as target gases and agreement within approximately 7 to $8 \%$ was obtained upon inversion of beam target at the same relative velocities. These data overlap the measurements of previous workers ${ }^{4,4}$ at the higher velocities, and are in good agreement with those results. Several "glory extrema" were observed which; along with those given by Bredewout, 47 were used to determine the product $\varepsilon \sigma$ for the argonkrypton potential. Epsilon $(\varepsilon)$ and sigma $(\sigma)$, the well depth and zero location, respectively, are the commonly used descriptive parameters for the pair interaction potential. Using the experimentally determined product $\varepsilon \sigma$, three $\mathrm{Ar}-\mathrm{Kr}$ potentials were selected with the proper $\varepsilon \sigma$ and theoretically calculated cross sections were compared to the experimental data.

A considerable amount of theory and calculational effort lies between the raw experimental data and use of these results in a meaningful test of an intermolecular potential. The objective of this report is to present the details of our data reduction procedures and to show the comparison with the theoretical calculations. The results are summarized in Table 9 .

It should be noted here that these values given in Table 9 supercede any previously given for two reasons: 1) certain early experiments were omitted because the beam was formed under conditions that produced a small fraction of "clusters" that led to slightly higher (and incorrect) cross sections; 2) The resolution correction was not included in previous reports.

The data reduction starts with the determination of the cross sections from Beer's Law by determining the slope of

$$
\ln I / I_{0}=-n \quad \ell_{\text {ef } f} Q_{\text {exp. }} \text {, }
$$

where $I$ and $I_{0}$ are the intensities of the attenuated and unattenuated beams,. respectively, $n$ is the density in and lef $f$ the effective length of the target cell.
Qexp is the desired "experimental" cross section. Following Beier ${ }^{4.45 c}$ the effective length of the target cell was ascertained to be $1.1406 \mathrm{~cm}$. An example of the raw experimental data is shown in Figure 20 for an argon beam/krypton target in (a) and the inverse system in (b). Figure $20 a$ is the natural logarithm of the ratio of the attenuated beam intensity to the unattenuated beam intensity for an argon beam on krypton scattering gas as a function of the density of krypton in the target cell at $v_{r}=5.29 \times 10^{4} \mathrm{~cm} \mathrm{sec}^{-1}$. The solid circles are measured intensity rătios down tó an attenuation: of $1 / e^{-2}$ which were used to obtain the solid straight line (2-parameter least square fit). The resultant cross sections were. $Q_{\text {exp }}=466 \AA^{2}$ and: $Q\left(v_{l}\right)=417 \AA^{2}$. Figure $20 \mathrm{~b}$ is the natural logarithm of the ratio of the attenuated beam. intensity to the unattenuated beam intensity for a krypton beam on an argon scattering gas as a function of the density of argon in the target cell at $v_{\mathrm{r}}=5.30 \times 10^{4} \mathrm{~cm} \mathrm{sec}-1$. The resultant cross sections were $Q_{\exp }=$ $542 \AA^{2}$ and $Q\left(v_{r}\right)=388 \AA^{2}$. Several points. are worthy of note in this example. First, the cross sections should be equal for the same relative center-of-mass velocity upon inversion of the beam and target gases. In the example, which agree to $\sim 7 \%$, the corrected $Q\left(v_{\mathrm{r}}\right)$ were 417 and $388 \AA^{2}$, respectively. Secondly, the plots of $\ln I / I_{0} v s$. density, $n$, in the target cell, shoula pass through the origin. The data were fitted by the method of least squares to both a one parameter function forcing the line through the origin and also to a two parameter equation allowing an intercept. The intercept was very close to the origi,n in all cases, however, a slight difference was always encountered in $Q_{\text {exp }}$. The results of the two methods of data reduction are shown with the experimental parameters in Table 9 as Qexp. 'Thirdly, the density range of the data must be considered carefully. At high pressures multiple collisions occur and the data do not follow Beer's Law. This can be seen vividly by the "tailing" off of the data in Figure $20 \mathrm{~b}$. The solid triangles are measured intensity ratios with attenuations below $1 / e^{2}$ and show deviations. from Beer's Law. Careful consideration of the composite data revealed that multiple collisions were not significant down to attenuation of approximately $1 / \mathrm{e}^{2}$. This was chosen as the cutoff point. After least. squaring, a few points with standard deviations over $3 \sigma$ were discarded. At low pressures in the target cell, errors can occur. when the background pressure outside of the cell is nonnegligible thereby causing a change in the effective path length. Furthermore, our calibration method was least accurate 
Table 9

EXPERIMENTAL TOTAL CROSS SECTIONS FOR THE ARGON/KRYPTON SYSTEM

\begin{tabular}{|c|c|c|c|c|c|c|c|c|c|}
\hline $10^{4}$ & $\begin{array}{c}v_{1} \vdots \\
\mathrm{cm} \sec ^{-1} \\
\end{array}$ & $\begin{array}{l}T_{s} / T_{t} \\
\left({ }^{\circ} \mathrm{K}\right)\end{array}$ & $\left(10^{4} \mathrm{~cm}^{v_{b}} \sec ^{-1}\right)$ & $\begin{array}{l}Q_{\exp ^{a}} \\
\left(A^{e}\right) \\
\end{array}$ & $\begin{array}{c}\Delta Q \\
\left(A^{2}\right) \\
\end{array}$ & $\begin{array}{l}Q\left(v_{r^{\prime}}\right)^{a} \\
\left(A^{2}\right) \\
\end{array}$ & $\begin{array}{l}Q_{\text {ex }} \mathrm{p}^{\mathrm{b}} \\
\left(\mathrm{A}^{<}\right)^{-} \\
\end{array}$ & $\begin{array}{c}\Delta Q \\
\left(A^{2}\right) \\
\end{array}$ & $\begin{array}{l}Q\left(V_{r}\right)^{b} \\
\left(A^{2}\right)^{2} \\
\end{array}$ \\
\hline & $\begin{array}{l}.3 .33 \\
3.33 \\
3.33\end{array}$ & $\begin{array}{l}75 / 130 \\
75 / 130 \\
75 / 130\end{array}$ & $\begin{array}{l}2.79 \\
2.79 \\
2.79\end{array}$ & $\begin{array}{l}634 \\
654 \\
657\end{array}$ & $\begin{array}{l}6 \\
6 \\
7\end{array}$ & $\begin{array}{l}551 \\
569 \\
572\end{array}$ & $\begin{array}{l}600 \\
621 \\
589\end{array}$ & $\begin{array}{l}5 \\
6 \\
5\end{array}$ & $\begin{array}{l}521 \\
540 \\
512\end{array}$ \\
\hline & $\begin{array}{r}3.70 \\
3.70\end{array}$ & $\begin{array}{l}100 / 130 \\
100 / 130\end{array}$ & $\begin{array}{l}3.23 \\
3.23\end{array}$ & $\begin{array}{l}554 \\
575\end{array}$ & $\begin{array}{l}7 \\
8\end{array}$ & $\begin{array}{l}503 \\
522\end{array}$ & $\begin{array}{l}555 \\
540\end{array}$ & $\begin{array}{l}7 \\
7\end{array}$ & $\begin{array}{l}504 \\
490\end{array}$ \\
\hline & $\begin{array}{l}3.93 \\
3.93\end{array}$ & $\begin{array}{r}75 / 300 \\
.75 / 300\end{array}$ & $\begin{array}{l}2.79 \\
2.79\end{array}$ & $\begin{array}{l}668 \\
672\end{array}$ & $\begin{array}{l}8 \\
8\end{array}$ & $\begin{array}{l}498 \\
501\end{array}$ & $\begin{array}{l}629 \\
640\end{array}$ & $\begin{array}{l}7 \\
8\end{array}$ & $\begin{array}{l}468 \\
477\end{array}$ \\
\hline & $\begin{array}{l}3.97 \\
3.97\end{array}$ & $\begin{array}{l}120 / 130 \\
120 / 130\end{array}$ & $\begin{array}{l}3.53 \\
3.53\end{array}$ & $\begin{array}{l}555 \\
540\end{array}$ & $\begin{array}{l}9 \\
8\end{array}$ & $\begin{array}{l}512 \\
498\end{array}$ & $\begin{array}{l}516 \\
527\end{array}$ & $\begin{array}{l}8 \\
8\end{array}$ & $\begin{array}{l}476 \\
486\end{array}$ \\
\hline & $\begin{array}{l}4.25 \\
4.25\end{array}$ & $\begin{array}{l}100 / 300 \\
100 / 300\end{array}$ & $\begin{array}{l}3.23 \\
3.23\end{array}$ & $\begin{array}{l}625 \\
611\end{array}$ & $\begin{array}{l}8 \\
8\end{array}$ & $\begin{array}{l}497 \\
486\end{array}$ & $\begin{array}{l}600 \\
582\end{array}$ & $\begin{array}{l}8 \\
7\end{array}$ & $\begin{array}{l}478 \\
463\end{array}$ \\
\hline & $\begin{array}{l}4.48 \\
4.48\end{array}$ & $\begin{array}{l}120 / 300 \\
120 / 300\end{array}$ & $\begin{array}{l}3.53 \\
3.53\end{array}$ & $\begin{array}{l}584 \\
570\end{array}$ & $\begin{array}{l}8 \\
8\end{array}$ & $\begin{array}{l}481 \\
470\end{array}$ & $\begin{array}{l}545 \\
552\end{array}$ & $\begin{array}{l}7 \\
7\end{array}$ & $\begin{array}{l}449 \\
455\end{array}$ \\
\hline & $\begin{array}{l}4.68^{c} \\
4.68^{c}\end{array}$ & $\begin{array}{l}120 / 300 \\
120 / 300\end{array}$ & $\begin{array}{l}2.44 \\
2.44\end{array}$ & $\begin{array}{l}833 \\
831\end{array}$ & $\begin{array}{l}31 \\
30\end{array}$ & $\begin{array}{l}465 \\
463\end{array}$ & $\begin{array}{l}826 \\
830\end{array}$ & $\begin{array}{l}30 . \\
30\end{array}$ & $\begin{array}{l}461 \\
463\end{array}$ \\
\hline & $\begin{array}{l}5.14 \\
5.14\end{array}$ & $\begin{array}{l}180 / 300 \\
180 / 300\end{array}$ & $\begin{array}{l}4.33 \\
4.33\end{array}$ & $\begin{array}{l}482 \\
484\end{array}$ & $\begin{array}{l}9 \\
9\end{array}$ & $\begin{array}{l}425 \\
427\end{array}$ & $\begin{array}{l}454 \\
462\end{array}$ & $\begin{array}{l}8 \\
9\end{array}$ & $\begin{array}{l}400 \\
408\end{array}$ \\
\hline & $\begin{array}{l}5.29 \\
5.29 \\
5.29\end{array}$ & $\begin{array}{r}196 / 300 \\
\therefore \quad 196 / 300 \\
196 / 300\end{array}$ & $\begin{array}{l}4.52 \\
4.52 \\
4.52\end{array}$ & $\begin{array}{l}497 \\
491 \\
476\end{array}$ & $\begin{array}{l}11 \\
11 \\
10\end{array}$ & $\begin{array}{l}445 \\
440 \\
426\end{array}$ & $\begin{array}{l}470 \\
466 \\
457\end{array}$ & $\begin{array}{l}10 \\
10 \\
10\end{array}$ & $\begin{array}{l}420 \\
417 \\
409\end{array}$ \\
\hline & $5.30^{c}$ & $244 / 300$ & 3.48 & 564 & 31 & 404 & 542 & 29 & 388 \\
\hline$\because !$ & $\begin{array}{l}5.74 \\
5.74\end{array}$ & $\begin{array}{l}244 / 300 \\
244 / 300\end{array}$ & $\begin{array}{l}5.04 \\
5.04\end{array}$ & $\begin{array}{l}464 \\
450\end{array}$ & $\begin{array}{l}9 \\
8\end{array}$ & $\begin{array}{l}425 \\
411\end{array}$ & $\begin{array}{l}432 \\
438\end{array}$ & $\begin{array}{l}7 \\
8\end{array}$ & $\begin{array}{l}394 \\
400\end{array}$ \\
\hline & $\begin{array}{l}6.83 \\
6.83\end{array}$ & $\begin{array}{l}375 / 300 \\
375 / 300\end{array}$ & $\begin{array}{l}6.25 \\
6.25\end{array}$ & $\begin{array}{l}396 \\
379\end{array}$ & $\begin{array}{l}11 \\
10\end{array}$ & $\begin{array}{l}379 \\
362\end{array}$ & $\begin{array}{l}366 \\
361\end{array}$ & $\begin{array}{r}10 \\
9\end{array}$ & $\begin{array}{l}350 \\
344\end{array}$ \\
\hline
\end{tabular}

abtained from 1-parameter fit.

bobtained from 2-parameter fit.

"Kiypton beam; argon tarjet gas.

at very low pressures. Data were taken above these limiting low pressures.

A computer program was written to produce a plot of the raw data points in the form of $\ell n I / I_{0}$ vs. the target molecular number density. This allows an inunediate visual display of these data which is an aid in making qualitative judymints of the fit of the data points to Beer's Law.

The measured values of $Q \operatorname{cxp}$ as derived from Beer's Law are too small since they do not take into account the finite angular resolution of the detector. These values are corrected to obtain an effec- tive cross section, $Q_{\text {of } f}$, by adding the correction $\Delta Q$.

The methods for calculating $\Delta Q$ have been derived by von $\mathrm{Busch}^{4} 9$ for cylindrical beam geometries. These methods were used by Bredewout. ${ }^{7}$ to correct for cross section measurements of an Ar-Kr scattering system.

A diagram of our beam defining and detecting elements is shown in Figure 21 . The $Y$-dimension is greatly expanded from the $x$-dimension to show the effects of the various radii on the resolution corrections. 


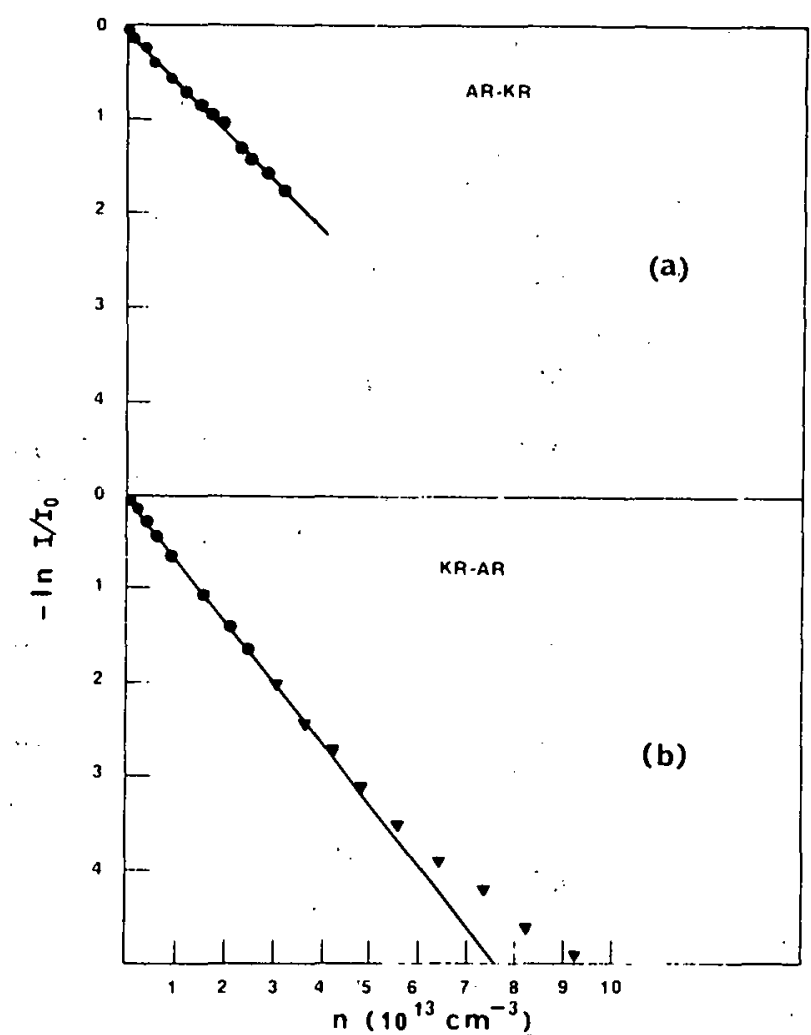

FIGURE 20 - An argon beam/krypton target in (a) and the inverse system in (b).
Since the collimator $\mathrm{C}_{2}$ subtends a smaller solid angle from the source than the detector opening, $c_{2}$ is treated as the detector aperture when applying the procedure of von Busch. The results of this calculation must give too large a correction because in general not all the scattered particles from the target that can pass through $\mathrm{C}_{2}$ are collected by the detector. This is because the solid angle subtended by the detector from a scattering point in the target is smaller than that subtended by $\mathrm{C}_{2}$ by the ratio of 0.55 .

The primary equation defining the correction $\Delta Q$ is:

$$
\Delta Q=\int_{0}^{\infty} \int_{0}^{\pi} W(\theta) 2 \pi \sigma\left(\theta, v_{r}\right) \sin \theta P\left(v_{r}\right) \cdot d \theta d \nu_{r},
$$

where $\sigma\left(\theta, v_{\mathrm{r}}\right)$ is the differential scattering cross section as a function of scattering angle $\theta$ and relative velocity $\nu_{r} ; P\left(\nu_{r}\right)$ is the relative velocity distribution function; $W(\theta)$ is an angular.resolution function that is defined by the geometry of the beam defining apertures.

The function $W(\theta)$ is the probability that a particle scattered through an angle $\theta$ will pass through the aperture of collimator $\mathrm{C}_{2}$. In order to calculate this function we first determine the intensity distribution of the unscattered beam in the plane of collimator $\mathrm{C}_{2}$. This distribution is given by the following expression:

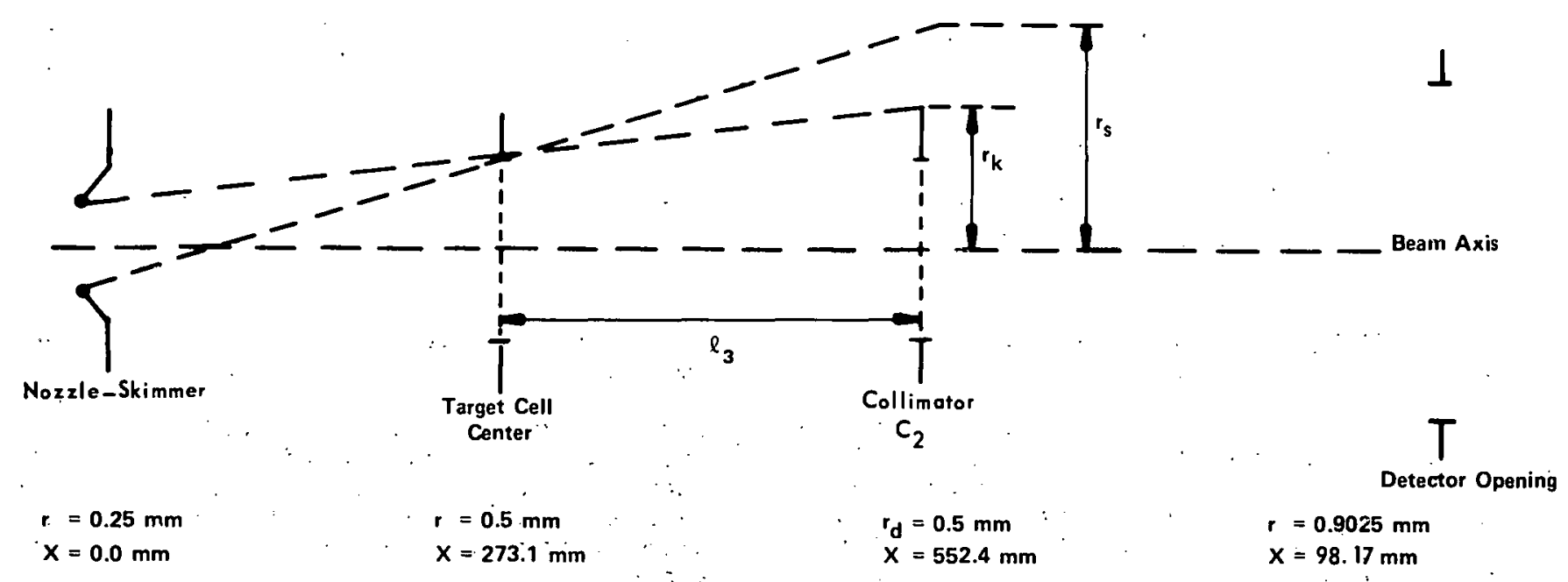

SCALE:

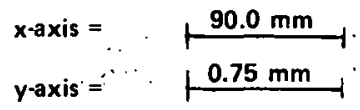

FIGURE 21 - Diagram (not-to-scale) of the experimental components and their dimensions necessary to determine the resolution corrections. 


$$
\begin{aligned}
& i(r)=1 \text { if } r \leqslant r_{k} \\
& i(r)=0 \text { if } r \geq r_{s} \\
& i(r)=\frac{1}{\pi\left(r_{s}-r_{k}\right)^{2}}\left[\left(r_{s}+r_{k}\right)^{2}\right. \\
& \operatorname{arc} \cos \left\{\frac{r^{2}+r_{s} r_{k}}{r\left(r_{s}-r_{k}\right)}\right\} \\
& \left.-2\left\{r^{2}\left(r_{s}+r_{k}\right)^{2}-\left(r^{2}+r_{s} r_{k}\right)^{2}\right\}^{\frac{1}{2}}\right] \\
& \quad \text { if } r_{k}<r<r_{s}
\end{aligned}
$$

The radii $r_{s}$ and $r_{k}$ are shown in Figure 21 and depict the limits of the umbra and penumbra of the unscattered beam in the plane of $\mathrm{C}_{2}$.

To calculate $W(\theta)$, it is convenient to transform variables from $\theta$ to $\rho$, where $\rho$ is a corresponding displacement of a scattered particle from the original unscattered direction in the plane of $\mathrm{C}_{2}$. The transformation is given by $\rho=\ell_{3} \theta$ where $l_{3}$ is the distance from the scattering point in the target cell to $C_{2}$ and is equal to $279.3 \mathrm{~mm}$. Now:

$$
\begin{aligned}
& w(\rho)=\left[\int_{0}^{\max \left(\rho, r_{d}\right)-\rho} i(r) r d r+\frac{1}{\pi} \int_{\left|\rho-r_{d}\right|}^{\rho+r_{d}} i(r)\right. \\
& \left.\operatorname{arc} \cos \frac{r^{2}+\rho^{2}-r_{d}^{2}}{2 \rho r} r d r\right] \\
& \div\left[\int_{0}^{r d} i(r) r d r\right]
\end{aligned}
$$

The numerator in the above expression represents the contribution to the flux passing through $C_{2}$ of particles that have been scattered through a displacement $\rho$. The denominator represents the flux of the unscattered beam that passes through $C_{2}$. The radius of $C_{2}$ is defined as $r_{d}$ and is equal to $0.5 \mathrm{~mm}$.

The scattering length $\ell_{3}$. is actually variable because of the finite length of the target. However; since this length is small compared to $l_{3}$, the average length as measured f.rom the oenter of the target to $C_{2}$ is used, and $l_{3}$ is treated as a constant.

For a potential of the type $V(r)=-C_{s} / r^{s}$, the correction becomes 47

$$
\begin{aligned}
& \Delta Q=\int\left[W(\theta)(.175 / \pi)\left(Q_{\text {eff }}{ }^{2} / \mathrm{Fa}_{0}^{2}\right)\right. \\
& \left.\mathrm{k}_{1}^{2}\left(1+0.56 / \mathrm{X}^{2}\right) \exp \left\{-0.7\left(\frac{\theta}{0 \pi}\right)^{2}\right\}\right] \theta d \theta
\end{aligned}
$$

where

$$
\left(\frac{1}{\theta \pi}\right)^{2}=(.193 / \pi)\left(Q_{\text {ef }} / F_{0}\right) k_{1}^{2}\left(1+0.40 / X^{2}\right) .
$$

Here $\sin \theta$ has been replaced by $\theta ; k_{1}=$ $\mathrm{m}_{1} v_{1} / \hbar$ and is the wavenumber of the primary beam particles with velocity $\nu_{1}$; Fa is the appropriate Berkling function; $\mathrm{x}=$ $v_{1} / v$ as defined by Berkling et al. 50 This exponential form of $V(r)$ uses $S=6.7$ to make a more realistic potential than does the form where $S=6$ as used by von Busch (see Ref. 47).

To calculate $\Delta Q$ and $W(\theta)$, the integrations are performed numerically on the in-house Modcomp IV (Modular Computer Systems, Inc.) computer using Simpson's rule. Since $\Delta Q$ is a function of $Q_{\text {ef } f}$, an iteration procedure is performed with the initial value of $Q_{\text {eff }}$ equal to $Q_{\exp }$. Each following calculation uses $Q$ eff $=Q \exp +\Delta Q$ with $\Delta Q$ as the previously calculated value. The iteration is ended when the change in $Q_{e f f}$ is less than $1.0 \AA^{2}$.

An accurate correction for the fact that the detector opening subtends a smaller solid angle from the target than is subtended by $C_{2}$ has not been derived. As a first approximation the correction factor was reduced by 0.55 , which is just the ratio of these two solid angles as mentioned above.

The preceding calculation of $\Delta Q$ assumes a purely attractive potential form $\mathrm{V}=$ $\mathrm{C}_{\mathrm{s}} \mathrm{r}^{\mathrm{s}}$ with $\mathrm{s}=6.7$. Bredewout ${ }^{4}$ shows an added correction because of oscillations in the differential cross sections. To take this correction into account, the $\Delta Q$ as calculated by the above procedure is modified by adding $G=1.70 \mathrm{Ag} / \mathrm{Q}_{\mathrm{L}} \mathrm{cos}$ $\left(2 n_{0}+0.92 \pi\right) \Delta Q$. The amplitude of the glory oscillations as read from the theoretical plot of the total cross sections, which were calculated using the modified Buckingham exponential-6 potential, is $\mathrm{Agl}, \mathrm{Q}_{\mathrm{LL}}$ is the estimated Landau-Lifshitz semiclassical average cross section ${ }^{5}$, no is the maximum phase shift calculated for the relative velocity of the measured total cross section. These corrections are quite small and are tabulated in Table 10 .

Table 10 shows a summary of the calculated corrections to the cross sections $Q_{\exp }$ as derived from a two parameter fit of the raw data to Beer's Law and to $Q$ exp as derived from a one parameter fit of the same data. In this table, $\Delta \mathrm{Q}_{\mathrm{R}}$ is the correction before correcting for the smaller solid angle of the detector and for the glory oscillations in the differential cross section. The correction which includes all of the factors mentioned above is called $\Delta Q$. 
Table 10

AR-KR RESOLUTION CORRECTIONS

\begin{tabular}{|c|c|c|c|c|c|c|c|c|c|c|c|}
\hline $\begin{array}{l}\text { Exp } \\
\text { No. }\end{array}$ & $\left(10^{4} \mathrm{~cm}-\sec ^{-1}\right)$ & $\begin{array}{l}Q e \times p^{a} \\
(\AA) \\
\end{array}$ & $\begin{array}{l}\Delta Q_{R} \\
(\hat{A})^{2} \\
\end{array}$ & $\begin{array}{l}Q e \times{ }^{b} \\
(A)^{p_{2}} \\
\end{array}$ & $\begin{array}{l}\Delta Q^{c} \\
(\AA)^{2} \\
\end{array}$ & $\begin{array}{l}Q_{\text {eff }}{ }^{d} \\
(\AA)^{2} \\
\end{array}$ & $\mathrm{G}$ & $\begin{array}{l}\Delta Q R \\
(\AA)^{2} \\
\end{array}$ & $\mathrm{G}$ & $\begin{array}{l}\Delta Q^{c} \\
(\AA)^{2}\end{array}$ & $\begin{array}{l}Q_{e f f}^{d} \\
(\AA)^{2} \\
\end{array}$ \\
\hline $\begin{array}{l}24 \mathrm{C} \\
24 \mathrm{D}\end{array}$ & $\begin{array}{l}5.135 \\
5.135\end{array}$ & $\begin{array}{l}454 \\
462\end{array}$ & $\begin{array}{l}14.5 \\
15.0\end{array}$ & $\begin{array}{l}482 \\
484\end{array}$ & $\begin{array}{l}8 \\
9\end{array}$ & $\begin{array}{l}462 \\
471\end{array}$ & $\begin{array}{l}0.05 \\
0.05\end{array}$ & $\begin{array}{l}16.3 \\
16.4\end{array}$ & $\begin{array}{l}0.05 \\
0.05\end{array}$ & $\begin{array}{l}9 \\
9\end{array}$ & $\begin{array}{l}491 \\
493\end{array}$ \\
\hline $\begin{array}{l}26 \mathrm{C} \\
26 \mathrm{D} \\
26 \mathrm{E}\end{array}$ & $\begin{array}{l}5.294 \\
5.294 \\
5.294\end{array}$ & $\begin{array}{l}470 \\
466 \\
457\end{array}$ & $\begin{array}{l}16.9 \\
16.5 \\
15.9\end{array}$ & $\begin{array}{l}497 \\
491 \\
476\end{array}$ & $\begin{array}{l}10 \\
10 \\
10\end{array}$ & $\begin{array}{l}480 \\
476 \\
467\end{array}$ & $\begin{array}{l}0.09 \\
0.09 \\
0.09\end{array}$ & $\begin{array}{l}18.7 \\
18.3 \\
17.3\end{array}$ & $\begin{array}{l}0.09 \\
0.09 \\
0.09\end{array}$ & $\begin{array}{l}11 \\
11 \\
10\end{array}$ & $\begin{array}{l}508 \\
502 \\
486\end{array}$ \\
\hline $27 \mathrm{~B}^{\mathrm{e}}$ & 5.301 & 542 & 47.9 & 564 & 29 & 571 & 0.09 & 51.2 & 0.09 & 31 & 595 \\
\hline $\begin{array}{l}28 \mathrm{~A} \\
28 \mathrm{~B}\end{array}$ & $\begin{array}{l}4.485 \\
4.485\end{array}$ & $\begin{array}{l}545 \\
552\end{array}$ & $\begin{array}{l}14.1 \\
1.4 .5\end{array}$ & $\begin{array}{l}5.84 \\
570\end{array}$ & $\begin{array}{l}7 \\
7\end{array}$ & $\begin{array}{l}552 \\
559\end{array}$ & $\begin{array}{l}-0.09 \\
-0.09\end{array}$ & $\begin{array}{l}16.1 \\
15.4\end{array}$ & $\begin{array}{l}-0.09 \\
-0.09\end{array}$ & $\begin{array}{l}8 \\
8\end{array}$ & $\begin{array}{l}592 \\
57.8\end{array}$ \\
\hline $\begin{array}{l}29 A^{e} \\
29 B^{e}\end{array}$ & $\begin{array}{l}4.685 \\
4.685\end{array}$ & $\begin{array}{l}826 \\
830\end{array}$ & $\begin{array}{l}58.8 \\
59.3\end{array}$ & $\begin{array}{l}833 \\
831\end{array}$ & $\begin{array}{l}30 \\
30\end{array}$ & $\begin{array}{l}856 \\
860\end{array}$ & $\begin{array}{l}-0.07 \\
-0.07\end{array}$ & $\begin{array}{l}59.7 \\
59.5\end{array}$ & $\begin{array}{l}-0.07 \\
-0.07\end{array}$ & $\begin{array}{l}31 \\
30\end{array}$ & $\begin{array}{l}864 \\
861\end{array}$ \\
\hline $\begin{array}{l}30 A \\
30 B\end{array}$ & $\begin{array}{l}4.246 \\
4.246\end{array}$ & $\begin{array}{l}600 \\
582\end{array}$ & $\begin{array}{l}14.3 \\
13.5\end{array}$ & $\begin{array}{l}625 \\
611\end{array}$ & $\begin{array}{l}8 \\
7\end{array}$ & $\begin{array}{l}608 \\
589\end{array}$ & $\begin{array}{l}-0.02 \\
-0.02\end{array}$ & $\begin{array}{l}15.5 \\
14.8\end{array}$ & $\begin{array}{l}-0.02 \\
-0.02\end{array}$ & $\begin{array}{l}8 \\
8\end{array}$ & $\begin{array}{l}633 \\
619\end{array}$ \\
\hline $\begin{array}{l}31 \mathrm{~A} \\
31 \mathrm{~B}\end{array}$ & $\begin{array}{l}3.928 \\
3.928\end{array}$ & $\begin{array}{l}629 \\
640\end{array}$ & $\begin{array}{l}11.9 \\
12.4\end{array}$ & $\begin{array}{l}668 \\
672\end{array}$ & $\begin{array}{l}7 \\
8\end{array}$ & $\begin{array}{l}636 \\
648\end{array}$ & $\begin{array}{l}0.11 \\
0.11\end{array}$ & $\begin{array}{l}13.4 \\
13.6\end{array}$ & $\begin{array}{l}0.11 \\
0.11\end{array}$ & $\begin{array}{l}8 \\
8\end{array}$ & $\begin{array}{l}676 \\
680\end{array}$ \\
\hline $\begin{array}{l}32 \mathrm{~A} \\
32 \mathrm{~B}\end{array}$ & $\begin{array}{l}3.974 \\
3.974\end{array}$ & $\begin{array}{l}516 \\
527\end{array}$ & $\begin{array}{l}12.7 \\
13.2\end{array}$ & $\begin{array}{l}555 \\
540\end{array}$ & $\begin{array}{l}8 \\
8\end{array}$ & $\begin{array}{l}524 \\
535\end{array}$ & $\begin{array}{l}0.08 \\
0.08\end{array}$ & $\begin{array}{l}14.6 \\
13.9\end{array}$ & $\begin{array}{l}0.08 \\
0.08\end{array}$ & $\begin{array}{l}9 \\
8\end{array}$ & $\begin{array}{l}564 \\
548\end{array}$ \\
\hline $\begin{array}{l}33 \mathrm{~A} \\
33 \mathrm{~B}\end{array}$ & $\begin{array}{l}3.703 \\
3.703\end{array}$ & $\begin{array}{l}555 \\
540\end{array}$ & $\begin{array}{l}12.4 \\
11.8\end{array}$ & $\begin{array}{l}554 \\
575\end{array}$ & $\begin{array}{l}7 \\
7\end{array}$ & $\begin{array}{l}562 \\
547\end{array}$ & $\begin{array}{l}0.08 \\
0.08\end{array}$ & $\begin{array}{l}12.4 \\
13.3\end{array}$ & $\begin{array}{l}0.08 \\
0.08\end{array}$ & $\begin{array}{l}7 \\
8\end{array}$ & $\begin{array}{l}561 \\
583\end{array}$ \\
\hline $\begin{array}{l}34 \mathrm{~A} \\
34 \mathrm{~B} \\
34 \mathrm{C}\end{array}$ & $\begin{array}{l}3.333 \\
3.333 \\
3.333\end{array}$ & $\begin{array}{l}600 \\
621 \\
589\end{array}$ & $\begin{array}{l}10.6 \\
11.3 \\
10.5\end{array}$ & $\begin{array}{l}634 \\
654 \\
657\end{array}$ & $\begin{array}{l}5 \\
6 \\
5\end{array}$ & $\begin{array}{l}605 \\
627 \\
594 .\end{array}$ & $\begin{array}{l}-0.11 \\
-0.11 \\
-0.11\end{array}$ & $\begin{array}{l}11.8 \\
12.5 \\
13.3\end{array}$ & $\begin{array}{l}-0.11 \\
-0.11 \\
-0.11\end{array}$ & $\begin{array}{l}6 \\
6 \\
7\end{array}$ & $\begin{array}{l}640 \\
660 \\
664\end{array}$ \\
\hline $\begin{array}{l}35 \mathrm{~A} \\
35 \mathrm{~B}\end{array}$ & $\begin{array}{l}6.831 \\
6.831\end{array}$ & $\begin{array}{l}366 \\
361\end{array}$ & $\begin{array}{l}18.8 \\
18.3\end{array}$ & $\begin{array}{l}396 \\
379\end{array}$ & $\begin{array}{r}10 \\
9\end{array}$ & $\begin{array}{l}376 \\
369\end{array}$ & $\begin{array}{l}-0.06 \\
-0.06\end{array}$ & $\begin{array}{l}21.8 \\
20.1\end{array}$ & $\begin{array}{l}-0.06 \\
-0.06\end{array}$ & $\begin{array}{l}11 \\
10\end{array}$ & $\begin{array}{l}407 \\
389\end{array}$ \\
\hline $\begin{array}{l}36 \mathrm{~A} \\
36 \mathrm{~B}\end{array}$ & $\begin{array}{l}5.745 \\
5.745\end{array}$ & $\begin{array}{l}432 \\
438\end{array}$ & $\begin{array}{l}1.2 .7 \\
13.0\end{array}$ & $\begin{array}{l}464 \\
450\end{array}$ & $\begin{array}{l}7 \\
8\end{array}$ & $\begin{array}{l}439 \\
446\end{array}$ & $\begin{array}{l}0.06 \\
0.06\end{array}$ & $\begin{array}{l}14.6 \\
13.7\end{array}$ & $\begin{array}{l}0.06 \\
0.06\end{array}$ & $\begin{array}{l}9 \\
8\end{array}$ & $\begin{array}{l}473 \\
458\end{array}$ \\
\hline
\end{tabular}

abtained from 2-parameter fit.

bobtained from 1-parameter fit.

$\Delta Q=. \Delta Q_{R}(1+G) \times 0.55$.

$Q_{e f f}=Q_{e x p}+\Delta Q$.

Krypton beam; argon target gas.

The effect of velocity distributions in the scattered and scattering gas must be taken into account and applied as a correction to $Q_{\text {eff }}$. This was done by use of the functions tabulated by Berkling et al. ${ }^{50}$ The target cell obviously possessed $a$ Maxwellian velocity distribution. Because of the relatively high Mach number in the beam, and the resultant velocity peaking, we assumed the beam velocity to be monochromatic with regard to choice of

the proper Berlking correction function. This is the $\mathrm{Fa}_{0}(6, \mathrm{X})$ function and was applied to $Q_{\text {eff }}$ to obtain the average relative velocity cross section:

$$
Q\left(v_{r}\right)=\frac{Q}{F a_{0}} \frac{f}{(6, X)} \frac{v_{b}}{v_{r}}{ }^{2 / 5},
$$

where $v_{r}=\left(v_{b}{ }^{2}+v_{t}{ }^{2}\right)^{\frac{1}{2}}$. 


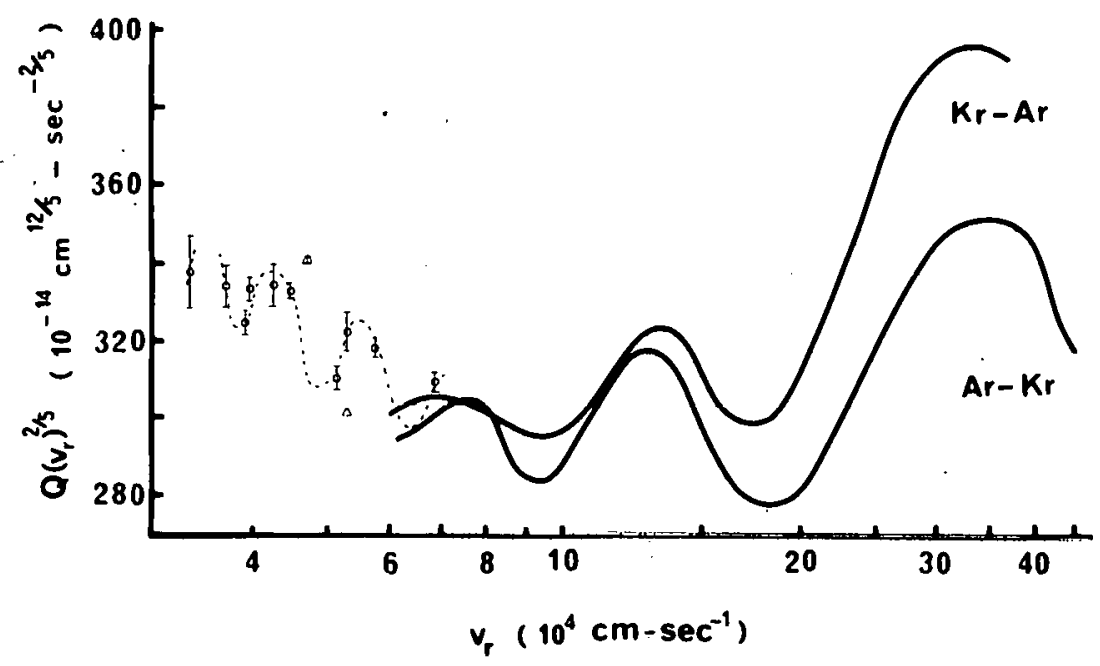

FIGURE 22 - Total cross sections of Ar-Kr with the primary velocity dependence removed versus the relative velocity.

The results of the 1- and 2-parameter fits were essentially the same within the experimental uncertainty. We have chosen to use the 2-parameter fit because of generally smaller average deviations. The slight shift of the line away from the origin is possibly from a small systematic error (probably the lack of complete pressure equilibration between the individual points).

In the "low energy" region of relative velocitie's, there appear characteristic undulations in $Q\left(v_{r}\right)$ superimposed on the monotonic $\left(v_{r}\right)^{-\frac{2}{2} / 5}$ power dependence of the Schiff-Landau-Lifshitz (SLL) approximation. ${ }^{51}$ These undulations, whose maxima and minima are the "glory extrema," occur because of interferences between particles of different angular momenta interacting with the effective potential field. The location of the glory extremas ${ }^{2}$ can be used to provide an estimate of the product $E \sigma$. Provided with some guidelines regarding the general characteristics of the potential, one can thereby hopefully reduce the number of potentials which must be considered in detail.

The measured cross section at each velocity was averaged and multiplied by $v_{r}{ }^{2 / 5}$ to remove the primary velocity dependence
This quantity, $Q\left(v_{I}\right) v^{2 / 5}$, is shown in Figure 22 with the smoothed data of Bredewout. 47. The open circles are the averages of the individual experiments using an Ar beam on a $\mathrm{Kr}$ target at each velocity as given in Table 9. The triangles are the experiments using a $\mathrm{Kr}$ beam on an Ar target for comparison. The dashed line is the estimated oscillatory behavior of the present work. The solid curves are the smoothed data for $\mathrm{Ar}-\mathrm{Kr}$ and $\mathrm{Kr}-\mathrm{Ar} g i v e n$ in Ref. 47. The symmetric undulating, dotted curve was drawn through the present Ar-Kr data to show five extrema in addition to those revealed by the previous work. The locations of the extrema (Figure 23) were estimated from this curve and are given in Table 11 along with those given in Ref. 47.

The locations of the extrema may be used to obtain an estimate of the product $\varepsilon \sigma$ as mentioned previous $1 y$.

Specifically, the locations are given by: 52

$$
\mathrm{N}-\frac{3}{8}=0.3012 \frac{\varepsilon \sigma}{h v_{N}}\left[1-\frac{0.354(\varepsilon / \mu)^{\frac{1}{2}}}{v_{N}}\right],
$$




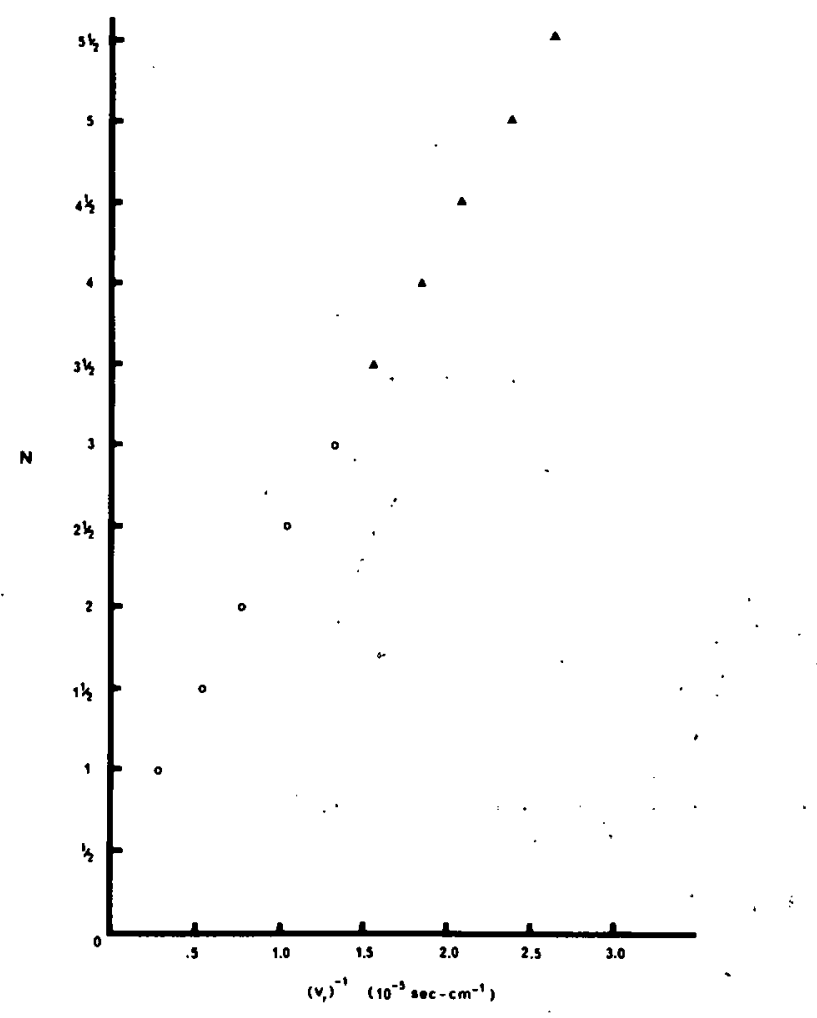

FIGURE 23 - Location of the glory extrema as a function of the inverse relative velocity. The triangles are the extrema as determined graphically from the dashed curve in Figure 22.' The circles are the extrema as given for $A r-K r$ in Ref. 47 .

Table 11

RELATIVE VELOCITY LOCATIONS OF EXPERIMENTAL GLORY EXTREMA. FOR AR-KR

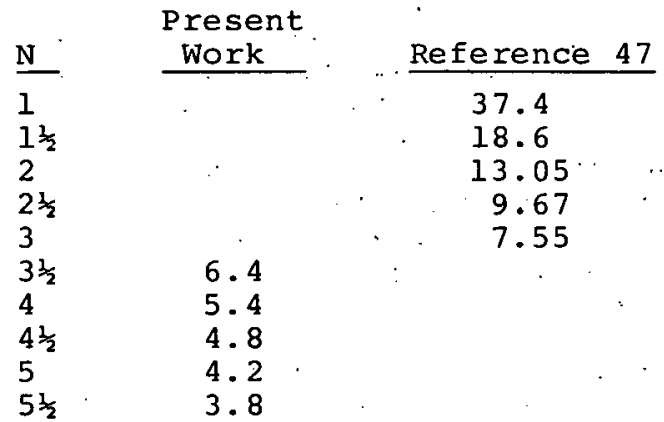

${ }^{a}$ Velocities are in units of $\left(10^{4} \mathrm{~cm}^{\left.-\mathrm{sec}^{-1}\right)}\right.$

where $v_{N}$ is the velocity of the Nth extrema. Customarily, the maxima are represented by integers and the minima by $\frac{1}{2}$ integers. We have plotted $\left(v_{N}\right)^{-1}$ in. Figure 23 and used the derivative of the above equation:

$$
\frac{\partial N}{\partial\left(v_{N}\right)-1}=0.3012 \frac{\varepsilon \sigma}{h}\left[I-0.703(\varepsilon / \mu)^{\frac{1}{2}}\left(v_{N}\right)^{-1}\right],
$$

along with the slope of the graph at $\left(v_{N}\right)^{-1}=0$, to determine $\varepsilon \sigma$ as approximately $7.86 \times 10^{-22}$ erg $\mathrm{cm}$.

In order to test intermolecular potentials against the experimental data, the theoretical cross sections were calculated by the equation :

$$
Q=\frac{4 \pi h^{2}}{\left(\mu v_{I}\right)^{2}} \sum_{\ell}(2 \ell+1)\left(\sin n_{\ell}\right)^{2},
$$

where $\mu$ is the reduced mass of the system and $\eta_{l}$ are the phase shifts. The phase shifts were evaluated by the WKB method as given by Marchi. ${ }^{3}$ Each phase shift $n_{\ell}$ is evaluated as a function of the angular momentum quantum number $\ell$ by the equation:

$$
\dot{n}_{\ell}=\frac{\pi}{4}+\frac{\ell \pi}{2}-q r_{1}+\int_{r_{1}}^{\infty}\left(F^{\frac{1}{2}}-q\right) d r,
$$

where $F=q^{2}-\frac{2 \mu}{\hbar^{2}} V(r)-\frac{\left(\ell+\frac{1}{2}\right)^{2}}{r^{2}} \times 10^{16}$

and $q=\frac{\mu v}{\hbar}$.

The particle separation distance is $r$, and $V(r)$ is the interaction potential. The lower limit of integration, $r_{1}$, is the largest value of $r$ that gives a zero value for $F$. The integral is evaluated by summing the two parts

$$
\int_{r_{1}}^{r_{2}}\left(F^{\frac{1}{2}}-q\right) d r+\int_{r_{2}}^{\infty}\left(F^{\frac{1}{2}}-q\right) d r,
$$

where $r_{2}$ is that value for $r$ above which $V(r)$ is effectively zero.

The first integral is evaluated numerically using:Weddles' rule: An explicit expression can be used for the second integral since here $V(r) \approx 0$ between $r_{2}$ and $\infty$. Now $F^{\frac{1}{2}}$ becomes:

$$
F^{\frac{1}{2}}=q\left(r^{2}-A^{2}\right)^{\frac{1}{2}} / r,
$$

where $A=\left(l+\frac{l}{2}\right) / q$.

Integrating,

$\int_{r_{2}}^{\infty}\left(F^{\frac{i}{2}}-q\right) d r=q\left[\left(r^{2}-A^{2}\right)^{\frac{1}{2}}-A \cos ^{-1}(A / r)\right]$.

Phase shifts were calculated for several hundred $\ell$. values at each velocity until the magnitude dropped below four milliradians.

The theoretical cross sections were evaluated with the above procedure using three interatomic potentials for Ar-Kr. The 
potentials and parameters used are given in Table 12. Parameters for the Modified Buckingham (exp-6) and Lennard-Jones (12-6) potentials were obtained from potentials given for the pure gases which within $10 \%$ reproduced the thermal diffusion factors for argon and krypton. ${ }^{4}$ It was reasoned that thermal diffusion is a property that is quite sensitive to the potential and thus should yield a reasonably accurate value for the well depth. The potential parameters for $\mathrm{Ar}-\mathrm{Kr}$ were then obtained from those for the pure gases by application of the usual combination rules. The theoretical curves are shown with the experimental data in Figure 24 .

The absolute cross sections measured in this experiment compare favorably with theoretical cross sections derived from potentials that are determined by experimentally independent methods. The results also agree with measurements by other workers. The location of the glory extrema along with those given in Reference 3 determine the product $\varepsilon \sigma$ to be $7.86 \times 10^{-22}$ erg cm. The Barker potential, with $\varepsilon \sigma=$ $8.00 \times 10^{-22}$ erg $\mathrm{cm}$, fits the data given by Bredewout 4 , and our cross section values at the high velocities. This is shown in Figure 24. At lower velocities our data appear to fit the theoretical $(\exp -6)$ curve, which has $\varepsilon \sigma=7.80 \times 10^{-22}$ erg $\mathrm{cm}$. The Lennard-Jones $(12-6)$ potential, with $\varepsilon \sigma=7.70 \times 10^{-22}$, yielded the poorest agreement with experiment.

(Robert W. York, William L. Taylor and Richard E. Miers)

Table 12

SELECTED INTERMOLECULAR POTENTIALS FOR AR-KR

1. Barker $^{\mathrm{a}} \mathrm{V}(\mathrm{r})=\varepsilon V(r)$ *

$$
\begin{aligned}
& V(r) *=\exp \left[a(1-x) \sum_{i=0}^{5} A_{i}(x-1)^{j}\right]-\sum_{j=0}^{2} c_{2 j+6} /\left(\delta+x^{2 j+6) ;} x=r / r_{m}\right. \\
& \mathrm{C}_{6}=1.08756 \quad \mathrm{~A}_{0}=0.25909 \\
& C_{8}=0.17017 \quad A_{1}=4.62939 \\
& C_{10}=0.02394 \quad A_{2}=8.7656 \\
& \mathrm{a}=12.5 \quad \mathrm{~A}_{3}=25.2696 \\
& \delta=0.01 \quad A_{4}=102.0195 \\
& \varepsilon / k=167.04^{\circ} \mathrm{K} ; r_{m}=3.8859 \AA \quad(\sigma=3.4712) ;
\end{aligned}
$$

2. Modified Buckingham (Exp-6)

$$
\begin{aligned}
& V(r)=\frac{\varepsilon}{1-6 / \alpha}\left[\frac{6}{\alpha} \exp [\alpha(1-r / \mathrm{rm})]-(\mathrm{r} / \mathrm{rm})^{6}\right] \\
& \varepsilon / k=166.92 ; r_{m}=3.7955 \AA(\sigma=3.3846) ; \alpha=14.46
\end{aligned}
$$

3. Lennard-Jones $(12-6)$

$$
\begin{aligned}
& V(r)=4 \varepsilon\left[\left(\frac{\sigma}{r}\right)^{12} \cdot\left(\frac{\sigma}{r}\right)^{6}\right] \\
& \varepsilon / k=160.95 ; \sigma .=3.4635 \AA
\end{aligned}
$$

${ }^{a}$ see ref 47 . 


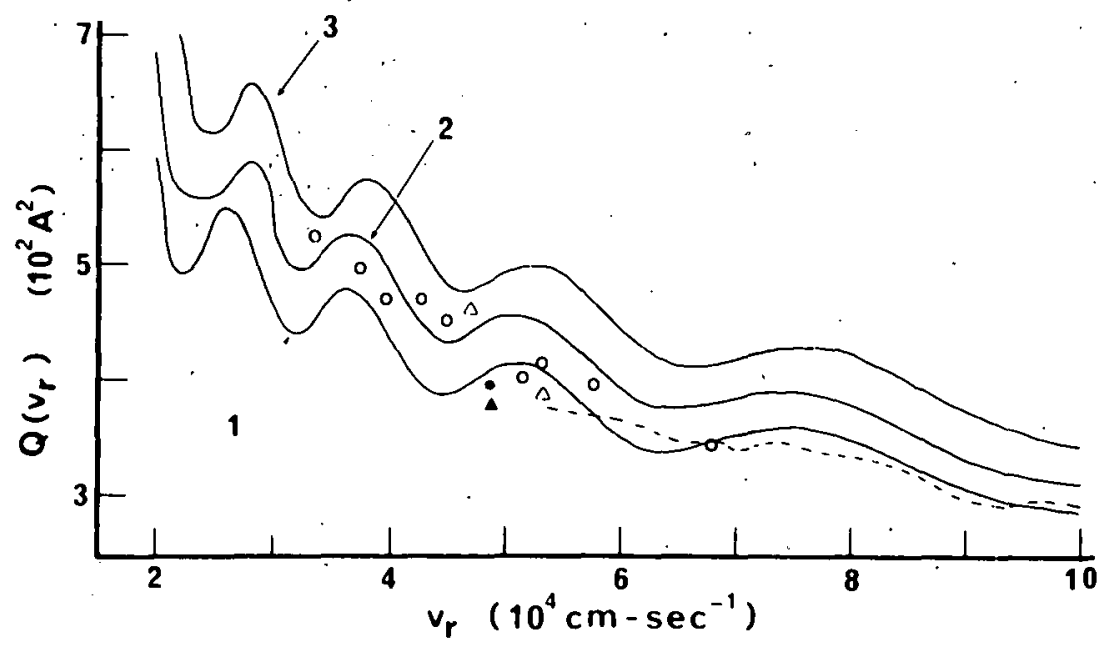

FIGURE 24 - Comparison of the experimental total cross section with theoretical cross sections calculated using three Ar-Kr potentials. The open circles are the present Ar-Kr results, the open triangles are the Kr-Ar experiments in this work, the closed cixcle and triangle are the work of Ref. 46, and the dashed curve is the smoothed Ar-Kr data of Ref. 47. The theoretical curves are the cross sections obtained using: 1) Barker. potential, 2) Modified Buckingham (exp-6) potential, and 3) Lennard-Jones $(12-6)$ potential. 


\section{References}

1. Mound Laboratory Activities for the Division of Physical Research: January-June 1975, MLM-2241. (November ?1, 1975), p. 7 .

2. H. W. Wolley, R. B. Scott, F. G. Brickwedde, J. Res. of N.B.S., 41,374 (1948).

3. W. K. Meckstroth and D. White, I. Chem. Phys., 34, 3723 (1971).

4. Mound Laboratory Activities for the Division of Physical Research: January-June 1974, MLM-2168. (August 30, 1974), pp. 27-30.

5. A. Babloyantz and A. Bellemans, Mol. Phys., 3313 (1960).

6. C. E. Messer, J. Mellor, J. A. Krol, and I. S. Levy, J. Chem. Eng. Data, 6, 328 (1961).

7. C. E. Messer and I. S. Levy, Inorg. Chem., 4, 543 (1965).

8. L. B. Lundberg, D. T. Cromer and C. B. Magee, Inorg. Chem., 11, 400 (1972).

9. A. Abragam and B. Bleaney, Electron Paramagnetic Resonance of Transition Ions, Clarendon Press, oxford, 1970.

10. Ibid., p. 456 .

11. B. R. McGarvey, J. Phys. Chem., 71, 51 (1967).

12. J. J. Reilly and R. H. Wiswall, Jr., Inorg. Chem., 13, 218 (1974).

13. D. C. Hoffman, J. J. Reilly, F. J. Salzano, C. H. Waide, R. H. Wiswall and W. E. Winsche, presented at U.S.-Japan Seminar on Hydrogen Energy, Tokyo, Japan, July 21-24, 1975, BNL-20168.

14. Mound Laboratory Activities for the Division of Physical Research: January-June 1975, MLM-2241 (November 11, 1975), pp. 24-25.

15. R. M. Cotts, Ber. Bunsenges, Phys. Chem., 76, 760 (1972).

16. L. E. Drain, Proc. Phys. Soc. (London), 80, 1380 (1962).

17. A. Abragam, The Principles of Nuclear Magnetism, Oxford University Press, 1961.

18. T. W. Newton, The Kinetics of the oxidation-Reduction Reactions of Uranium, Neptunium, plutonium and Americium in Aqueous Solutions, USERDA Report TID-26506 (August 1975), $131 \mathrm{pp}$.

19. G. L. Silver, J. Inorg. Nucl. Chem., 30, 1317 (1968).

20. G. L. Silver, J. Inorg. Nucl. Chem., 33, 577 (1971).

21. G. L. Silver, J. Inorg. Nucl. Chem., 36, 939 (1974).

22. G. L. Silver, Topics in Aqueous Plutonium Chemistry, MLM-2108 (March 15, 1974), ค. $18-21$.

23. D. A. Costanzo, R. E. B1ggers, and J. T. Be11, J. Inorg. Nuc1. Chem., 35, 609 (1973).

24. Newton, op. cit., Chapter 7 .

25. Newton, op. cit., pp. 5-6. 
26. J. T. Bell, H. A. Friedman, and M. R. Billings, J. Inorg. Nucl. Chem., 36, 2563 (1974).

27. G. L. Silver, Disproportionation of Tetravalent and Pentavalent Plutonium in the Presence of Hexavalent Plutonium, MLM-1744 (December 22, 1970); pp. 12-14.

28. Mound Laboratory Chemistry and Physics Progress.Report: October-December 1:971, MLM-1888 (August 21, 1972), p. 13 .

29. Mound Laboratory Chemistry and Physics Progress Report: April-June 1972, MLM1955 (December 29;.1972), p. 14 .

30. Mound Laboratory Chemistry and Physics Progress Report: January-March 1972, MLM-1903 (October.20，1972)， p. 20.

31. Mound Laboratory Activities for the Division of Physical Research: July-December 1975, MLM-2296 (May 14, 1976); p. 23.

32. J. M. Cleveland, The Chemistry of Plutonium, Gordon and Breach, New York, 1970, pp. 22-26.

33. R. J. Field, E. Koeroes and R. M. Noyes, Oscillations in Chemical Systems. I. The Mechanism of Temporal Oscillation in the Homogeneous Bromate-Cerium-Malonic Acid System, RLO-2230-T-2-1, Richland Operations Office, Richland, Washington (1971), $71 \mathrm{pp}$.

34. Mound Laboratory Activities for the Division of Physical Research: July-December 1975, MLM-2296 (May 14, 1976), p. 29

35. G. L. Silver, Plutonium Disproportionation Reactions: Some Unresolved Problems MLM-1807 (May 10, 197I), $56 \mathrm{pp}$.

36. Mound Laboratory Activities for the Division of Physical Research January-June 1974, MLM-2168. (August 30, 1974), pp. 31-35.

37. Mound Laboratory Activities for the Division of Physical Research: July-December 1973, MLM-2118 (February 28, 1974), pp. 32-35.

38. Mound Laboratory Activities for the Division of Physical Research: January-June 1975, MLM-2241 (November 11, 1975), pp. 29-31.

39. Mound Laboratory Activities for the Division of Physical Research: July-December 1975, MLM-2296 (May 14; 1976), pp. 25-29.

40. Mound Laboratory Activities for the Division of Physical Research: July-December 1972, MLM-2013 (February 14, 1973), pp. 56-59.

41. Mound Laboratory. Activities for the Division of Physical Research: July-December 1975; MLM-2296 (May 14; 1976), p. 42.

42. G. A. Burney and R. M. Harbour, Radiochemistry of Neptunium, NAS-NS-3060 (December 1974), pp. 169-170.

43. Mound Laboratory Activities for the Division of Physical Research: January-June 1975, MLM-2241 (November 11, 1975), p. 40

44. Mound Laboratory Activities for the Division of Physical Research: July-December 1975, MLM-2296 (May 14, 1976), p. 43 .

45. Mound Laboratory Activities for the Division of Physical Research: July-December: 1975, MLM-2296 (May 14, 1976), Pp. 46-52.

45 (a). Mound Laboratory Activities for the Division of Physical Research: JanuaryJune 1973, MLM-2068 (August 22,1973), pp. 12-14.

45 (b). Stable Gaseous Isotope Separation and Purification: October-December 1971, MLM-1886 (February 10, 1972), pp. 12-13. 
45 (c) . Mound Laboratory Activities for the Division of Physical Research: JulyDecember 1975, MLM-2296 (May 14, 1976), Pp. 46-52.

45 (d). Stable Gaseous Isotope Separation and Purification: Apri1-June 1972, MLM-1943 (August 18, 1972), pp. 11-13.

46. E. W. Rothe and R. H. Neynaber, "Mea'surémënts" of Absolute Total Cross Sections for Rare-Gas Scattering," J. Chem. Phys., 43, 4177 (December 1965).

47. J. W. Bredewout, "Glory Undulations in the Total Cross Section for Scattering of Heavy Rare Gas Atoms," Thesis, ,Rijksuniversiteit Leiden (Netherlands) (September 1973).

48. H. J. Beier, "Scattering from Helium Atomic Beams in Rare Gases," Zeit. f. Physik, $196,185(1966)$.

49. F. von Busch, "Der Einfluss des Winkelauflosungsìer̈mogens auf die Messung totaler atomarer Streuquerschnitte,"."zeit. f:" physik, 193, 4l2,(1966).

50. K. Berkling, R. Helbing, K. Kramer, H. Pauly $\because{ }^{\circ}$. 'schlièr and P: Toschek, "Effective Collision Cross Sections in "Sçattering Experiménts;" Zeit. f. Physik, 166,406 (1962).

51. R. B. Bernstein and K. H. Kramer, "Comparison and Áppraisal of Approximation Formulas for Total Elastic Molecular Scattering Cross Sections, "J. Chem. Phys." 38, 2507 (May 1963).

52. E. W. Rothe, P. K. Rol, and R. B. Bernstein, "Interaction Potentials from the Velocity Dependence of Total Atom-Atom Scattering Cross-Sections," Phys. Rev.", 130,2333 (June 1963).

53. R. P. Marchi, "Intermolecular Potentials and Their Relation to Molecular Beam Scattering Data," Thesis, Purdue University (January 1963).

54. W. L. Taylor and S. Weissman, "Isotopic Thermal Diffusion Factors for Argon and Krypton," J. Chem. Phys., 59, 1190 (August 1973). 


\section{Distribution}

\section{EXTERNAL}

Technical Report.Library, Monsanto, St. Louis TID-4500, UC-4 and 22. (169)

J. A. Chacon, DAO

R. B. Craner, SLA

R. K. Flitcraft, MRC

W. J. Haubach, Molecular and Geo-sciences Br., Divistion of Physical Research, ERDA

F. D. Stevenson, Molecular and.Geo-Sciences Br., Division of Physical Research, ERDA

c. P: Sutter/R. N. Diebel, Atlantic Richfield Hanford. Company, ERDA

\section{Consultants}

W. E. Moddeman

University of Dayton Research Institute

D; White

University of. Pennsylvania

R. N: Zare

Columbia University

\section{INTERNAL}
V. L. Avona
W. T. Cave
R. J. DeSando
C. W. Huntington
B. E. Jepson
L. V. Jones
J. R. MCClain
E. Michaels
W. J. Roos
W. M. Rutherford
R. A. Schwind
G. L. Silver
W. L. Taylor
H. L. Turner
R. E. Vallee
R. M. Watrous
Document Control
Library (15)
Publications (15) 